\title{
Factors Relevant to Utility Integration of Intermittent Renewable Technologies
}

Yih-huei Wan and Brian K. Parsons

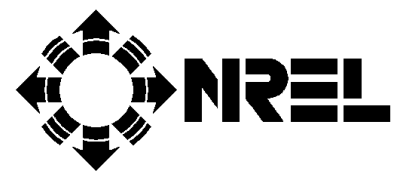

National Renewable Energy Laboratory 1617 Cole Boulevard Golden, Colorado 80401-3393 A national laboratory of the U.S. Department of Energy Managed by Midwest Research Institute for the U.S. Department of Energy under contract No. DE-AC36-83CH10093 


\section{Factors Relevant to Utility Integration of Intermittent Renewable Technologies}

Yih-huei Wan and Brian K. Parsons

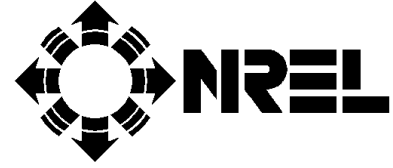

National Renewable Energy Laboratory 1617 Cole Boulevard Golden, Colorado 80401-3393

A national laboratory of the U.S. Department of Energy Managed by Midwest Research Institute for the U.S. Department of Energy under contract No. DE-AC36-83CH10093

Prepared under Task No. AS815440

August 1993 


\section{NOTICE}

This report was prepared as an account of work sponsored by an agency of the United States government. Neither the United States government nor any agency thereof, nor any of their employees, makes any warranty, express or implied, or assumes any legal liability or responsibility for the accuracy, completeness, or usefulness of any information, apparatus, product, or process disclosed, or represents that its use would not infringe privately owned rights. Reference herein to any specific commercial product, process, or service by trade name, trademark, manufacturer, or otherwise does not necessarily constitute or imply its endorsement, recommendation, or favoring by the United States government or any agency thereof. The views and opinions of authors expressed herein do not necessarily state or reflect those of the United States government or any agency thereof.

Available electronically at http://www.doe.gov/bridge

Available for a processing fee to U.S. Department of Energy and its contractors, in paper, from:

U.S. Department of Energy

Office of Scientific and Technical Information

P.O. Box 62

Oak Ridge, TN 37831-0062

phone: 865.576 .8401

fax: 865.576.5728

email: reports@adonis.osti.gov

Available for sale to the public, in paper, from:

U.S. Department of Commerce

National Technical Information Service

5285 Port Royal Road

Springfield, VA 22161

phone: 800.553 .6847

fax: 703.605.6900

email: orders@ntis.fedworld.gov

online ordering: http://www.ntis.gov/ordering.htm 


\section{Preface}

Factors Relevant to Utility Integration of Intermittent Renewable Technologies is a study and literature review looking at various factors relevant to the integration of intermittent renewable energy technologies into electric systems. The three topics covered in this report are interface factors, operability/stability factors, and planning factors that electric utilities have to address before large-scale integration of intermittent renewable energy technologies can take place. The purpose is to assess the state of knowledge of these factors and their relative significance today, and thus provide guidance to analysts in their evaluation of technologies and to researchers in their pursuit of tools and strategies to define and mitigate potential impacts.

This report is one of a series of analyses being undertaken by the Analytic Studies Division of the National Renewable Energy Laboratory to provide insights into issues pertinent to renewable energy research and development activities. The Office of Utility Technologies of the Department of Energy funded this study.

The authors are indebted to many people who reviewed the draft of this report and offered helpful comments. We especially want thank Joe Iannucci of Pacific Gas and Electric Company for his comments and valuable suggestions.

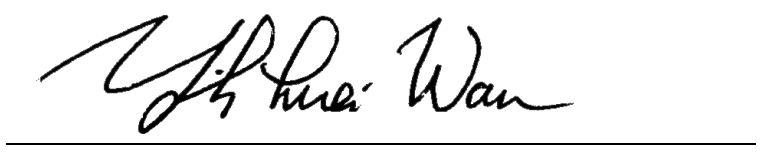

Yih-huei Wan

Senior Utility System Analyst

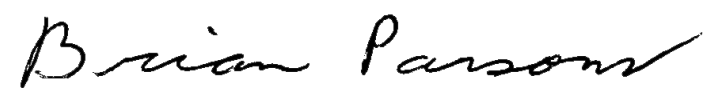

Brian Parsons

Senior Engineering Analyst

Approved for the

NATIONAL RENEWABLE ENERGY LABORATORY

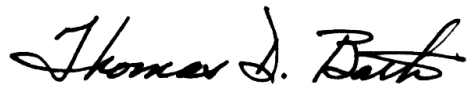

Thomas D. Bath, Director Analytic Studies Division

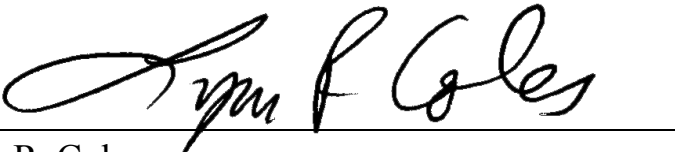

Lynn R. Coles

Manager, Analysis \& Assessment Projects

Technology \& Resource Analysis Branch 


\section{Executive Summary}

\section{Objective}

This study of the factors relevant to integrating intermittent renewable technologies into utility systems is one of a series of analyses being undertaken to provide insights into issues pertinent to renewable energy research and development activities. The purpose of this study is to assess the current state of knowledge of various factors that utilities must address in integrating intermittent renewable technologies, such as windor solar-based systems, into utility power-supply systems.

Past studies indicated that utilities have concerns about the substantial differences between intermittent renewable technologies and conventional sources of utility power supply. These issues and concerns can impede the deployment of renewable technologies in utility systems if questions remain unanswered or technologies appear detrimental to standard utility operations. The goal of this study is to assess the relative significance of these concerns today and thus guide analysts in their evaluation of various technologies and researchers in their pursuit of tools and strategies to define or mitigate impacts.

Integration studies from the late 1970s and early 1980s provide a starting point for assessing relevant issues, but these older studies have not been consolidated into a consistent data base nor updated to today's higher standards of analytic capability. Many recent studies have added to the knowledge base of renewable technology integration issues. In addition, significant changes have taken place in the utility marketplace regarding regulatory practices, energy and environmental policies, the resource selection process, and the development of non-utility generators. These changes have altered the type and level of information needed to promote the integration of renewable technologies. This study is a first step toward addressing these information needs.

The information resources for the study are primarily published reports and data from industry or research laboratory work produced over the last ten years. Much of these information resources were products of work sponsored by the U.S. Department of Energy (DOE), the Electric Power Research Institute (EPRI), and other interested utilities or organizations.

The main topics covered in this report are:

- Interface Factors

These are hardware and design-related interconnection issues such as harmonics, personnel safety, and system protection. The interface issues exist for small single-unit systems as well as for large-scale multi-unit installations.

- Operating Factors

These issues relate to the impact of intermittent renewable energy technologies on the second-bysecond, minute-by-minute, and hour-by-hour operations of the power systems such as generation control, load following, unit commitment, reserve requirement, and system voltage regulation. Intermittent renewable energy technologies have different operating characteristics, and their impacts on power system operations have to be addressed to assure reliable system performance. 
- Planning Factors

These factors deal with longer term utility activities, such as capacity expansion or integrated resource planning. Intermittent renewable energy generation technologies have different characteristics and attributes than conventional generation technologies. Accurate planning models and methodologies that can adequately evaluate the value of intermittent renewable energy technologies must be made available to utilities. Such models and methodologies would allow utility planners and regulators to incorporate intermittent renewable energy technologies into normal utility planning and resources selecting processes.

A comprehensive bibliography is provided at the end of this report for readers seeking more detailed information and research results on integration issues discussed in the report.

\section{Results of the Study and Discussion}

This study has found that several commonly held perceptions regarding integration of intermittent renewable energy technologies into utility systems are not valid. Technology advancement and operating experience have enabled utilities to address most of these perceived concerns. The results are summarized in the following:

- Contrary to common perceptions that interconnections of intermittent renewable energy technologies and utility systems are problematic and costly and that major issues regarding harmonics, protection, and safety remain, the study has found that hardware and system design advances have eliminated most of the concerns about interface. Furthermore, the cost of hardware is going down.

- The arguments that intermittency causes large economic penalties for utilities and integration of intermittent renewable energy technologies is only feasible at a very low penetration level turn out to be overly pessimistic. These pessimistic views resulted from early studies with very conservative assumptions, but more recent studies have shown that the effects are less severe than originally believed. The study results and actual operating experience have shown that cost penalties have not occurred at low to moderate penetration levels and that higher penetration levels are feasible.

- The common views that intermittent renewable energy technologies only provide replacement energy to the utility systems but no capacity value and that they require significantly lower costs to be competitive in the utility industry are misleading. The studies have shown that intermittent renewable energy technologies can have capacity values. Renewable technologies are competitive today in many situations. The renewable technologies were at a disadvantage because their unique attributes and characteristics were not always considered by the conventional planning process.

Many technical concerns associated with integrating intermittent renewable energy generation into utility systems have been identified. However, the literature reviewed does not reveal any unsolvable technical problems. The study concludes that most interfacing issues are resolved or solvable with state-of-the-art hardware and design. Solutions to the problems are often case specific, because there are only limited installations and a generalized analytic procedure has not been fully developed and tested. Costs of these technical solutions also vary, and allocating these costs among all the affected parties remains an institutional issue. Operating experience has further shown that electric utilities can accommodate dispersed generations in the otherwise passive distribution network without apparent adverse effects. Literature indicates that grid-connected dispersed photovoltaic (PV) systems, in particular, can be integrated into utility distribution circuits with little effects on service quality. 
Penetration limits of intermittent renewable energy technologies depend upon utilities' existing generation mix and their regulating capabilities, load characteristics, resource availability, and correlations between system load and resources. Furthermore, studies have shown that penetration limits usually are not technical limits, but economic limits where additional operational costs are greater than the added value of intermittent renewable energy technologies. These costs and values change from system to system. Both renewable technologies and electric utility systems continue to evolve around new designs and new technologies. New development will change the characteristics of the electric systems and renewable technologies, and they in turn will impact the feasible penetration of intermittent renewables in the electric systems. A generalized conclusion on the maximum penetration limits for utility systems is very difficult to draw.

Research has shown a wide range of feasible penetration levels of intermittent generations in utility systems. Experience from wind farm operations in California shows that the electric system can operate normally when wind generation is supplying $8 \%$ of the system demand during the utility's off-peak hours. Studies showed that short-term wind speed and solar irradiance predictability and a proper system control strategy were important factors that could facilitate a higher penetration level. Spatial diversity of wind resources were generally not exploited in the early studies; transmission requirements and network response were not studied in detail.

Storage may increase the value of intermittent generation. However, studies generally show that dedicated storage systems for renewables are not viable options for utilities because of added capital costs of current storage technologies. Storage can add flexibility and value to utility operations, but it should generally be a system-wide consideration based on the merit of the storage system. Using existing hydropower facilities as energy storage systems for renewable energy technologies is a promising concept, but more research is needed to determine the effect on existing hydropower operations and to assess the environmental impact of potentially increased fluctuations of downstream flow.

\section{Conclusions}

Current installations of PV and wind-generation systems are far fewer than the feasible level indicated by the literature. In the near-term, it appears that there are no technical constraints that impede the integration of intermittent renewable technologies into the utility systems. However, technical issues alone do not explain all the barriers facing intermittent renewable technologies. Other issues and concerns may have limited the market penetration of these technologies. This report identifies the following prominent factors:

\section{- Economic Factors}

The cost of many intermittent renewable technologies remains the major limiting factor despite the remarkable progress made during the last decade. Current capital costs of many of these technologies are not competitive enough for utilities to accept them. Using conventional economic analysis, planning criteria, and current costs, many renewable technologies currently cannot generate electricity at a cost that is competitive with other conventional generating technologies.

Transmission cost, which will be associated with every resource expansion plan, may also affect the cost of intermittent renewable technologies. However, the burden may be disproportionally heavy for intermittent renewable technologies because significant resources generally come from the periphery of utility systems where the transmission links to system load centers are weak. Preliminary study has already identified the transmission cost as one of the barriers for large-scale development of wind resources in the Northwest. 


\section{- Institutional Factors}

Lack of experience and information are two critical factors that impede electric utilities' decisions to employ renewable energy technologies. Many utilities are unaware of recent technology and performance improvements of intermittent renewable generations, and so still regard renewable energy technologies as uncertain. They often associate major technical and financial uncertainties as well as risks with such technologies. Utilities are also concerned about the loss of operating flexibility when nondispatchable intermittent renewable technologies are included in the power-supply system.

- Regulatory Factors

Existing regulatory practices may be unintentionally biased against renewable energy options. Ratemaking processes that do not reflect the operating characteristics and attributes of renewable energy systems are examples of problem areas. Current wind- and solar- energy technologies entail high capital costs but there is no fuel cost and the operating costs are low. However, electric utilities selecting an expansion plan with renewable energy technologies will face a heavy financial burden trying to recover the high capital investment during earlier years of the plan.

Using competitive bidding procedures to acquire new capacity for electric utilities is rapidly becoming the preferred mechanism in the utility industry. Many bidding solicitations do not properly account for technology attributes such as environmental and fuel-diversity benefits that are significant with renewables. Bidding solicitations that emphasize price and operational characteristics (e.g., dispatchability) will put intermittent renewable technologies at a disadvantage.

\section{- Technical Factors}

Comprehensive models capable of evaluating renewable energy technologies are few, and data requirements are very site-specific. Electric utilities either lack the necessary information or do not have adequate analytic tools to use it. Lack of planning tools for utilities to evaluate the cost and impact of intermittent renewable technologies has hampered the efforts of some utilities and utility commissions to include intermittent renewable technologies in resource planning. Some existing models have been adapted to handle nondispatchable resources, but a uniform planning methodology to account for the stochastic nature of the intermittent renewable resources is not available. Input data availability is another obstacle. Long-term, site-specific wind resource and solar radiation data that enable utilities to conduct a detailed analysis of the renewable energy generation are often lacking.

Some of these issues can be dealt with by increasing efforts to disseminate available information on operating experience and by accelerating technology- transfer activities. Other issues must be addressed by further research and development. Some issues need immediate attention because they are barriers or perceived as barriers to the utilities' integration of intermittent renewable technologies. Others will not become significant factors until the penetration of renewables reaches beyond today's low level.

\section{Remaining Technical Issues}

Gaps in knowledge or partial understanding of specific topic areas prove to be barriers to adoption of intermittent renewable energy technologies. As technologies develop, further resolution of a number of important issues will aid in understanding and acceptance of renewables by utilities. Of first order importance are issues related to electric utilities' understanding of all the costs and benefits of intermittent 
renewable energy technologies. These are covered in the first four topic areas below. Longer term issues that may benefit from further research are related to the maximum penetration of intermittent renewables. These issues will rise in importance as penetration of intermittent renewables reaches a much higher level. These longer term issues are discussed in the final two topic areas below.

\section{Utility Planning Models and Methodologies}

The lack of standard planning models and methodologies to assist utilities in planning and valuing intermittent renewable technologies is a significant barrier. Today, electric utilities do not necessarily include renewable energy technologies in their planning process because standard techniques and data for evaluating them are not readily available. Improved planning models that properly evaluate the benefit and cost of all generation technologies will facilitate the integration of renewable energy technologies by utilities.

\section{Institutional Issues}

Studies have indicated that economic and technical issues are not the only barriers to the development of intermittent renewable technologies. Institutional concerns such as regulatory and utility decisionmaking processes may also impede the development and integration of intermittent renewables. Identifying those institutional obstacles and developing proper remedies to eliminate them are important near-term strategies for intermittent renewable technologies development.

\section{Resource Assessment}

Utilities need resource data specific to their service territories in order to evaluate the potential contributions of those resources to their systems and design a development strategy for those resources. Generalized resource data often do not include detailed information necessary for utility resource planning. Analyzing long-term, detailed resource data for their statistical properties may help utilities developing short-term as well as long-term forecasting capabilities for intermittent renewable resources. The results can also be used to derive quantitative information regarding resource spatial and temporal diversities. All this information is important for utilities to develop plans to integrate intermittent renewable resources.

\section{Implementation Issues}

Interfacing the intermittent renewable energy technologies with utility transmission and distribution systems is a critical issue facing intermittent renewables. Despite significant progress in the past decade regarding our understanding of the interface problems and the performance of hardware, standard designs and study procedures are not yet available. The interfacing costs are still too high, especially for interfacing small intermittent renewable energy projects with the utility systems. Transmission access and cost are real concerns to the large-scale development of renewable energy, and they could potentially be a major barrier in the future.

\section{Operational Studies}

Many integration studies appeared to establish some hard limits on intermittent renewable energy penetration, sometimes without proper recognition of exactly what mechanisms are responsible for these limits. Further studies on the operating issues are still required to answer the questions on optimal penetration levels. 


\section{Mitigation Techniques}

Various fast-response generators and energy-storage systems can be employed to supplement the loadfollowing capability of a power system to accommodate intermittency of wind and solar resources. These measures are valuable tools that will enable utilities to integrate the intermittent renewable energy resources into their systems at higher penetration levels. 


\section{Contents}

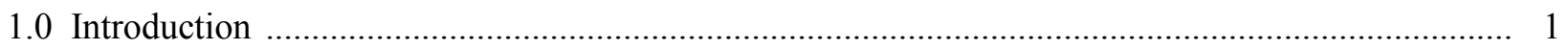

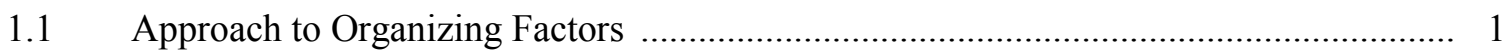

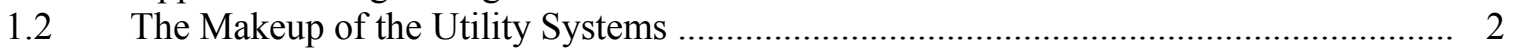

1.2.1 Generating Plants ........................................................................... 2

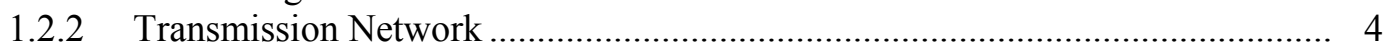

1.2.3 Distribution Network ................................................................. 5

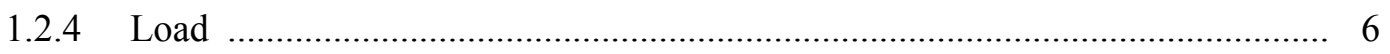

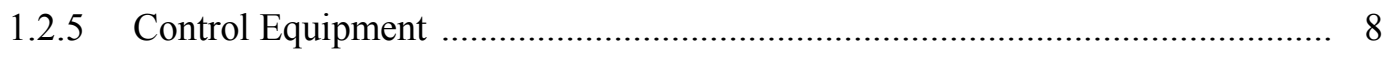

$1.3 \quad$ Definition of Intermittent Technologies ............................................................ 9

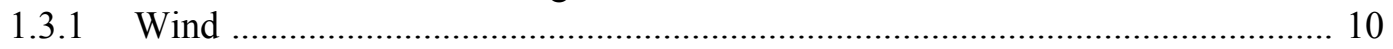

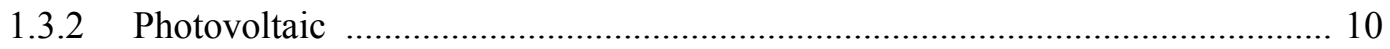

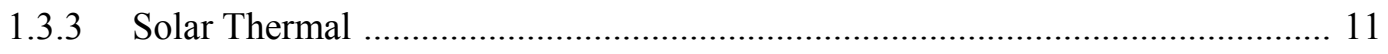

$1.4 \quad$ Impact of Renewable Energy Technologies on Utility Systems .................................. 11

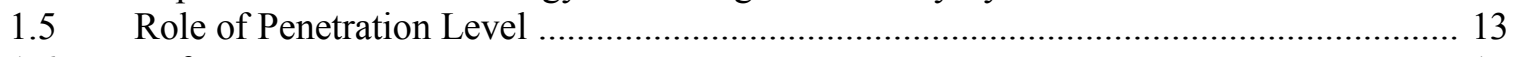

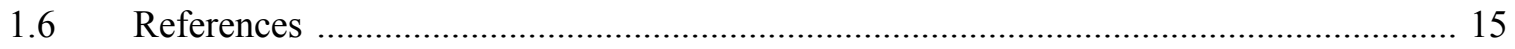

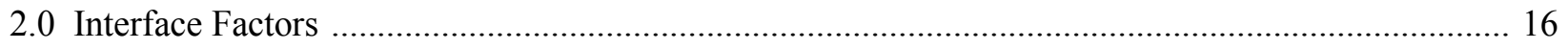

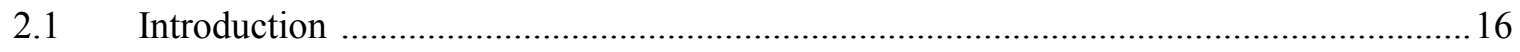

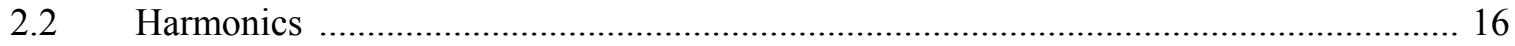

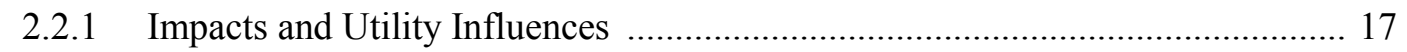

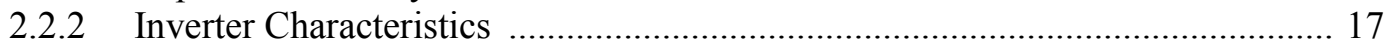

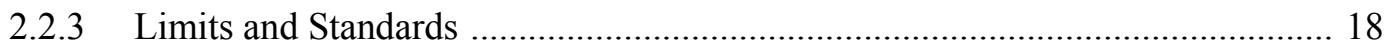

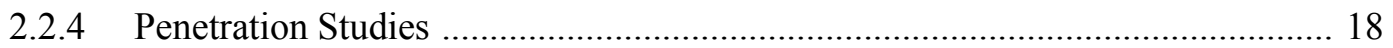

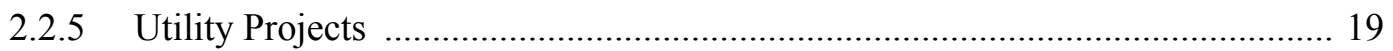

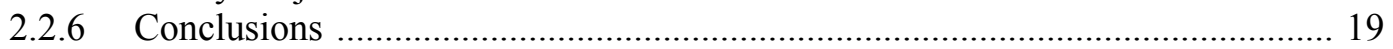

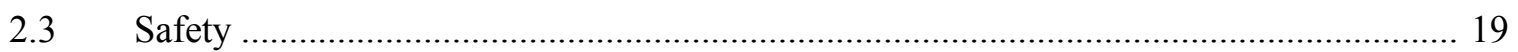

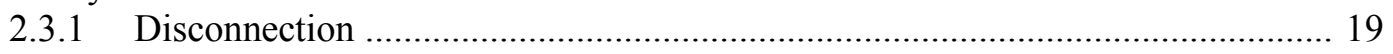

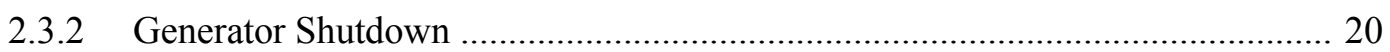

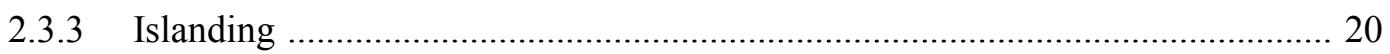

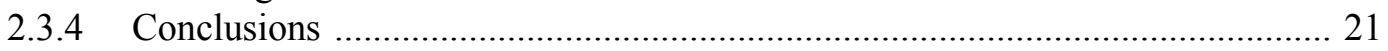

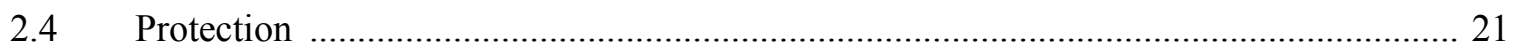

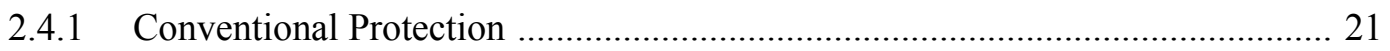

2.4.2 Impacts of Distributed Generators on Distribution System Protection ............. 22

2.4.3 Generator and Interface Design Considerations .......................................... 23

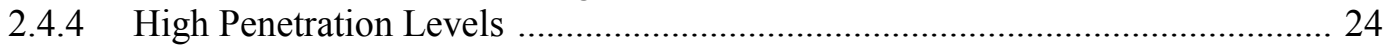

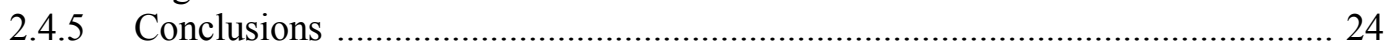

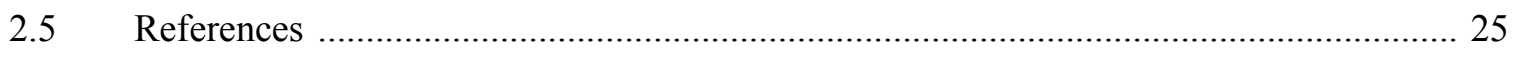

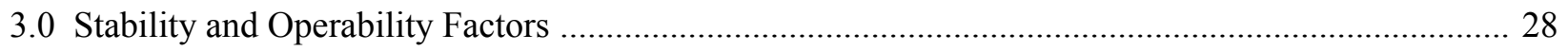

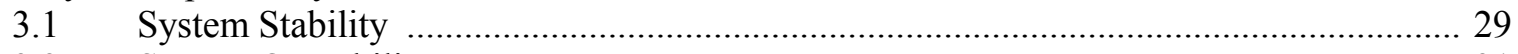

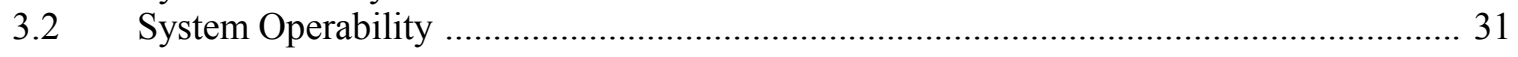

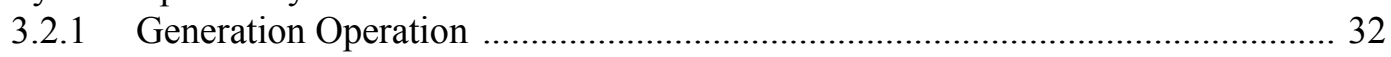

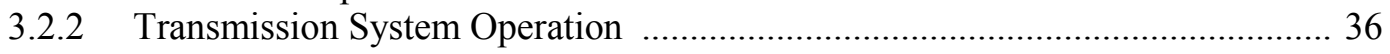

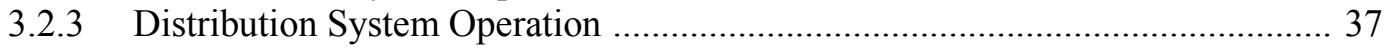

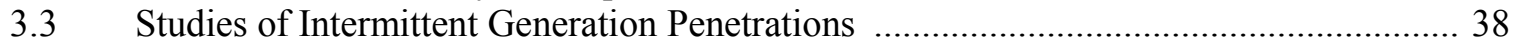

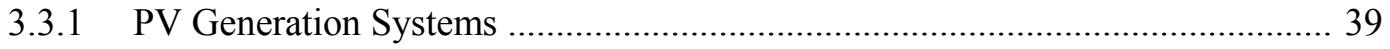

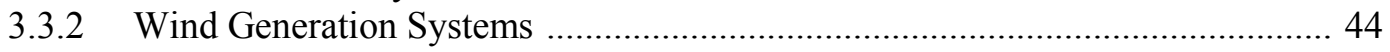




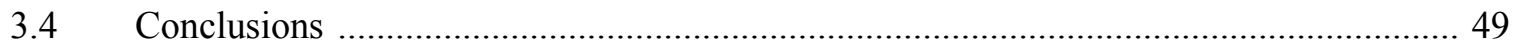

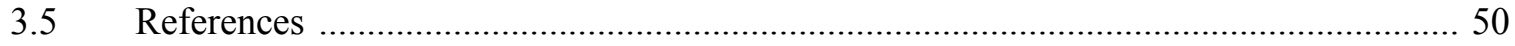

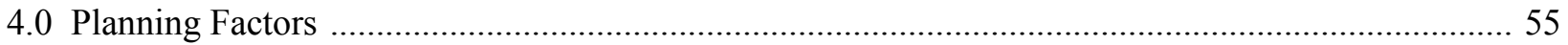

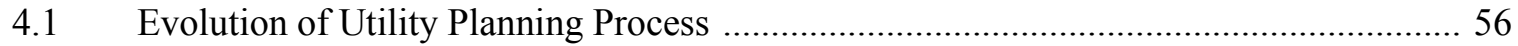

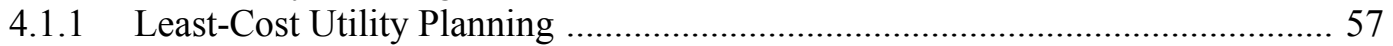

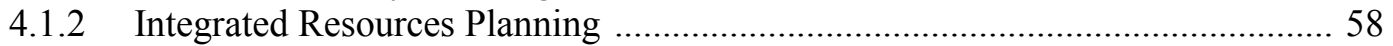

4.2 Planning for Intermittent Renewable Technologies ...................................................... 59

4.2.1 Valuation of Intermittent Renewable Generation Technologies ....................... 61

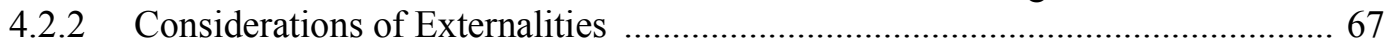

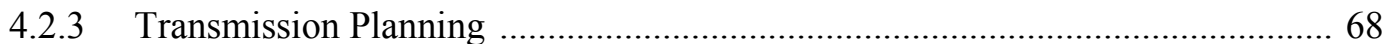

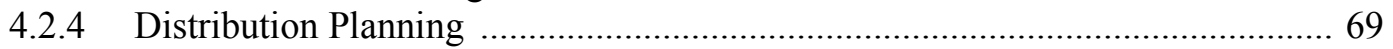

4.2.5 Other Corporate and Strategic Concerns ............................................................ 70

4.3 Issues Affecting Intermittent Renewable Technology Planning ..................................... 71

4.3.1 Operating Flexibility .................................................................................... 71

4.3.2 Planning Models for Intermittent Renewable Technologies .............................. 71

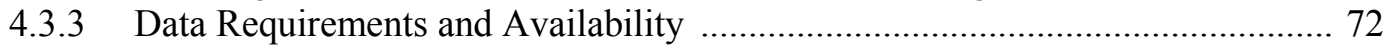

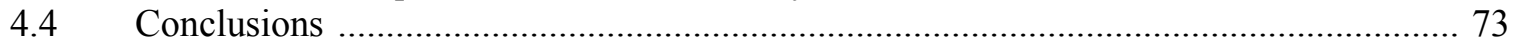

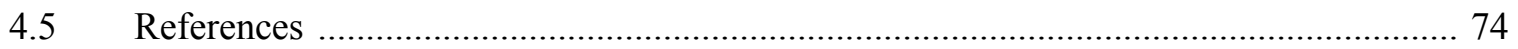

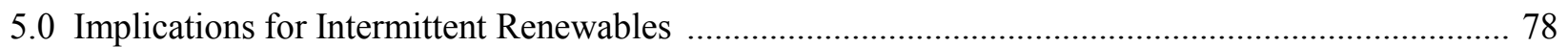

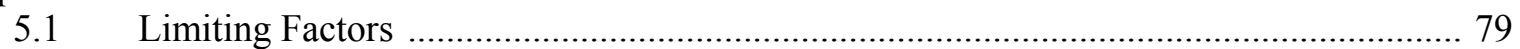

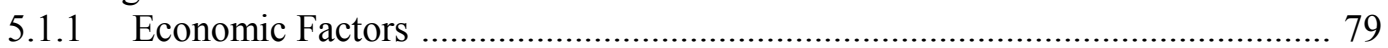

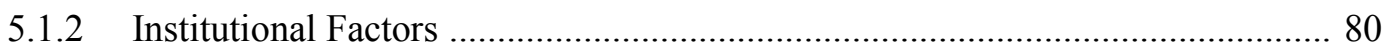

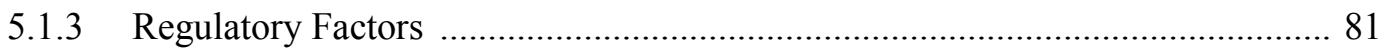

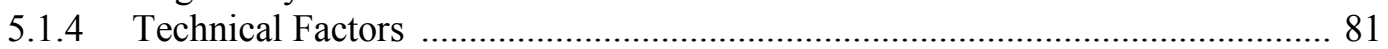

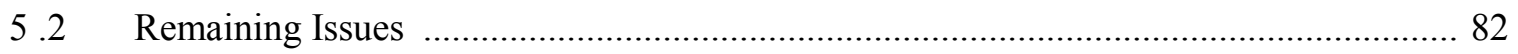

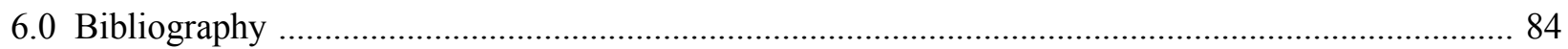




\section{List of Figures}

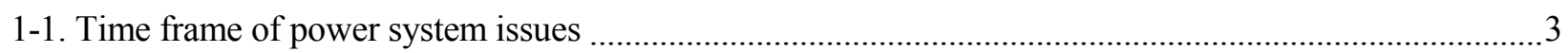

1-2. (a)Hypothetical utility daily load profile and (b)load duration curve ..................................................... 7

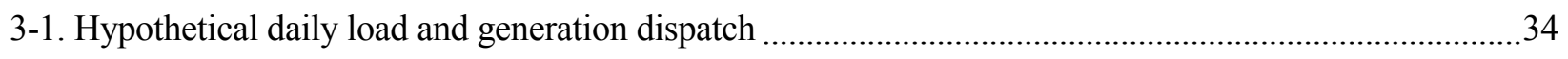

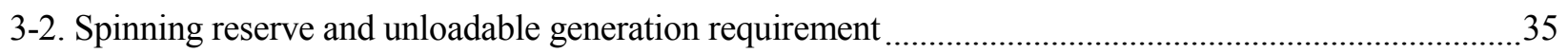

4-1. Wind generation ELCC as a function of penetration level .................................................................64

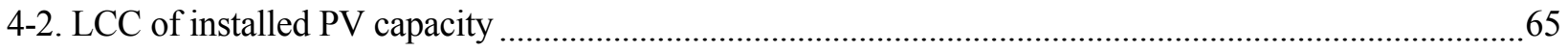

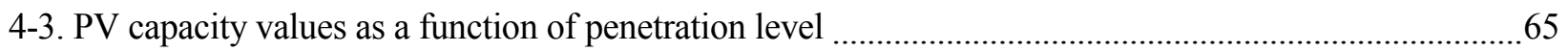




\subsection{Introduction}

This study assesses the current state of knowledge of the various factors that utilities must address regarding integration of renewable technologies that have intermittent output, such as wind- or solar-based systems, into utility power-supply systems. Many of the characteristics of these intermittent renewable energy technologies are substantially different from those of conventional utility power sources. Past studies have indicated that utilities have concerns that need to be addressed prior to large-scale integration of these intermittent renewables. Integration of renewable technologies into utility systems may be impeded if their benefits are difficult to define, questions remain unanswered, or technologies appear detrimental to utility operations. This study's goal is to identify the primary utility issues so that research can focus on those specific areas. This will guide researchers to develop pertinent tools and information for utilities to mitigate potential problems.

Much of the early development work on integration issues in the late 1970s and early 1980s has provided the starting point for assessing relevant issues. But these older studies have not been consolidated into a consistent data base or updated to today's standards of analytic capability. A few recent studies have added to the knowledge base of utility issues related to the penetration level of renewable technologies. In addition, there have been significant changes in the utility marketplace regarding regulatory policies, decision making, and the development of independent power producers. These changes have altered the type and level of information needs regarding integration of renewable technologies. This study is a first step to address these information needs.

This report will discuss three categories of integration issues: (1) interface factors, (2) stability and operability factors, and (3) planning factors. The information contained in this study is derived from published reports and data from industry or research laboratory work produced over the last ten years, much of which was sponsored by the U. S. Department of Energy (DOE), the Electric Power Research Institute (EPRI), and other interested utilities and organizations. A comprehensive bibliography is provided at the end of this report for readers seeking more detailed information and research results on integration issues discussed in the report.

\subsection{Approach to Organizing Factors}

For discussion purposes, the multitude of utility integration issues have been divided into three categories:

\section{Interface Factors}

Interface factors are primarily hardware and designed-related interconnection issues, especially those focused on the utilities' distribution level. The electric utilities' distribution systems are not designed to accommodate dispersed generating devices. A large number of renewable energy generators connected to a basically passive distribution grid may reverse the intended line flow of a feeder circuit, thus upsetting the coordination of protection devices on that circuit and possibly damaging the equipment. It may also become a safety hazard for utility workers who must maintain and repair the lines and equipment because workers could be unaware that an active unit is connected to a feeder. Some types of renewable energy technologies may generate excess harmonics and cause adverse effects on utility service quality. Most of these problems are not unique to the intermittent renewable technologies and must be addressed by all generation technologies connected to the distribution systems. These issues are discussed in Chapter 2. 


\section{Stability and Operability Factors}

When the installed capacities of renewable energy generating units reach appreciable size, normal utility operations will be affected. Researchers have identified several factors related to generation stability and operation that may limit the economic penetration level of renewable energy technologies in the utility power-supply sector. For example, the load- following capability and operating-reserve requirement of a utility may determine the maximum amount of non-dispatchable generations that can be incorporated into a utility generation mix without compromising normal utility operations. Chapter 3 provides a discussion of these operating issues and summarizes the results of selected recent studies.

\section{Planning Factors}

Issues that affect utility planning and decision making are reviewed in Chapter 4 . Intermittent renewables can be difficult to analyze, which makes valuation and planning more difficult. Closely related to planning factors are institutional, regulatory, and economical considerations that may hamper the integration of renewable energy technologies into the electric utility industry.

This study focuses primarily on stability, operability, and planning factors because many of the interface factors appear to be moot with state-of-the-art equipment design or include issues and concerns that have a much broader implication than just intermittent renewable technologies. Chapter 2 summarizes the utility interfacing issues and the results of research and development aimed at resolving these issues. Should the reader desire further information on interfacing factors, several sources are listed as references.

Another method of looking at the three categories listed above is to consider the time range of the event or activity. Several authors have presented this type of time-scale analysis. On a logarithmic scale, the time spans of transient events can be graphed along with those of longer term processes such as facility planning. Figure 1-1 illustrates the general time frame for typical utility issues and includes the approximate relationship among interface, stability and operability, and planning factors. The time frame also includes the time required for modeling to investigate the particular impact.

\subsection{The Makeup of the Utility Systems}

When considering issues and impacts on a utility power system, it is necessary to consider the major component parts of the system and their interrelationships. For this study, the electric power system is viewed in light of five different subsystems: generation, transmission, distribution, load, and control equipment. Electricity is produced at central generating plants and then transmitted and distributed over the transmission and distribution network to serve the electric loads. Control equipment ensures that the whole operation is carried out reliably and economically.

\subsubsection{Generating Plants}

Generation is the source of energy supply in the electric utility system. Electricity is produced at generating plants that typically consist of turbines and synchronous generators. Depending on the fuels used in the plant to provide power for generating electricity, the plants are conventionally classified as fossil fuel, nuclear, or hydro plants. The fossil fuel category can be divided further according to the type of fossil fuel used, e.g., coal, oil, or natural gas. The economies of scale achieved in generating units over the past 40 years have resulted in large central generation stations being the predominant form of generating facility. 


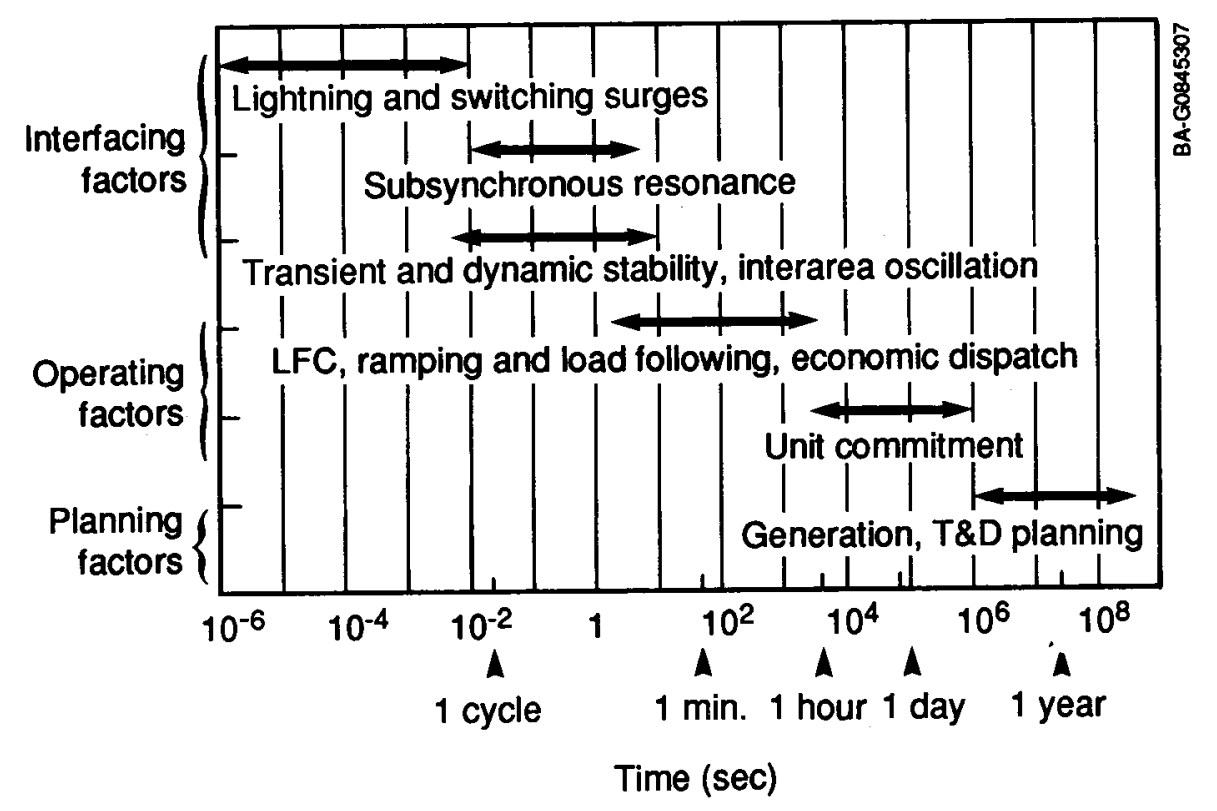

Figure 1-1. Time frames of power system issues

The load on an electric utility is the aggregate of electric demands of all its customers and losses. The demand for electricity fluctuates so that the system load of a utility changes constantly. Utilities normally do not control the demand, and the precise value of the demand at any instant is difficult to predict, but a utility usually knows its daily and seasonal load patterns within a small band of error through experience and various forecasting techniques. Most electric systems cannot store electricity, and utilities have to adjust their generation continuously to meet the actual load demand. This generation adjustment is called load following. Individual generators vary in their ability to follow load or to change their output rapidly. A generator's ability to change output is defined as its ramping rate and is often expressed in terms of megawatts per minute or percentage of unit capacity per minute.

From the utility's operational point of view, generating plants are classified as baseload plants and intermediate/peaking plants. Baseload plants are those that have a very high load factor (in the range of $80 \%$ ). They are normally designed to operate at a constant load level during normal operations. Because their output generally does not vary, these plants can be optimized for specific operating ranges and fuel usage; therefore, better efficiency can be achieved. Capital costs of baseload plants on a per kilowatt (kW) basis are high but variable costs (i.e., fuel, operation and maintenance [O\&M]) are low. Typical utility baseload generating plants include large nuclear, hydro, and coal-fired plants. They are expensive to build, but their production costs are low. Large baseload generating units may be used to follow the load swing to a limited extent. However, doing so may incur heavy penalties in plant component life and thermal efficiency. Continuously varying the load level of large generating units that are designed for baseload operation interferes with plant stability and controllability at low-load level and causes excessive thermal stress on plant components.

Peaking plants are usually used to serve the load for a few hours of the day during the system's peak demand period. Hence, the load factor is low (ranging from 5\% to 20\%). Short start time and fast ramping rate characterize these units. Capital costs of peaking plants are lower but their variable costs are higher because 
more expensive fuels are used and additional O\&M costs are incurred because of frequent start-up and shutdown. Natural gas combustion turbine or diesel engine generators are primary peaking plant choices. Conventional and pump-storage hydro power plants are also used for this purpose.

Intermediate plants are used to follow the daily or seasonal load fluctuations, and the output of these plants is adjusted up or down to balance the variations of the demand during the day. They are also called cycling ${ }^{1}$ units. Their load factor and costs lie in between the baseload plants and peaking plants. Intermediate generating plants are designed to use a variety of fuels such as coal, oil, or natural gas.

Utilities plan and build generating plants so that the load can be served reliably and economically. All three types of generating plants are required to accomplish this task. The plant mix has to provide utilities with adequate ramping and load-following capabilities so that load fluctuations can be met, and the resulting plant mix should properly minimize the capital and variable costs. In choosing various types of plants, utilities have to consider the type and size of each generating plant in relation to the system load and its pattern of variations. Fuel availability or limitation, fuel costs, capital costs, and maintenance requirements and costs are important factors in considering a plant mix. Utilities use various planning techniques and operating procedures to optimize their generation plant mix and operations.

The existing generation capacity in the United States totals about 730 gigawatts (GW) [1]. Currently, the contribution of renewable energy, other than hydro, to electric utility power generation is small $(<0.5 \%)$, but its potential is enormous [2]. One of the most distinct advantages of renewable energy technologies over conventional fossil-fueled power plants is that renewable technologies rely mostly on nondepletable energy sources such as sunlight and wind. The supplies of fossil fuels can be disrupted by some external factors, and their long-term prices are expected to rise as resources are depleted. Renewables have nondepletable supplies and no fuel cost escalations.

\subsubsection{Transmission Network}

The function of the transmission system is to move bulk power from generating plants to load centers. The predominant transmission system today is an alternating current (AC) network, which consists of tens of thousands of miles of extra-high voltage (EHV) lines and hundreds of thousands of miles of high voltage lines. Interconnecting these lines are thousands of substations with transformers, breakers, switches, relays, and metering apparatus. A few EHV direct current (DC) transmission lines or back-to-back DC ties exist in the United States primarily for point-to-point nonsynchronous power transfers.

There are three distinct AC transmission networks operating in North America: the eastern network, comprising most of the eastern and midwest United States and eastern Canada; the western network, covering western states and western Canada; and the Texas system, serving most of the state of Texas. Utilities within each transmission network are interconnected electrically with their neighboring systems and are operated in synchronization with each other. In contrast, the three transmission networks in North America are not interconnected or synchronized and have only a few back-to-back EHV DC links between them to allow very limited continuous transfers.

Traditionally, transmission systems are built to serve each individual utility's own load. Interutility ties are developed to enhance power system reliability by allowing power exchanges during emergencies and by

\footnotetext{
${ }^{1}$ The term cycling, as applied to an electric utility generator, has been loosely used to mean any one or a combination of the following three modes of generator operation: (1) on/off operation (weekend or overnight shutdown and start-up); (2) short-term load following (ramping up and down by system AGC); and (3) longer-term load following (backing down and stepping up in anticipation of load changes).
} 
allowing opportunistic or economic energy transfers among the interconnected utilities. With interutility ties in place, utilities can share generation reserves so that reserves held by each individual utility can be less than that amount needed by an isolated utility to maintain an acceptable system reliability. This reserve sharing will reduce generation costs of the interconnected utilities.

The transmission system, however, is not generally designed to transfer large amounts of power across one or several utility service territory boundaries. Considerable power-production cost disparities among different regions have developed since the 1970s. These production cost differences, along with the emergence of independent power producers (IPPs) and co-generators, have caused increasing demands on the transmission system to perform inter-regional transactions on a continuous or firm basis. Substantial economic and firm power transfers are occurring in utility power systems. These transactions have resulted in substantial savings or additional revenues to the utilities involved. The existing transmission system is adequate to meet these demands but is operating close to its capacity [3]. Opportunities, however, exist for additional transactions, as well as savings, if sufficient transmission capacity were available to allow such additional exchanges.

Increasing environmental and health concerns, competitive land use, and the regulatory siting and permitting processes have made it very difficult and costly to construct new transmission lines, especially lines that will cross several utility service areas to take advantage of potential new energy resources or economic transactions. The difficulty of building new transmission lines also raises the issue of access to existing transmission networks. The questions of who will have the right to access the transmission network and at what price have been extensively debated recently.

The most vocal advocates of open access to transmission networks are qualifying facilities (QFs), IPPs, public utilities (mostly municipalities), wholesale requirement customers, and some rural electric cooperatives. They perceive transmission access as a key to a more competitive power-supply market. Recent Federal Energy Regulatory Commission (FERC) rulings have made wholesale wheeling a mandatory precondition for approving some utility merger cases. The present FERC position seems to exclude QFs from full transmission rights. There have been several proposals by various organizations on

the transmission access and pricing issues. Besides institutional issues, open transmission access does have technical concerns that need to be addressed. Transmission capacity limitations, loop flow problems, system stability concerns, and planning uncertainties are all important technical issues. Utilities are also concerned about wholesale (and perhaps even retail) customer bypass and revenue loss as a result of open transmission access.

\subsubsection{Distribution Network}

The distribution network is responsible for taking the power from the high voltage transmission network, stepping (transforming) it down to lower voltages, and eventually delivering the electricity to end users. This part of the electric power system is closest to the electric utility customers. Therefore, its performance and reliability directly impact the service quality the customers are receiving.

The distribution network typically consists of substation transformers, protection and switching equipment, three-phase and single-phase distribution circuits, and distribution transformers. These circuits normally have a single source of power supply, and the power generally flows on these circuits in one direction (from substation to customers). The phase-to-phase voltage of the distribution circuits in the United States ranges from 4,160 to 34,500 Volts (V), with a large number operating at $12,470 \mathrm{~V}$.

Many renewable energy technologies are feasible for dispersed operations. Under the dispersed operating modes, renewable energy equipment is directly tied to the utility distribution system. Some studies [4] 
suggest that interconnections of renewable energy facilities at the utility distribution network have several distinct transmission and distribution benefits or values to the utility. Research ${ }^{2}$ is under way to identify all the benefits from distributed generation using renewable energy technologies.

Most of the hardware and design-related interface issues occur at the distribution voltage level. Utilities design and construct distribution systems to serve the load. Accommodating distributed generators at their distribution systems is not generally considered during the distribution planning process. Concerns of personnel safety, equipment protection, harmonics interference, and voltage fluctuations arising from the integration of renewable energy technologies are most prominent, even at very low system-penetration levels. Before large-scale interconnections of distributed renewable energy facilities can happen, these hardware and design-related interface issues must be fully addressed. Significant progress has been made in this field.

\subsubsection{Load}

Load on the electric power system arises from customer demand, and it is the driving force behind every electric utility activity. Because the distribution network, transmission network, and generating plants take progressively longer times to build, utilities must begin to plan and build these facilities well ahead of the time the facilities are actually needed. Also, plans must be flexible enough to allow modifications if conditions change. When finished, the new facilities will last for decades. In order for the utility to meet the current demand and plan for the future demand of electricity, the utility must have a good estimate of its future load.

Figure 1-2(a) shows a hypothetical utility daily load profile. This chronological load profile is obtained by plotting hourly system load consecutively for a day. Figure 1-2(b) shows the system load duration curve (LDC) of a hypothetical utility. The LDC is a plot of the utility's system load for a specified period of time. (Hourly load data for one year is used for Figure 1-2(b).) The LDC is obtained by sorting 8,760 chronological load datum points for a year in descending order and then plotting the points from highest to lowest. The abscissa in the LDC plot indicates the number of hours that the load exceeds a given value.

From these figures, it can be seen that a utility's minimum load can be less than $40 \%$ of its peak load, and peak load conditions occur only for a very small percentage of time. These are typical load variations the utilities must meet. Utilities usually install sufficient baseload generation capacities and operate them continuously at a constant output level to carry the minimum load. Adequate intermediate generation capacities are cycled to follow the daily or seasonal load changes. Peaking plants are used only for relatively short periods of time to cover the infrequent system peak demand.

These figures also illustrate the operational concerns of integrating intermittent renewable energy generation into the utility system: utilities have to alter the operation of other conventional generation plants to accommodate or absorb intermittent generations. Intermittent generation generally cannot be controlled by utilities (its output depends on meteorological conditions), and intermittent generation cannot contribute to a utility's load-following capability because it cannot be dispatched at will. The output fluctuation of intermittent generation may in fact increase the effective load variations that have to be covered by the rest of the generation system. The economic values of intermittent power generation vary with the time of its generation in relation to the system demand. The power produced by intermittent generations during system peak-load periods is worth much more than the power produced during the system minimum-load periods.

\footnotetext{
${ }^{2}$ For example, Pacific Gas and Electric Company (PG\&E), the National Renewable Energy Laboratory (NREL), and EPRI are engaging in a joint research project, Distributed Utility Valuation Project, that investigates the benefits of distributed supply- and demand-side options.
} 


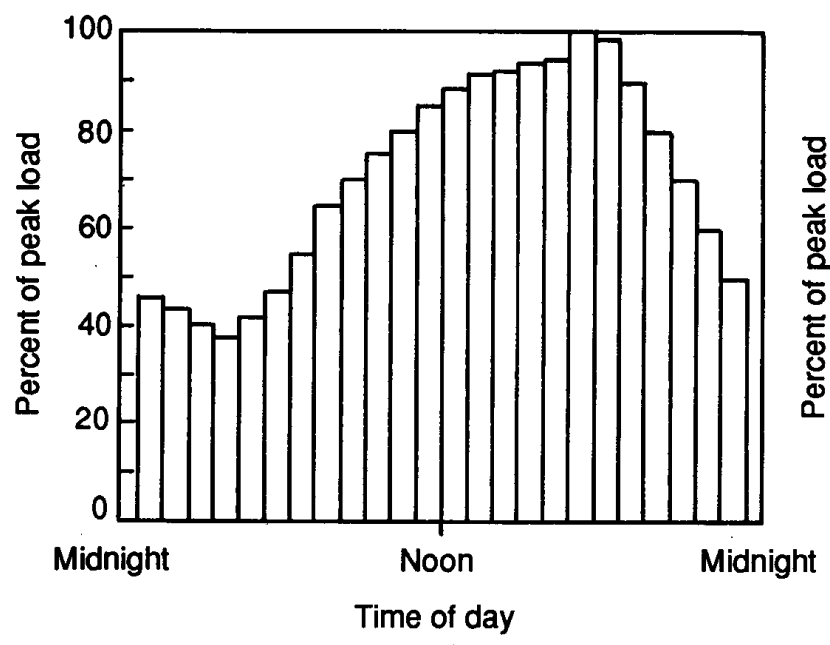

(a) A hypothetical daily load profile

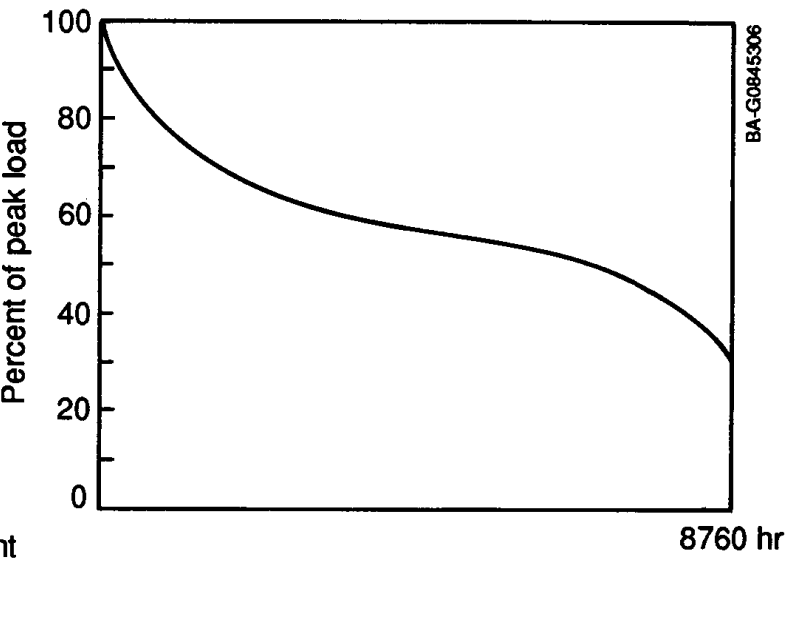

(b) A hypothetical annual LDC

Figure 1-2. (a)Hypothetical utility daily load profile and (b)load duration curve

Load forecasting is the first activity in the utility planning process. Both the magnitude and profile of the load are important to utilities. The shapes of a load profile curve and LDC depend on human daily activity schedules and weather conditions. Over longer periods, the shape of a load profile curve could be altered through various methods (i.e., efficiency improvement, conservation measures, etc.). Some utilities have used many direct load-control devices to manage the load profile for short periods. The ability to predict long- and short-term system load is vital to utilities. The methods employed by the utility to forecast load vary significantly, from simple trending of historic demands to very sophisticated end-use and econometric models. The demand for electricity is influenced by the following variables:

- Overall economic activities and population in the utility service area

- Weather conditions of the service area

- Price of electricity in relation to prices of other goods and competing energy sources

- Technological improvements of the energy end use.

To predict even one of these variables over relatively long periods involves large uncertainties. Despite the advancement in modeling techniques and computer capability, accurate load forecasting remains elusive. 
During the 1960s and early 1970s, utility loads grew steadily every year, with an average annual growth rate of about 7\% [1]. Load forecasting became a relatively straightforward process, and utilities could plan and build power plants confidently. During this period, even if the load forecasting was somewhat incorrect, the worst outcome would be that a few utilities would have more capacity than needed or a smaller generation reserve than desired. These imbalances would be corrected in a short time because of the continuing demand growth.

After 1973, the pattern of load growth became uncertain and much less predictable. At the same time, the cost of providing electric service escalated precipitously because of general inflation and increased fossil fuel price. Public awareness of environmental impacts and costs of meeting the electric demand also grew. Besides forecasting and meeting future loads, some utilities began to consider ways to control and shape the future demand so that costly capacity expansion could be avoided or postponed. Demand-side planning, including improved end-use efficiency, has now become part of the standard utility planning process. The new planning process has been called least-cost planning or integrated resource planning.

\subsubsection{Control Equipment}

The main objective of a power system operation is to ensure that the electric demand of the system is met by generation at all times in an economic and reliable manner. This objective requires utilities to operate their systems in a way that will minimize the cost of providing electric service while making sure that all facilities are operating within their design limits. Although this requirement represents a well- defined optimization problem in mathematical terms, it is too big and complex to solve in real time. In reality, the requirement is divided into several optimization problems so that solutions are feasible using current technologies. The control equipment of the modern power system is designed to achieve this objective.

Control equipment consists of a governor control at each generator and an automatic generation control (AGC) at the system level. A vast communication network links control equipment at different levels. Various telemetry channels gather data regarding power levels at each generating station and load center, reservoir level, network status, etc. These data are necessary for the control equipment to adjust the operating condition of each generator. The generation control function of the power system can be categorized in terms of time required to achieve the results.

At the generator level, the governor control senses its own shaft speed and adjusts the energy input to the prime mover (engine, steam, or hydro) that is driving the generator. The governor controls are designed so that the generator output will increase in response to a decrease of the generator shaft speed and vice versa. The governor characteristic is usually called a "droop characteristic" because of the negative torque-speed characteristic (turbine speed reduces as load increases). This control function is accomplished within several milliseconds.

If the power system is controlled only by the governor control function, the frequency will vary according to the system load. In order to maintain a constant $60 \mathrm{~Hz}$ system frequency at all load levels, the reference point of the governor control must be adjusted and the droop characteristic shifted, depending on the system load. This control function is known as load frequency control (LFC), and it is performed every 2-6 seconds. The LFC regulates the total generation output so that the generation can meet the system at a constant frequency of $60 \mathrm{~Hz}$.

To achieve optimal economy in the operation of the power system, the AGC also adjusts the output of each generator according to its efficiency, its fuel and operating costs, and its associated transmission losses so that the incremental production cost of each generator is equal. This control function is called economic dispatch (ED) and is performed every 2-10 minutes. 
Optimizing the overall cost of the power system operation requires proper scheduling of the generators. The scheduling has to take into consideration the regular generator maintenance schedule, generator start-up and shutdown costs, and the minimum fuel burn requirement. This part of the AGC function is called unit commitment (UC). The UC function determines hourly which generator to bring up or shut down. For longer terms, the UC function must also evaluate the seasonal availability of hydro resources to determine the optimal generation schedule. This schedule is usually made at least 24 hours in advance.

In addition to economic considerations, the ED and UC functions also will consider the operating reserve margin requirement. Operating reserve is necessary to guard against sudden loss of generation capacity caused by forced generator or tie-line outages. Two types of operating reserves are required: spinning reserve and nonspinning reserve. Spinning reserve is the difference between the total on-line generator capacity and the total output of those generators. The nonspinning reserve is the amount of generation capacity that can be brought on line in 10 minutes or less. Hydro power plants and some rapid-response combustion turbine generators are examples of units that can serve as nonspinning reserve. The amount of load the utility can interrupt in 10 minutes or less can also be counted as nonspinning reserve. Utilities normally carry enough operating reserve to cover the loss of the largest generating unit on a regional or subregional basis. Established operating guidelines also require that at least half of the operating reserve be spinning.

In addition, the power system control equipment includes an extensive communication network to link all parts of the control system. The function of the communication network is to ensure adequate transfer of data and control commands.

In order to ensure an economic and reliable operation of the interconnected electric power system, i.e., one area's control strategies do not interfere with the control and operation of its neighboring areas, the Operating Committee of the North American Electric Reliability Council (NERC-OC) has established guidelines for various functions of the power system control [5]. These guidelines constitute the minimum control standards in an attempt to monitor and regulate the control performance of all systems in the interconnected grid. All interconnected systems are expected to follow these guidelines in daily operating and long-term planning activities.

Renewable energy technologies affect every aspect of the power system control function. Some renewable energy resources, like solar and wind, are generally not dispatchable, and their availability is less predictable than that of conventional energy resources. For a shorter period, a large-scale integration of renewables can affect system LFC and operating reserve margin requirements. Over longer periods, renewable technologies will affect the ED and UC decisions as the intermittent output of the renewable generation technologies begins to alter the utility's load-following capability.

\subsection{Definition of Intermittent Technologies}

Intermittent technology refers to wind, PV, and solar-thermal-based systems that provide electrical energy output that varies over time with the natural fluctuations of the resources. Other than the deterministic

diurnal cycle, solar insolation is subject to random coverage of clouds, which makes short-term variations of solar energy difficult to forecast. Wind speed variations may follow a generally well-known daily or seasonal pattern, but specific short-term, minute-to-minute and hourly changes are hard to predict. Besides these temporal variations, wind and solar resources vary spatially, and the output from the same intermittent technologies could vary from site to site. 
Run-of-river hydropower generations follow the natural river flow fluctuations and, therefore, can be considered intermittent. However, there is a fundamental difference between the intermittencies of the runof-river hydro and the wind or solar power generation systems. The flow of a river usually does not change suddenly, and its fluctuations can be forecasted fairly accurately several hours or even days ahead. This predictability certainty makes a big difference to utility system operators. Instead of uncontrolled random changes, system operators can actually anticipate the changes and adjust other generations accordingly to compensate for the variations. For this reason, run-of-river hydro is not included in the discussions of intermittent technologies.

\subsubsection{Wind}

The use of wind as an energy source in electric utilities involves capturing the kinetic energy contained in the moving air masses and converting it to electric power and energy. A wind energy conversion system normally consists of a wind turbine with two or more blades attached to a single rotating shaft that is coupled to an electric generator. The wind turbine can be either a vertical axis or a horizontal axis design. Fundamental aerodynamic principles of air movement and lift explain the operation of wind turbines. The electric machine actually converts the energy of the rotational wind turbine shaft into electric energy.

Different types of electric machines are used in the wind generation system design. The induction generator is currently the most common type. Synchronous generators and variable-frequency AC generators are also feasible. In the case of variable-frequency $\mathrm{AC}$ generators, a static power converter is required to convert and regulate the electric output into a form suitable for interconnection with the utility system. A wind generation system may be connected to the utility system at the distribution voltage level. The distribution circuits can be dedicated lines, as in the wind farm configuration, or ordinary distribution lines that also serve utilities' loads.

With about 1,500 MW of installed capacity producing over 2.5 billion kWh of electricity per year[6], wind energy is already making sizable contributions to electricity generation in California.

\subsubsection{Photovoltaic}

Photovoltaic technology converts sunlight directly into electric energy using semiconductor devices. The PV technology has no moving parts. All PV systems start from a device called a PV cell, which produces DC electricity from sunlight. Different semiconductor materials and techniques are used to fabricate PV cells. Some of the common types of PV cells include single- crystalline silicon cells, semicrystalline silicon cells, and thin-film cells of amorphous silicon or copper indium diselenide. PV cells are arranged into flat solar panels or used with lenses to form concentrators of various sizes. The flat panels or concentrators then form arrays. A static power converter is required to convert the $\mathrm{DC}$ electric power into $60 \mathrm{~Hz} \mathrm{AC}$ for grid connections. The design of PV systems is highly modular and can be easily sized to match the needs of specific applications.

Efficiencies of PV systems range from $6 \%$ to as high as $30 \%$ in laboratory settings [7]. The most common PV system in use is a stand-alone applicatios where grid-connected electricity is not readily available. Despite its high initial capital cost, PV technology is currently economical in many stand-alone applications. Distributed PV systems are connected to utility distribution circuits; centralized PV systems can be connected to utility transmission lines. 


\subsubsection{Solar Thermal}

Solar thermal systems convert energy from sunlight into thermal energy for various applications. The solar thermal technologies that are relevant to electric utility integration are those using concentrated sunlight to generate electricity through conventional thermodynamic processes. Solar energy is concentrated by reflective surfaces or is used directly to heat a working fluid that powers a thermal engine to produce electric power.

Three types of solar thermal technologies using reflective surfaces--parabolic troughs, parabolic dishes, and central receivers--have evolved through research and development. They are capable of operating either in solar-only mode (where only solar heat is used) or in a hybrid mode (where heat from a conventional fuel source supplements the solar heat). The parabolic trough with a supplemental heat source is the most mature solar thermal technology today. Considerable operational experience also has been gained in central receiver technology with single steam cycle and thermal storage. Solar pond technology is a fourth method of capturing heat from the sun for conversion to electricity.

The parabolic trough system is the only solar thermal technology that is operated commercially. LUZ International has installed $355 \mathrm{MW}$ of parabolic trough generating capacity--called solar electric generating stations (SEGS)--in southern California. Solar heat is supplemented by natural gas burners. By FERC regulation, LUZ's natural gas usage is limited to $25 \%$ of total annual plant energy output. SEGS are considered dispatchable because of the supplemental heat from the firing of natural gas.

Both parabolic trough and central receiver systems are designed as centralized generating plants, whereas parabolic dishes with Stirling engines are more suitable for distributed systems. When operating in the hybrid mode with supplemental heat, the solar thermal plant behaves just like a conventional peaking or intermediate generation unit. Conventional control and operating strategies apply. The intermittent characteristics appear only when the solar thermal systems are operated in a stand-alone mode without storage or a supplemental heat source. In this mode, the output of the solar thermal system is subject to fluctuations of the available sunlight and will have characteristics somewhat similar to PV generation.

\section{$1.4 \quad$ Impact of Renewable Energy Technologies on Utility Systems}

During normal operations, electric utilities control and dispatch all generations to minimize the cost of producing electricity while maximizing system reliability. Each generation unit is committed and loaded according its heat rate, fuel cost and availability, associated transmission losses, and output ramp rate. The goal is to reliably satisfy the electric demand at the lowest possible cost. System performance is judged in terms of meeting operating guidelines established by the NERC-OC.

The renewable energy technologies considered in this report use wind and solar energy resources to generate electricity. The wind and solar power systems have no energy cost and low OM costs; the result is a very low production cost. The preferred electric system control strategy will always place those wind and solar generation units in high loading order, ${ }^{3}$ which means those units will tend to be loaded first and operated whenever the resources are available to displace the power produced by units using higher-cost fuel.

\footnotetext{
${ }^{3}$ Utilities load their on-line generators based on the short-term incremental production costs. Units with the lowest cost will be loaded first so that total production costs can be minimized. The loading order of generators is usually predetermined based on the unit's heat rate, fuel cost, and associated transmission losses. Units placed high on loading order in this report are units that have a low short-term incremental production cost and will be loaded first.
} 
However, unlike the operation of conventional generation units, system operators have no control over the availability and quantity of the wind and solar energy resources; weather variations dictate the output intermittency of these units. As described in section 1.2, system controls are constantly regulating generator output to match the load changes. The inclusion of intermittent energy technologies in the system means that conventional generators not only must follow the usual demand changes, but also must make up for the output variations caused by intermittent generators. Five normal functions of the generation operations could be impacted:

\section{- Load-Frequency Control}

When load exceeds generation, the system frequency will drop, and vice versa. Power system AGC monitors the system frequency to determine if generation and load are balanced. If AGC senses a decreasing system frequency, it will increase the output of the generators to match the load. When there is more generation than load, the system frequency will increase, and AGC will decrease the generator output. Intermittent renewable generation technologies generally cannot participate in these system frequency regulations because their output is independent of system frequency (no conventional drooping governor characteristics) and output control is feasible usually in one direction only (output curtailing).

\section{- $\quad$ Load Following}

If an increase in PV or wind power is not coincident with the system load increase, other generating units in the system will have to be off loaded in order to absorb all the PV or wind power. When meteorological conditions cause a decrease of PV or wind power, output from other units will have to increase to take up the generation slack. Utilities normally use intermediate plants to follow the load. However, when intermittent renewable energy generating plants are integrated in the power system, they tend to displace the intermediate plants based on short-term incremental production cost and plant operational characteristics. This practice may result in increased load-following duties for the remaining conventional generators assigned to the system regulation function.

\section{- Ramping Rate}

Ramping rate represents the generator's ability to change its output. When intermittent generation is added to the electric system, the ramping rate of on-line generators has to be increased to follow the combined load changes and output fluctuations of intermittent generations; e.g., load increase and intermittent generation decrease simultaneously, or vice versa. Both situations have the same effect: an apparent increased rate of change of the system load.

\section{- Unloadable Generation}

The down-ramping rate of a generator may be different from its up-ramping rate. Both rates are important to meet the normal system load-following requirement. The amount of generation that can be quickly off loaded (down ramping) is called unloadable generation. For a system consisting of only conventional generators, unloadable generation usually is not a concern. The system operator can always trip a generator if facing a sudden load decrease that cannot be matched by the system's downramp capability. In order to accommodate the maximum output from intermittent generating technologies, system operators have to make certain that on-line conventional generators can be backed down quickly enough, particularly when facing a simultaneous sudden increase of intermittent generation output and a system load decrease. Such an accommodation to absorb energy from intermittent generation cannot be made by tripping off a unit because the unit may be needed again shortly after being taken off line. 


\section{- Operating Reserve}

The impact on the electric system operating reserve is also related to the intermittency of some renewable generation technologies. Utilities carry operating reserve to guard against sudden loss of generation and unexpected load fluctuations. At least half of the operating reserve has to be spinning, and the remaining nonspinning reserve must be available to serve load within 10 minutes. Predictable generation and load variations for the next 10 minutes can be accommodated by dispatching necessary generation in anticipation of these variations. However, any probable load and generation variations that cannot be forecasted have to be considered when determining the amount of operating reserve. Carry operating reserves is expensive. If utilities cannot predict the short-term output fluctuations of intermittent renewable generations, more operating reserves will have to be scheduled to adequately regulate the system. This requirement will increase the cost of integrating intermittent solar and wind systems.

These five impacts on operational requirements mean that more units will be brought on line or put on regulating duty, which may increase the system operating cost (additional start-up and shutdown cycles, more fuel consumptions and maintenance).

Several renewable energy technologies require reactive power support from the electric system for proper operation. Examples are wind turbine systems using induction generators and power conditioning units with line-commutated inverters. When connected to an electric system in large numbers, the additional reactive power requirement will adversely affect the transmission and distribution system voltage profiles. Reactive power support and its control also raise concerns of system stability. Reactive power deficiency can cause voltage collapse ${ }^{4}$ and subsequent disintegration of the electric system. On the other hand, newer designs with advanced power conditioning units are capable of supplying reactive power to the electric network. Instead of adversely affecting the voltage profile of the network, such generation can help improve the voltage profile. Strategically located, these units will have additional transmission and distribution benefits to the system.

The development of renewable energy technologies will be affected by other transmission issues. Studies have shown that promising renewable resource sites are often far from existing growing load centers and existing transmission lines. Access to an existing transmission network and costs of new transmission lines to connect potential new renewable resources to load centers will strongly impact the development of these resources [8]. Large-scale installation of renewable technology generation will highlight the transmission access and pricing issue.

\subsection{Role of Penetration Level}

When the amount of renewable energy generation connected to a system is only a small fraction of the total system capacity, the impact on the system load-following and reserve margin requirements will be minimal. The demand for electricity is stochastic in nature. The output intermittency of the renewable energy generations is seen by the system control as merely an extension of natural load fluctuations. The output

\footnotetext{
${ }^{4}$ When reactive power demand of a region cannot be met because of a sudden increase in local reactive power demand, loss of a local generator, or loss of a transmission line that transfers reactive power into the region, bus voltages at that region can drop sharply. This sudden drop of voltage will trigger a protective device to take generators off line, which in turn can cause the disintegration of the interconnected electric network.
} 
intermittency of renewable energy generations and the utility's intrinsic load variations are generally independent of each other; their combined effect on the system control is random load fluctuations with perhaps wider variance.

The installed capacity of wind and solar energy systems today is relatively small compared to the host utility system load. Renewable energy systems, although connected to the electric utility network, are not treated by utilities as an integrated part of the generation mix. More than 1,500 MW of wind generation capacity is currently installed in California. At times, the wind generation may reach $8 \%$ of the host utility's system demand. Those wind generators are not under the utility AGC, but the utility's operation is not adversely affected.

At this very low penetration level, the issues that concern utilities are personnel safety, equipment protection, and service quality. These are basically design and hardware-related interfacing issues. These concerns, along with standard requirements for connection, are discussed in detail in Chapter 2. For intermittent energy generations that lack automatic reactive power adjusting capabilities, connection with a utility system may cause transmission and distribution operational problems by affecting the local reactive power flow and voltage profile. Some type of reactive power compensation may be required, even at a relatively low system penetration level of intermittent energy generations.

When the penetration level of the intermittent energy generations increases, the impact on the electric system real-time control will become significant. Two different situations arise with high penetration levels. One situation is that the total intermittent renewable generation capacities connected to a distribution feeder represent a very high percentage of local demand, e.g., in a PV subdivision or a wind farm, but the overall intermittent capacity is still only a small fraction of the total system capacity. In this case, the utilities will be confronted with problems of large voltage and power fluctuations in certain areas caused by rapid changes of the intermittent energy generation. Local service quality and local system reliability will be major concerns.

The other situation is that the intermittent energy generations supply a significant portion of the total system demand. Here, overall system stability and operations become important concerns. An example of the worst-case scenario would be a large storm front moving rapidly across a wind farm or large PV array that causes the maximum rate of decrease from these intermittent generations while the system load is experiencing the maximum rate of increase. The opposite condition--maximum rate of increase of the intermittent generations caused by rapid clearing of the sky when the system load is decreasing at a maximum rate--is easier to solve. In this case, system operators can simply curtail the intermittent generations. However, this practice will reduce the value of intermittent energy technologies. In order to cover the rapid changes of the intermittent energy output and load, system operators must commit more conventional generators on line as regulating units. Both the technical feasibility and economic impact of this practice concern utilities, in addition to the hardware-related interfacing issues. Chapter 3 examines these penetration-level and operability issues of intermittent renewable technologies.

Intermittent renewable energy technologies derive most of their value from displacing generation from conventional units that use higher-cost fuels. With an increased penetration level, more and more conventional generating units may be needed on line and partially loaded to add load-following capability and operating reserve to the system. The increased cycling duties and decreased efficiency caused by the partial loading of these generators will increase fuel consumption and maintenance costs. At certain penetration levels the savings offered by intermittent generations could be offset by the above operations, making it uneconomical to add intermittent generations into utility systems. Issues related to the valuation of intermittent renewable technologies are discussed in Chapter 4. 


\subsection{References}

1. Edison Electric Institute, Statistical Yearbook of the Electric Utility Industry/1989, EEI Washington, D.C. 1990.

2. Solar Energy Research Institute, The Potential of Renewable Energy--An Interlaboratory White Paper. 1990.

3. North American Electric Reliability Council, 1989 Reliability Assessment.

4. Shugar, D. S., "Photovoltaics in the Distribution System: The Evaluation of System and Distributed Benefits," Proceedings of the 21st IEEE Photovoltaic Specialist Conference, Kissimmee, Florida. May 1990.

5. North American Electric Reliability Council, NERC Operating Manual, 1991 edition.

6. Results From The Wind Project Performance Reporting System-1990 Annual Report. California Energy Commission. December 1991.

7. Williams, S. and Porter, K., Power Plays--Profiles of America's Independent Renewable Electricity Developers, Investor Responsibility Research Center, Washington, D.C. 1989.

8. Pacific Northwest Utilities Conference Committee, Blackfeet Area Wind Integration Study, PUNCC, Portland, Oregon. August 1991. 


\subsection{Interface Factors}

\subsection{Introduction}

Interface factors arise from the connection of electric generators to the utility distribution system. Potential problem areas include distortion of the $\mathrm{AC}$ waveform (harmonics), personnel safety, and disruption of protection schemes.

Large, central generating stations, or groups of modular generators with a common utility tie point (like wind farms), do not pose interface problems. Utilities are accustomed to this type of connection. The large amounts of power produced and consequent economies of scale afford the interconnection at the utility transmission system using standard utility equipment and protection schemes. There may be a direct communication link between the utility control center and the generation site to provide the system operator with real-time status information about the generators and to facilitate the utility control of these generators. Interface problems are more commonly associated with intermediate (in the range of 500-1,000 kW or less) and residential-sized systems that export excess power into the utility system. They are commonly connected to the distribution system without a communication link to the utility system operator. Utility grade interface equipment may be prohibitively expensive for smaller systems.

Interfacing issues may arise from the are a result of:

- Interconnecting different types of generators to utility distribution networks

- Changing from a passive distribution system to an active one

- Bi-directional power flow with more than one source

- $\quad$ Loss of utility control implied by independent generator ownership [1].

Potential problems are not unique to intermittent renewable technologies and must be addressed by all distributed generators 5 , small IPPs, and qualifying facilities (QFs). Hardware and performance specifications for interconnection are issued by utilities. Costs, including required utility-side system upgrades, are usually born by the generator owner/operator.

The conclusion, elaborated in the following sections, is that for interconnections of intermittent renewable technologies into a utility grid, most major technical issues have been addressed and acceptable interface equipment is commercially available. Work remains in technology-transfer areas. Existing technical results need to be translated into accepted standards, and interface hardware testing and certification programs need to be established. Future cost reductions with innovative equipment are anticipated; the testing and certification of advanced designs will also need to be addressed.

\subsection{Harmonics}

Harmonics are undesirable distortions of the utility AC sinusoidal voltage and current waveforms. The distortions are additional sinusoidal waves with frequencies that are integer multiples of the fundamental $60 \mathrm{~Hz}$ oscillation. Harmonic frequencies can cause overheating, malfunctions, and damage to both utility

\footnotetext{
${ }^{5}$ Distributed generators refer to all generators that are not integrated into the utility's AGC, i.e., the operations and output of those generators are independent of a utility's load and system frequency.
} 
distribution and customer load equipment. Harmonic distortion is currently an issue for utilities, even without the interconnection of distributed generators. Both utility transmission and distribution (T\&D) hardware (including transformers and capacitors) and nonlinear customer loads (including arc-furnaces and welders, rectifiers, and fluorescent lights) distort the in-service waveforms. Intermittent renewable generators can add to the harmonic distortion by producing power with less-than-perfect $60 \mathrm{~Hz}$ sinusoidal waveforms. Total distortion magnitudes depend on the generator, the utility hardware, and load characteristics. The effects are hard to define because harmonic magnitudes vary widely depending on sitespecific utility line impedances, and unexpected network response to harmonics can occur because of resonance.

Harmonic distortion by distributed generators is associated with the use of static power converters (inverters), which convert DC output to $60 \mathrm{~Hz}$ AC power. Therefore, harmonic issues are commonly associated with PV cell output. Synchronous and induction generators commonly used in wind power systems do not have significant harmonic output. However, new wind system designs using a DC bus in conjunction with a variable-speed generator may contribute harmonic distortion to the utility grid.

\subsubsection{Impacts and Utility Influences}

Impacts of harmonics on utility and customer equipment are summarized by Fuchs [2] and the DOE [3]. Major impacts include increased temperature rise and decreased equipment life. Generalized characterization of existing levels of harmonics in utility lines is difficult because of the wide variation of utility system characteristics. For example, rural feeders may have almost three times the impedance of urban feeders, resulting in three times the harmonic voltage for the same current harmonic levels. The Alabama Solar Energy Center put harmonics in perspective by comparing distortion levels caused by common household loads to those caused by residential-sized inverters [4]. A self-commutated inverter had third harmonic currents much less than most of the loads, while distortion from a line-commutated inverter was comparable to the distortion from a window air-conditioner.

Resonance effects are largely determined by the placement of power factor correction capacitors. In one PV study examining multiple generators on a feeder $[5,6]$, voltage total harmonic distortion $\left(\mathrm{THD}^{6}\right)$ varied from $6.2 \%$ to $2.4 \%$, depending on capacitor placement and connected load. Methods to predict and mitigate resonance effects are available [6]. In cases where resonance increases harmonic levels, several solutions are possible, such as using active harmonic canceling [7], changing the location of power correction capacitors [6], or using variable, programmable capacitors [8].

\subsubsection{Inverter Characteristics}

The harmonic content of intermittent generators is a result of inverter design characteristics. Linecommutated inverters use the change in polarity of $\mathrm{AC}$ voltage to control switching. Consequently, the inverter produces a $60 \mathrm{~Hz}$ square wave for single-phase devices. The line-commutated hardware is proven and inexpensive because of the absence of a complex control circuit, but these inverters may have unacceptably high harmonic output. Filters may be used to shape power waves but they add to the cost. Self-commutated devices have an internal oscillator, which allows much higher operating frequencies and,

\footnotetext{
${ }^{6}$ Total harmonic distortion (THD) of a periodic waveform is the ratio of the effective value of all the harmonics to the effective value of the fundamental, and it is usually expressed in percentage, e.g.,

$\mathrm{THD}($ for voltage $)=\frac{\sqrt{E_{3}{ }^{2}+E_{5}{ }^{2}+E_{7}{ }^{2}+\ldots}}{E_{1}} \%, \quad$ where $\mathrm{E}_{\mathrm{n}}$ is the $\mathrm{n}$-th harmonics.
} 
consequently, a lower harmonic content.

Commercial and federal research and development have made economical hardware with low harmonic output available for a wide range of power levels. These devices, originally developed with an eye toward PV generation or general power conversion applications, are applicable to DC wind technology as well. An excellent description of inverter design characteristics and a discussion of federally sponsored inverter development is provided by Stevens [5]. Single-phase, line-commutated units have produced current THD levels of $6 \%-23 \%$ in tests on several devices. Comparable self-commutated units have produced current THD levels of only $0.25 \%-3 \%$. Potential future improvements are discussed by Smith [7]. Recent advances in switch-mode converters have reduced the number of parts and the cost of self-commutated devices. Prices of single-phase, self-commutated units dropped below those of older-design, line-commutated units. There are indications that three-phase units are experiencing a similar trend. Lower costs should promote the application of self-commutated inverters and lessen the harmonic problems.

\subsubsection{Limits and Standards}

U.S. guidelines for allowable harmonic distortion on utility lines are available, but not universally accepted. The most commonly cited standard is ANSI/IEEE (America National Standard Institute/Institute of Electrical and Electronics Engineers) Std 519-1981 [9], which allows higher distortion levels for lower bus voltage ratings (with a maximum of 5\% voltage THD at $69 \mathrm{kV}$ or less for general power systems). This standard is currently being revised and will likely include specific allowable current distortion levels dependent on harmonic order and short circuit/rated current. EPRI has published proposed design targets for power conditioning equipment, which include total root-mean-square (RMS) current levels of 5\% and voltage levels of $2 \%$ [10]. Other applicable standards that mention harmonics are listed in the references. Existing standards are difficult to apply because no line impedances are specified. The often-cited ANSI/IEEE Std 519-1981 and others list only total line limits, not limits to individual device contributions.

At present, the number and power outputs of independently owned, utility-interconnected inverters are small. As a result, existing interconnection guidelines do not usually contain specific harmonic limits $[11,12]$. However, the utility may require that harmonics be reduced to an undefined "acceptable level" if it finds problems after installation. If future utility interconnection requirements follow existing harmonics standards and guidelines, acceptable inverter hardware is generally available.

\subsubsection{Penetration Studies}

A number of past studies have examined possible utility penetration limits of distributed power inverters based on harmonic distortion $[5,6,13,14,15,16]$. Typically, a harmonic distortion limit from $2 \%$ to $5 \%$ was selected, then the number of inverters necessary to reach the limit was calculated using the characteristics of specific, older-style, line- and self-commutated units (sometimes with filtering). The studies assumed the worst case of all harmonics being in phase and all units operating at peak output simultaneously. Results in these cited studies show the acceptable penetration levels of inverter- type generators ranging from $13 \%$ to $100 \%$ of the available line capacity. These studies illustrate that harmonics problems are a possibility if a large number of lower-quality inverters are rapidly deployed. Recent advances in self-commutated technology and lower costs have greatly reduced penetration limit concerns based on harmonics. 


\subsubsection{Utility Projects}

Acceptance of privately owned, grid-connected, distributed generators often entails utilities performing their own studies of potential impacts, including hardware testing and evaluation. Results have a large impact on the development and implementation of policies and guidelines. Smith [7] discusses a number of utility projects that include harmonics investigations. Just completed is a five-year test of 30 residential PV units on the same feeder in Gardner, Massachusetts, by New England Electric System [17]. For well-designed inverters, harmonic distortion was not found to be a problem; no harmful interactions with the utility were observed, and no limits on penetration could be inferred from the results. Power quality, including harmonics, will be part of the ongoing Photovoltaics for Utility-Scale Applications (PVUSA) investigations at Pacific Gas and Electric's Davis test site [18]. Successful completion of these and other investigations will increase utilities' confidence that harmonic levels produced by well-designed DC-AC inverters are acceptable.

\subsubsection{Conclusions}

Recent and anticipated commercial developments tied with realistic market-driven installation rates will most probably eliminate harmonics as a technical issue without further federal government funding.

Utilities' acceptance of inverter-type generators in their distribution systems will require further harmonics standards development and module testing and certification. These efforts should be maintained on a continuing basis as new technology becomes available. Acceptance may be accelerated through additional cost-shared demonstration and testing projects like those by PVUSA.

\subsection{Safety}

Dispersed generators, including intermittent renewable energy generation systems, add power sources to utility distribution grids. Safety concerns arise from the possibility that the generator may energize a line that would otherwise be dead. Scheduled and unscheduled distribution system maintenance and repair operations must be completely safe for the workers. Current utility maintenance and repair procedures require disconnection of all distributed generators. If all generators are not disconnected, under certain conditions that the generators may continue to operate and supply local load. Generator interface hardware designs must recognize this hazard, and the issue must be fully resolved to the satisfaction of all parties involved.

\subsubsection{Disconnection}

Utility work practices incorporate redundant procedures to ensure lineman safety. Sectionalizing switches are opened to isolate work areas, and lines are tested to ensure their de-energized status. Grounding cables are connected to prevent shocks that might arise from induced voltage or inadvertent re-connection [19]. In addition, current Occupational Safety and Health Administration (OSHA) regulations require workers to open manual disconnect switches at every possible source of power in an otherwise isolated line section before work begins $[20,21,22]$. Most utilities require a disconnect switch to be installed at the point of interconnection between the distributed generator and the utility grid. This switch has to be tagged and locked open to prevent unauthorized personnel from reconnecting the power before work is complete. Recommended work procedures outline communications between the system operator (who maintains records of private generator locations) and the lineman and incorporate appropriate disconnect/reconnect sequencing $[10,19]$. These established procedures seem adequate for near-term, low penetration levels. 
Several authors $[10,20]$ suggest adding more sectionalizing switches to areas with many distributed generators. This would decrease the number of disconnects that must be opened to isolate a section of line. Use of live-line procedures would eliminate the need for opening manual disconnects. However, live-line procedures take more time than existing procedures. Another future possibility is the use of an automated disconnection system [10]. Disconnection could be incorporated with other functions in a general automated distribution or load control scheme. Some form of verification of an open switch still would be necessary.

\subsubsection{Generator Shutdown}

The automatic disconnection of generators from the grid or the use of live-line procedures can eliminate safety hazards in the event the distributed generators continue to pump power into the grid after the loss of the utility voltage. A complementary approach is to ensure that these distributed generators shut down when utility power is lost. Utility power may be lost for many reasons. System disturbances such as faults, lightning, equipment failure, or frequency/voltage excursions can cause protective equipment to operate and de-energize a portion of the system. Properly designed distributed generator interface equipment should detect system disturbances and disconnect generators.

Power also can be lost because of line switching for routine maintenance work. In this case, there is usually no indication to the distributed generators that they should cease operation [10,23], and the generators may continue to energize an isolated grid section. Researchers and utilities call this condition run-on or islanding. $^{7}$

\subsubsection{Islanding}

A significant amount of research has focused on islanding issues. Circumstances that may lead to islanding have been identified and hardware and detection schemes have been tested and improved. Although the chances of islanding are very small, some occurrences are on record.

For islanding to occur, the isolated load and generation (including reactive power support for induction generators and line-commutated inverters) must be closely matched at the time of a no-fault utility disconnect. If a fault causes disconnect, properly designed distributed generator interface equipment will shut down the distributed generators. Without a close match, the generator output frequency and voltage will drift, and over/under frequency and voltage protection relays will disconnect the generator. A recent investigation concluded that islanding is an intrinsic possibility with all power conditioning systems, but the practical possibility of distribution system islanding for extended periods is limited by normal variations in load and intermittent renewable generator output [24].

Other researchers have analytically and experimentally investigated islanding, identifying possible conditions for specific equipment $[8,10]$. Hardware development has resulted in adding internal destabilizing circuits and internal trip mechanisms, which have further reduced the possibilities of islanding

\footnotetext{
${ }^{7}$ Islanding has traditionally meant an operating procedure to protect generators during a system contingency when system frequency continues to decrease. After automatic underfrequency load shedding fails to stabilize the system frequency, generators are isolated from the electric system with enough local loads left on the generators to keep them in operation. This "island" operation mode is aimed at protecting the generators and facilitating the restoration of the system after the contingency. Although it is desirable for generators to enter the islanding operation under certain system contingencies, the term islanding is used to describe the uncontrolled and undesirable operation of small generators connected to an otherwise de-energized electric system. It thus has a negative connotation in this context.
} 
$[5,15,25]$. However, in one test a commercial unit did run-on indefinitely under some conditions because of a malfunction of a capacitor in the detection circuits. This points out the need for certification testing of individual power conditioning units.

Incorporating islanding detection schemes in the distribution system is also possible. Ranade [15] and Wasynczuk [26] suggest monitoring harmonic impedance at power conditioning unit terminals. The impedances, and therefore harmonic levels, change dramatically after the disconnection of the utility power source.

\subsubsection{Conclusions}

Near-term, low-penetration safety issues can be addressed by existing hardware in the framework of current utility practice. Use of manual, lockable disconnect switches on intermittent generators will ensure deenergized lines. Temporary grounding provides an additional level of protection once line work has begun.

If the generator is not actively disconnected and locked out (because of worker error or interconnection of systems without the utility's knowledge), it can increase the chances of a sustained islanding condition. Incorporation of de-stabilizing and trip mechanisms to the power conditioning equipment adds another level of worker protection and nearly eliminates any islanding-related safety concerns. However, utilities express concern with any possibility for islanding. More testing of actual installations may be required [7] to resolve all safety-related issues.

At high penetrations, additional modifications of existing practice may be necessary to reduce maintenance time. More sectionalizing and switching devices will reduce the time required to isolate lines. Live-line work procedures also could be adopted. Automated disconnection or islanding detection could be incorporated in future automatic distribution control systems or load management systems.

\subsection{Protection}

Generators connected at utilities' distribution systems, including those using intermittent energy resources, may potentially upset conventional utility distribution system protection schemes. Specific issues associated with protection include fault current and overvoltage contributions of generators, detection of abnormal power conditions, protection coordination, and direct current injection. Researchers have found solutions that can be integrated into existing protection devices and generator hardware. However, utility protection schemes vary widely, and a detailed study using established techniques may be necessary to identify specific problems and solutions. Some identified solutions may be quite expensive, and gaining utility acceptance of lower-cost, alternative hardware may require substantial effort. Effective technology transfer and successful demonstration of new technologies in the utility environment will reduce concerns.

\subsubsection{Conventional Protection}

Distribution system protection elements recognize abnormal power conditions in voltage and current. When power deviates from established limits, the system acts to accomplish the following:

- Minimize utility and customer equipment damage

- Isolate the cause of the disturbance and minimize the area affected by any outages

- Reconnect without extended outage time if the disturbance is temporary. 
Conventional protection systems have a well-established record of performing these functions with high reliability. The nature of the protection scheme employed on a distribution line depends on the wire configuration (4-wire multigrounded, 3-wire single ground, and 3-wire ungrounded), layout (radial or network), transformer type, and utility practice. For detailed information, the reader is referred to Longrigg and Buell [27], who discussions of conventional protection for various system configurations.

\subsubsection{Impacts of Distributed Generators on Distribution System Protection}

Integrating distributed generators can potentially upset fault interruption coordination and may dictate utility equipment upgrades. The impacts on the utility side are highly dependent on the characteristics of the distribution system and protection scheme. Longrigg [28] recommends load flow, fault current, and transient stability analysis to identify any required changes in the distribution system. Solutions to problems using existing hardware are available, but costs may be high; a proper allocation of costs among all affected parties remains as a nontechnical issue.

\section{Fault Current Contributions of Distributed Generators}

The major protection concern addressed in the literature is fault current. Curtice and Patton [10] summarize the possibility of distributed generator fault contributions as a function of fault type, distribution line configuration, and generator configuration. Induction generators and line-commutated inverters contribute fault currents as large as start-up or in-rush currents that may occur for less than one cycle but are not capable of producing long-term fault current because they depend on line voltampere reactive $\left(\mathrm{VAR}^{8}\right)$ support. Synchronous generators can contribute significant fault currents. Transient contributions can be quite high (up to 7 times full load values), decaying rapidly to a steady-state contribution in the range of $100 \%-250 \%$ of peak operating current. Because steady-state fault current can be close to operating current, Moyle [23] recommends overcurrent relays with voltage restraint (trip only if voltage is low) for synchronous generators.

The fault current contribution of self-commutated inverters are design-specific, and protection must be individually examined. Generally, protection similar to that used for a synchronous generator is adequate [27]. Note that the short-circuit contributions of PV-powered inverters are limited to roughly $120 \%$ of the rated current.

The grounding design of distributed generators affects ground fault isolation and detection. Some designs may require grounding of the generator or secondary distribution transformer. References 10 and 29 include discussions of requirements for specific systems.

If a distributed generator adds to fault current, coordination of existing protection devices may be upset (e.g., fault current will not decrease monotonically farther from the substation), and the rating of existing protection devices may be exceeded. A number of studies examine the impacts of induction and synchronous generators on specific utility systems [1,29,30,31]. The results from these studies are specific to the distribution systems examined but do illustrate possible effects and show that analysis techniques are readily available. Lines that are loaded close to their capacity limit will have more difficulties in accommodating distributed generators. A utility may require distributed generator owners to pay for distribution equipment upgrades if the generator disrupts coordination or exceeds line equipment capacities.

\footnotetext{
${ }^{8}$ A unit of measure in the SI system for reactive power. In the literature, this term is generally interchangeable with reactive power.
} 


\section{Ferroresonance Overvoltages}

Voltage protection for the distribution system is not strongly affected by distributed generators. However, the potential for equipment damage by utility overvoltages should be recognized; surge arresters should be placed at proper locations. There is also some concern that self-excited induction generators under certain short-term islanding conditions may produce damaging overvoltages (up to three times normal) because of ferroresonance [32]. Overvoltage relays and arresters should be installed to prevent this problem.

\subsubsection{Generator and Interface Design Considerations}

Utility protection requirements strongly affect the design of interconnection and generator hardware. The generator-side protection functions include the following:

- Detect abnormal power conditions and disconnect during isolated operation

- Disconnect distributed generators during utility faults

- Synchronize the distributed generators with the utility network

- Interrupt utility current for faults on the load side of the distributed generator interconnection

- Protect distributed generator equipment from internal faults.

\section{Abnormal Power Conditions}

The literature contains many studies on protection equipment to detect abnormal power conditions. A change in voltage or frequency is a sign of loss of utility power or other equipment failure, and distributed generators should take appropriate actions to isolate themselves from the grid. A recent study done for several northeastern utilities recommended detailed relay settings for these systems to detect abnormal power conditions [32].

\section{Disconnect Coordination}

The response time of relays on the generator side must be coordinated with the reclosing sequence of distribution line protection equipment. A fast recloser could attempt to clear a temporary fault on the distribution line and reapply utility power before a distributed generator relay has a chance to open. Under those circumstances, there is a danger of severe damage to the distributed generator if it has drifted from synchronization. Curtice [1] and Rockwell [29] describe decay characteristics of different generator types. Synchronous generators pose the biggest problems. Stevens [5] proposed an ad hoc 20-cycle disconnect response for PV inverters.

Synchronization

Synchronizing a distributed generator with the utility waveform is a basic requirement and has not resulted in major integration issues. Hardware for all generator types and capacities is commercially available and economical. Integration with solid-state inverter functions may further reduce costs for future designs. 


\section{Direct Current Injection}

Use of transformerless power conditioning units for distributed generators resurrects the issue of direct current injection into the utility lines [7]. Direct current can saturate transformer cores, introduce nonlinearities, and result in overcurrents. Placing a separate isolation transformer between the inverter and the utility is commonly suggested but is an expensive solution. Curtice and Patton [10] suggest other mechanisms for detecting and preventing direct current injection if risks are high, including a small saturable monitoring transformer, Hall-effect sensing devices, resonant converter circuits, and capacitive decoupling devices.

Other Internal Faults and Failures

Overvoltage and undervoltage current and frequency relays detect distributed generator equipment failures and faults that affect the quality of power output. In addition, many research reports and standards are available on protecting generation equipment from internal faults and failures. This report does not address them because its focus is on utility-side effects.

\subsubsection{High Penetration Levels}

For high penetration of distributed generators, the problems of integration with existing protection hardware increase. An example is the penetration of single-phase generators nonuniformly deployed in an unbalanced three-phase circuit [10]. An additional equipment upgrade is possible, but alternative solutions are more probable in the long run. For example, Longrigg [28] suggests that microprocessor- based directional relays could be used to isolate faults and disconnect distributed generators as needed. A complete microcomputerbased protection scheme could be integrated into future distribution automation systems. The redesigned, computer-based distribution systems should not impose any penetration limits on intermittent generators, except for the capacity of the lines. Communication and reliability issues still must be addressed. Curtice [1] outlines functional requirements and a conceptual design of such a system.

\subsubsection{Conclusions}

Available research identifies many technical issues associated with distributed generators and utility protection. The literature reviewed did not identify any unsolvable problems. Interconnection of distributed intermittent generators to a distribution line operating below capacity poses no problem. Connection to a heavily loaded line (near its capacity) may disrupt protection coordination and require upgrading of relays. Technical solutions are not universal because both the utility and generator characteristics are quite variable. Financial responsibility for technical solutions (particularly costs of utility-side upgrades or costs of more frequent maintenance and replacement because of increased switching operations) is a remaining institutional issue.

Specific protection integration studies examining load flow and fault current may be required before installing a distributed generator to identify potential problems and possible solutions. Costs for these studies may be prohibitive for small installations. A cost/risk methodology is available to select among various protection hardware options [33]. Assessment includes equipment reliability, cost, lost revenue, and potential damage. Application of this analytic method is appropriate because interface hardware requirements and their costs can dominate small system costs. Most utilities have partially recognized the cost/quality trade-off by decreasing interconnection hardware requirements for smaller generators $[11,12]$. Issues that remain to be resolved include: 
- Quality (and cost) of protection equipment necessary as a function of generator capacity (e.g., high-cost, high-reliability grade versus lower-cost and lower-quality grade relays).

- Existing utility interface requirements (these requirements usually reflect rotating generator needs and do not recognize that inverters may not require the same protection).

- Use of inexpensive solid-state relays (solid-state relays can reduce cost; their use on the distributed generators should be discussed, particularly when used with inverters where protection functions can be easily integrated in the circuits, and settings may be adaptable).

- Backup and redundancy of protection requirements for distributed intermittent generators in the utility grid.

In the long term, a high penetration level of distributed generators will require a rethinking of the distribution system design philosophy. Protection requirements can be integrated with the automation of distribution networks.

\subsection{References}

1. Curtice, D., et al., Protection and Safety of Electric Distribution Systems with Dispersed Storage and Generation Devices, ORNL/Sub/80-7974-1. Oak Ridge National Laboratory. April 1984.

2. Fuchs, E.F., Investigations on the Impact of Voltage and Current Harmonics on End-Use Devices and Their Protection. DE-RA-50150-23. University of Colorado. January 1987.

3. Department of Energy. Summary of Investigations on the Impact of Systems Voltage Harmonics on End-Use Devices. July 1988.

4. Wallace, D.B., "PV Power Conditioner Harmonics," Proceedings of the Joint ASME-ASES Solar Energy Conference, Knoxville, Tennessee. March 1985.

5. Stevens, J., The Interconnection Issues of Utility-Intertied Photovoltaic System. SAND87-3146. Sandia National Laboratories. November 1988.

6. Dugan, R.C., Computer Simulation Harmonics Study: Analysis of the Effects on Two Distribution Feeders on Harmonics Produced by the Proposed John F. Long 100-house Photovoltaic Development, ORNL/Sub-81/95011/1. Oak Ridge National Laboratory. August 1983.

7. Smith, C.L., Utility Integration of Photovoltaic Systems, EPRI RP3179, Summary presented at US/EC Workshop, Madrid, Spain. September 1990.

8. Rizy, D.T., Jewell, W.T., Stovall, J.P., Operational and Design Considerations for Electric Distribution Systems with Dispersed Storage and Generation (DSG), ORNL/CON-134. Oak Ridge National Laboratory. September 1984.

9. ANSI/IEEE Std 519-1981, IEEE Guide for Harmonic Control and Reactive Compensation of Static Power Converters.

10. Curtice, D., Patton, J.B., Interconnecting DC-Energy Systems: Response to Technical Issues. EPRI/AP/EM-3124. June 1983. pp. 78. 
11. Southern California Edison Company, Requirements for Operating, Metering, and Protective Relaying for Cogenerators and Small Power Producers. June 1988.

12. Pacific Gas and Electric Company, Power Producer's Handbook. May 1990.

13. Takeda, Y., Hashimoto E., Hayashi, T., Takigawa, K., "Utility Interface Problems of Distributed PV System," Proceedings 17th IEEE Photovoltaics Specialists Conference, Orlando, Florida. May 1984. pp. 541-546.

14. Cokkonides, G., Banta, L., Birdwell, G., Meliopoulos, A.P., Vachtsevanos, G., "Investigation of Utility Interface Problems of Photovoltaic Systems Experimental and Simulation Studies," Proceedings 17th IEEE Photovoltaics Specialist Conference, Orlando, Florida. May 1984.

15. Ranade, S.J., "Characteristics and Impact of Utility Interactive Photovoltaic Prototypes on the Feeder Serving the Southwest Residential Experimental Station," New Mexico State University, Las Cruces, New Mexico. January 1987.

16. Fitzer, J., Dillion, W.E., Ramesh, S., Shen, T.H., Impact of Residential Utility Interactive Photovoltaic Power Systems on the Utility, SAND-84-7008. Sandia National Laboratories. September 1986.

17. Kern, E.C., Gulachenski, E.M., Kern, G.A., "Cloud Effects on Distributed Photovoltaic Generation: Slow Transients at the Gardner, Massachusetts Photovoltaic Experiment," IEEE Transactions on Energy Conversion, Vol. 4. June 1989. pp. 184-190.

18. PVUSA Information Brochures, PVUSA Project Management Office, 3400 Crow Canyon Road, San Ramon, California.

19. ANSI/IEEE Std 1001-1988, IEEE Guide for Interfacing Dispersed Storage and Generation Facilities with Electric Utility Systems.

20. Reddoch, T.W., Rizy, D.T., "Electric Utility Intertie Issues for Small, Dispersed Power Sources," EPRI Conference Proceedings: Solar and Wind Power--1982 Status and Outlook, August 25-27, 1982. Providence, RI. EPRI AP-2884-SR. February 1983. pp. 4-71 to 4-78.

21. ANSI/IEEE Std 929-1988, IEEE Recommended Practice for Utility Interface of Residential and Intermediate Photovoltaic (PV) Systems.

22. ANSI/IEEE Std 1021-1988, IEEE Recommended Practice for Utility Interconnection of Small Wind Energy Conversion Systems.

23. Moyle, R., Chernoff, H., Patton, J. Schweizer, T., "Grid-Connected Distributed Solar Power Systems," Proceedings 16th IEEE Photovoltaics Specialists Conference, San Diego, California. September 1982. pp. 1172-1175.

24. Ranade, Satish J., Prasad, Nadipuram R., Omick, Steven R., Islanding in Dispersed, UtilityInteractive Photovoltaic Systems, SAND88-7042. Sandia National Laboratories. May 1989.

25. Jones, R.A., Sims, T.R., et al., Investigation of Potential Islanding of Dispersed Photovoltaic Systems, SAND87-7024. Sandia National Laboratories. October 1988. 
26. Wasynczuk, O., "Integration of Dispersed PV Generation into Utility Distribution Systems: Stability, Interaction and Fault Tolerance," Proceedings Intersociety Energy Conversion Engineering Conference, San Francisco, California. August 1984. pp. 2145-2151.

27. Longrigg, P., Buell, E.H., et al., Research Recommendations for AC Interfacing Between Electric Utility Transmission and Distribution Systems and Wind, Photovoltaics, and OTEC Energy Systems, SERI/TR-216-2400. Solar Energy Research Laboratory. March 1985.

28. Longrigg, P., "Effects on Electrical Distribution Networks of Dispersed Power Generation at High Levels of Connection Penetration," SERI/TP-214-2008. Paper presented at the 18th IECEC, Orlando, Florida. August 1983.

29. Bawn, W.E., Guerrero, J.V., "Utility Concerns about Interconnected Small Wind Energy Conversion Systems," Technical Memorandum. Rocky Flats Wind Systems Program. TM-IP-81-2. November 1980.

30. Curtice, D., Patton, J., Operation of Small Wind Turbines on a Distribution System. DE-AC0476DP03533. Systems Control, Inc. March 1981.

31. Rizy, D.T., Jewell, W.T., "Power Quality and Protection of Electric Distribution Systems with Small, Dispersed Generation Devices," Southwestern Symposium on System Theory. March 1984.

32. Wagner, C.L., Feero, W.E., Gish, W.B., Jones, R.H., "Relay Performance in DSG Islands," IEEE Transactions on Power Delivery, Vol. 4, No. 1. January 1989. pp. 122-130.

33. Curtice, D., Bowe, T. R., Iqbal, S., Dapkus, W. D., Rizy, D.T., Cost/Risk Tradeoffs of Alternate Protection Schemes for Small Power Sources Connected to the Electric Distribution Systems, ORNL/Sub/81-16957/1. 1984. 


\subsection{Stability and Operability Factors}

The current electric utility industry comprises large central power generation facilities connected by high voltage transmission lines. Electric power is produced at the central generation facilities and transferred through high-voltage transmission lines to load centers. The electricity is then distributed, through a vast network of low-voltage distribution lines, to customers. Within the large transmission network, many control areas are formed either by a single utility or a power pool consisting of several utilities. Each control area covers a specific geographic area and regulates generators within the control area to meet indigenous load demands and maintain scheduled energy interchange across control area boundaries.

The voltage and frequency of the electric power provided by the utilities have to be within certain specified limits. Because the loads are always changing, each control area needs to constantly adjust the generator output to match the loads and maintain the frequency and power interchange schedule among neighboring control areas. This continuous adjusting process is known as regulation. Most of the regulation is accomplished automatically by the load frequency control function of the AGC. Load frequency control responds to system frequency variations and net area interchanges. It then regulates generator outputs to maintain the system frequency and to keep the desired area interchanges within the prescribed limits.

When operating the power system to provide electric service, utilities are primarily concerned with cost and reliability. Their objective is to supply the most reliable electric service at the lowest possible cost. The utilities generally have no control on the demands to be served. They must plan and operate the power system to meet the demands and maintain certain performance standards. Conventional generation units such as base-load units and intermediate or peaking units are planned and built to perform specific functions. Their loading orders are predetermined; utilities have total control on these units. To cope with forced outages, utilities build adequate generation reserves and establish tie lines to neighboring systems.

The intermittency of the renewable energy resources, on the other hand, presents a unique challenge to system operators. The intermittent renewable generations will not contribute to system frequency regulation because the output of renewable generation depends on variable weather conditions, not system frequency. To realize maximum economic benefits from renewable energy resources, renewable energy generators operate whenever the energy resources are available. This operating mode excludes the renewable energy generators from being considered load-following units. To accommodate the intermittent generations, utilities have to assign regulating functions to other conventional generation units. The potential impacts on system performance include higher-than-normal fluctuations of voltage, frequency, and tie-line flows, and increased regulating duties at the conventional generators.

Thus, incorporating the intermittent generations into the utility system adds burdens to system controls. Besides the usual load variations, the system also must cope with the changes caused by the variable output of the intermittent generations. The utility's operating and control systems have to make appropriate adjustment to compensate for the variations of the intermittent power. The problems imposed on the system generation control by different renewable generation technologies also vary. For example, PV generation output generally has better correlation with utility demand on a daily or seasonal basis because airconditioning loads during the summer cooling season are closely correlated to the amount of direct solar irradiation. However, cloud coverage and storms will greatly affect PV generation. Wind generation does not have this fixed diurnal cycle, but it may also display predictable daily or seasonal patterns. The correlation between wind and system demand is less certain and site specific; some sites have predictable correlation between wind generation output and system demand, but many others do not. When resources of intermittent availability are introduced into the electric system, utilities must consider the overall impacts on system stability and operability. 


\subsection{System Stability}

The stability of a system with interconnected dynamic components is defined by its ability to return to normal or stable operation after having been subjected to disturbance [1]. The stability of the electric power system, sometimes called synchronous stability, refers to the system's ability to maintain nominal frequency and voltage without losing synchronism among its synchronous generators after some system disturbance.

Traditionally, electric power system engineers are concerned with two types of stability problems: steadystate stability and transient stability. Steady-state stability concerns small system perturbations such as random changes of loads or changes of network configuration caused by line switchings. Transient stability is the ability of a system to survive the shocks of major disturbances such as a loss of a large generator or a fault on a major transmission facility. Recently, a new type of system instability, which results in system voltage collapse or abnormally high and low voltage conditions, has been observed. This type of system instability is believed to be caused by problems relating to the system's dynamic responses to transmission line loading and reactive power deficiency [2].

The electric power system is constantly subjected to small perturbations that are first absorbed by the machine inertias through energy exchanges between the machines and the system. For longer disturbances, (usually several seconds), the automatic voltage regulator of the synchronous generator and load-frequency control function of the AGC will maintain the required balance between load and generation. The power system control maintains steady-state stability by committing proper generation capacities to assure sufficient generation reserves (spinning and nonspinning reserve) and by ensuring that enough regulating units are available to follow the continuous random changes of the system.

The limit of steady-state stability is the maximum amount of power that can be generated and delivered to the load while still maintaining proper system voltage and frequency. For a given system configuration and generation mix, the steady-state stability limit is a function of generator operating state (generator terminal voltage magnitude and phase angle, etc.). System operators, with the help of system control equipment and experience with loads, normally have sufficient generation capacity committed to guard against any generator operating close to its stability limit.

Transient stability concerns the electromechanical swings of generator rotors following a major system disturbance. Under normal operation, the synchronous torques that exist within the generators hold the power system together in a stable equilibrium state. This state is characterized by the balance between mechanical torque and electric power within each generator. Some major disturbances, which are usually caused by faults, upset the torque-power balance within each generator. The rotors of each individual generator then will be subjected to accelerations or decelerations, thus causing large angular rotor swings.

Depending on the nature and duration of the fault, the transient rotor swings may be damped out in a second, allowing the system to recover, or they may continue and grow in severity. When the individual rotor angles swing beyond a certain critical angle, the synchronous torque can no longer pull them back and hold them in synchronism; the terminal voltage and armature current of such generators become unstable. The protection device usually will isolate such generators from the system and shut them down to avoid any damage to the generator. The remaining system could stabilize by settling down in a new equilibrium state, or the rotor swings could continue, causing the system to lose synchronism and eventually collapse.

Voltage collapse problems have been attributed to the increased loading of transmission lines, insufficient local reactive power supply, and shipping of power across a long distance $[3,4]$. The event is characterized by a slow variation in the system operating state, caused by the increase in loads, in such a way that voltage magnitudes gradually decrease until a sharp, accelerated change suddenly occurs. Traditional warning 
signals such as wide swings of voltage magnitude and angle and frequency drifting are not observed prior to the voltage collapse. Research has shown that the collapse dynamics cannot be described solely by the generator dynamics, which are traditionally believed to be responsible for the power system transient instabilities.

Analyses of these problems have been approached in many ways, and general models to explain the dynamics of voltage collapse have been proposed [5,6,7,8]. In general, knowledge about voltage collapse is not as complete as that of traditional transient stability problems. Various indices for assessing the power system's vulnerability to voltage collapse are being studied $[9,10,11,12]$, but the electric utilities' experience and ability to predict how close the system is to the threshold of voltage collapse are still far from perfect.

Impacts of Intermittent Generation

PV power systems do not employ rotational machines to generate electricity, and their short circuit current capabilities are quite limited compared with traditional rotating generators. For this reason, static power converters for PV power systems generally monitor the AC voltage and frequency of the utility side and disconnect the PV system from the utility network under any abnormal conditions. These features make the PV energy systems immune to the transient swing problems of rotating machines. Wasynczuk [13,14] studied the dynamic behavior of dispersed PV power systems on the electric distribution network. The dynamic response of dispersed PV systems following common electric system disturbances such as load switching and feeder faults were modeled and simulated in the study. Results indicated very robust dynamic performance of both line- and self-commutated PV power systems. Little or no adverse dynamic interactions between the PV system and electric distribution network were observed, even when the dispersed PV systems represented a very high percentage of the feeder capacity.

Individual small wind turbines likewise will not have a noticeable impact on the stability of the electric power system. Because they are small, individual machines can lose synchronism with the system as a result of some local network disturbance and be isolated from the network. But the system will hardly be affected.

Large wind turbines have low-speed, large-diameter blades coupled to an electric generator by a high-ratio gear box. This feature results in a large turbine inertia and low mechanical stiffness between turbine and generator, implying that localized dynamic behavior of one wind turbine will not appreciably affect the dynamic behavior of neighboring wind turbines [15]. One study by Sadanandan et al. [16] looked at the transient stability problems of a utility grid with a large amount of wind generations. In this study, the Tennessee Valley Authority (TVA) system was modeled, with wind power supplying $30 \%$ of the peak demand. The result showed that under certain contingency conditions, wind turbines within a cluster could become unstable, but the system would remain stable. Herrera et al. [17] reported that the low mechanical stiffness between turbine and generator also gives the large wind turbines excellent transient stability properties. Because the large turbine inertia and the generator inertia are essentially decoupled, short electrical transients tend to impact only the generator inertia whereas similar mechanical transients such as wind gusts primarily affect the turbine inertia. This unique behavior of a large wind turbine has the following implications: 
- Fault clearing times ${ }^{9}$ and the duration of short-term load contingencies are not so critical as with the conventional rotating generators

- Synchronism with an electrical system under gusty wind conditions is not a problem

- Synchronization of a wind turbine with the electric power system can be achieved with speed errors of several percent and phase angle mismatches of $30-40^{10}$ degrees.

The transient phenomena of the wind turbine was also studied by Chan et al. [18]. Models for a wind turbine and a wind turbine cluster were developed to analyze the dynamics of voltage and power fluctuations resulting from wind gusts and turbulence and transient swings resulting from network disturbances. The simulation results indicated that wind turbine transients induced by the speed fluctuations of wind will not cause stability problems. The simulated wind turbine cluster also remained stable within the system if a network fault could be cleared within five cycles.

Thomas et al. [19] suggested an AC/DC/AC link between wind generation systems and the electric grid: wind turbines with a variable-speed generator and a converter producing DC power at the wind farm and an $\mathrm{AC}$ inverter at the point of interconnection with the electric grid. The study concluded that with proper compensation, large wind turbine arrays with $\mathrm{AC} / \mathrm{DC} / \mathrm{AC}$ links would not significantly affect system stability. This scheme enables the wind turbines to operate at variable speeds and offers better protection and coordinated control of the wind turbine arrays while minimizing their electric power fluctuations.

Wind energy systems using induction machines and PV systems with line-commutated inverters require the electric system to provide reactive power during their operations. The additional VAR requirement and its associated voltage regulation will certainly increase the operating difficulties and transmission losses of the host electric systems. At a high penetration level, the amount of reactive power required may induce a system instability problem. A newer design of variable-speed wind turbine systems and PV systems using self-commutated inverters can offer advanced operational capabilities. Through advanced switch technologies, new inverters can operate at both lagging and leading power factors [20]. The ability to control and supply reactive power to the electric network is of great value to the utilities. System operators can use the VAR control capability offered by an advanced inverter design to alleviate the potential voltage instability of the transmission system as well as to reduce transmission losses.

\subsection{System Operability}

Utilities operate electric systems to provide electric services to their customers. Service reliability, quality, and cost are the most important considerations when utilities are planning and operating a system. Utilities have made a great effort to optimize all aspects of their activities to assure service quality and the lowest possible cost.

\footnotetext{
${ }^{9}$ Fault clearing time is the interval between the instant when an abnormal condition (short circuit between conductors, short circuit between conductor and ground, etc.) on an electric circuit actuates a protective device and the instant when the protecting device interrupts the continuity of the circuit. Depending on the severity of abnormal conditions and type of protecting devices, the clearing time ranges from a cycle to tens of cycles.

${ }^{10}$ When conventional generators are synchronized with the electric system, their frequencies have to be the same and their voltages have to be of same magnitude and in phase. This study showed that in the case of synchronizing wind generation systems with an electric system, these requirement can be relaxed because of soft coupling between wind turbines and wind generators.
} 
To include intermittent generation technologies in the electric system poses new problems to the utilities. Utilities have little control over these generations; power from intermittent generations depends on weather conditions. On the other hand, utilities have to accept the output from intermittent energy resources whenever it is available in order to capture all economic value and minimize system production cost. A certain degree of operational flexibility is lost to utilities in this mode of operation. The following sections discuss these and other issues related to the operation of electric systems with intermittent generations.

\subsubsection{Generation Operation}

Operation of electric system generation is controlled by the AGC, which performs two functions: load frequency control and economic dispatch. Control objectives of AGC are system stability and minimum system production cost. The former requires that the system has sufficient generation on line to meet the load demands at all times, and the latter means that generation units need to be dispatched according to their incremental cost. The control performance is judged by the deviations of ACE (area control error), which consists of a net deviation from the scheduled area interchange plus a quantity proportional to the net system frequency deviation. The ACE is calculated as follows [21]:

$$
\mathrm{ACE}=\Delta \mathrm{P}_{\mathrm{I}}+10 \beta \Delta \mathrm{f}
$$

where $\quad \Delta \mathrm{P}_{\mathrm{I}}=\quad$ net area interchange, in $\mathrm{MW}=$ scheduled interchange - actual interchange

$\beta=\quad$ frequency bias constant, in MW per $0.1 \mathrm{~Hz}$

$\Delta \mathrm{f}=\quad$ system frequency deviation from $60 \mathrm{~Hz}$, in $\mathrm{Hz}$

A nonzero ACE indicates the power imbalance between generation and load at any instant. The bias constant $\beta$ represents the sensitivity of the power imbalance to the system frequency deviation for a particular control area.

Guidelines on acceptable ACE variations under normal and emergency conditions have been established by the NERC-OC for the utility industry. Utilities operating inside the interconnected system are expected to provide corrective actions to maintain the ACE within the specified allowable limits. For example, utilities are required to make the $\mathrm{ACE}$ equal to zero at least once every 10 minutes. Utilities also have to keep the average ACE in each 10-minute period to within the allowable limit $\left(\mathrm{L}_{\mathrm{d}}\right)$, given as:

$$
\mathrm{L}_{\mathrm{d}}=0.025 \Delta \mathrm{L}+5 \mathrm{MW}
$$

where $\Delta \mathrm{L}$ is the maximum hourly load change a utility ever experienced during its peak day. Under emergency conditions, the allowable average ACE in a 10 -minute period is $3 \mathrm{~L}_{\mathrm{d}}$, but utilities must still make ACE equal to zero within 10 minutes after the emergency condition. These criteria are developed so that no utility might put undue burden on others.

Introducing intermittent generation into the utility system will affect the utility's normal generation operations. The following are brief discussions of some of the impacts. 


\section{Load Following}

The random changes in electricity demand are beyond the control of the electric utilities. Generations must be adjusted constantly to follow the load fluctuations so that a balance between load and generation can be maintained at all times. Not all generators will be used for load following duties. A utility's load following capability depends on the ramping capability of its on-line generating units that are being used for load following. Utilities must maintain adequate ramping capabilities from its on-line generators to follow load changes so that the operating criteria of ACE are satisfied.

Both the short-term (1-3 minutes) and longer term (10-30 minutes) ramping rates of conventional generating units are of interest when intermittent resource generation is included in the utility generation mix. Figure 3-1 shows a typical daily load profile of a utility and the generation mix used to meet the load. Figure 3-1(a) shows generator dispatching without intermittent generations, and 3-1(b) shows generator dispatching with intermittent generations. Without intermittent generation, loading of the baseload units is kept constant; intermediate and peaking generating units are used to follow the daily load changes. When intermittent power producing units (PV or wind) are included in the utility generation operation, the load following capability of conventional generating units must increase to cover the combined changes of load and the intermittent generation output. Figure 3-1(b) shows that both the ramping and cycling duties of intermediate generating units could be affected in this case. Excess generation could also result during the period of minimum load.

\section{Operating Reserve and Unloadable Generations}

The operating reserve is required to assure adequate system performance and to guard against sudden capacity loss caused by forced generation or transmission outages and load forecasting errors. It takes several minutes to several hours to bring a generator on line from a cold start. However, any generation and load imbalance must be corrected almost instantly. If an on-line generator is lost, the system cannot wait several minutes to have another generator brought on line to meet the load. Utilities carry spinning reserves (the difference between the total capacity of generating units assigned to regulation duty and the actual loading on those units) in their normal operation so that such a sudden loss of generation will not result in a loss of load.

Each region or subregion in the interconnected electric system must have sufficient spinning reserve responsive to AGC to provide the regulating margin necessary to maintain system frequency and an area interchange schedule. In addition, reserve capacity that can be brought up to meet the demand in 10 minutes should be available in each region. Without an adequate operating reserve, sudden large load changes of the system (loss of generator or large load) may result in excessive inadvertent tie-line flows for an interconnected utility and noticeable degradation of service quality.

The NERC-OC guidelines specify that each region or subregion must carry sufficient operating reserve to provide a normal regulating margin and cover the loss of generation resulting from the most severe single contingency. For an interconnected power system, this condition usually means the loss of the largest single generator within the region or subregion; therefore, the operating reserve must be greater than the capacity of the largest single generator. At least half of this operating capacity should be spinning and the remaining part should be ready in 10 minutes.

Another side of the operating reserve issue is the unloadable generation. It is part of the normal system load following requirement, but is associated mainly with the generator's ability to ramp down. The unloadable generation is the amount of generation that can be quickly backed off from the regulating unit to match the 


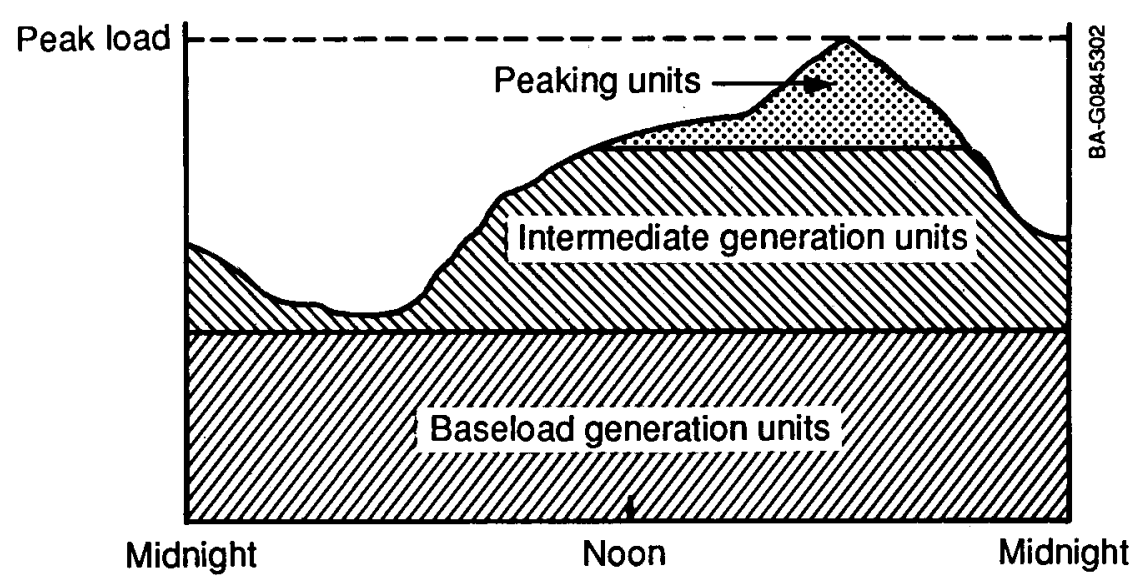

(a) Without intermittent generation

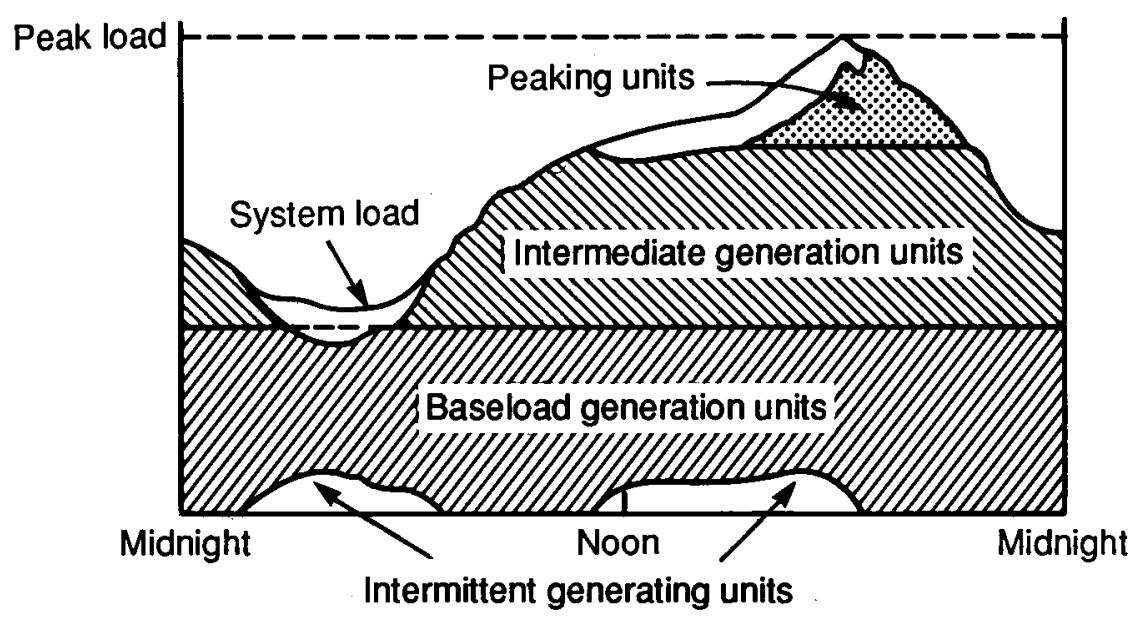

(b) With Intermittent generation

Figure 3-1. Hypothetical daily load and generation dispatch

sudden loss of a large load. A sudden increase of intermittent energy generation will have the same effect on the system control as a sudden load decrease. To maintain the balance between load and generation, the system control must quickly decrease the output of the regulating units.

The unloadable generation is not a critical concern for utilities using only conventional generators. Normal utility load variations during a specific period are fairly predictable. When it is necessary to bring a generator on line during a normal system load increase, system operators know how much capacity is needed from the generator and for how long. Similarly, when a generating unit is shut down during a period of decreasing system demand, system operators are confident that the capacity of this unit will not be needed in the near future.

In the event of a large sudden drop of load that cannot be matched by a system's down-ramping capability, system operators can trip a generator off line to prevent a large frequency excursion. However, such a tripping decision is not possible if the generations from intermittent sources suddenly increase to a very high 
value. The unit to be tripped may be needed on line soon if the output of intermittent generations subsequently decrease. Therefore, when large intermittent generations are introduced into the power system, more unloadable generation may have to be scheduled from other on-line conventional generators to accommodate a sudden increase in intermittent generation. System operators must make sure that such online conventional generators can be operated at a lower minimum output level.

Figure 3-2 shows the operating reserve and unloadable generation concepts. The generation operating level equals the system demand plus the required spinning reserve to cover the sudden increase of load and the sudden loss of generation, as shown in the figure. Integration of intermittent energy generations into the utility system will impact the system regulation performance and reserve requirement. The primary energy sources of intermittent generations are not controllable and they may change rapidly. More spinning reserve, therefore, may be required to compensate a sudden decrease in intermittent generations so the power system can maintain the same regulating margin. The right column in Figure 3-2 illustrates the additional spinning reserve requirement when intermittent generation is included in the system generation mix.

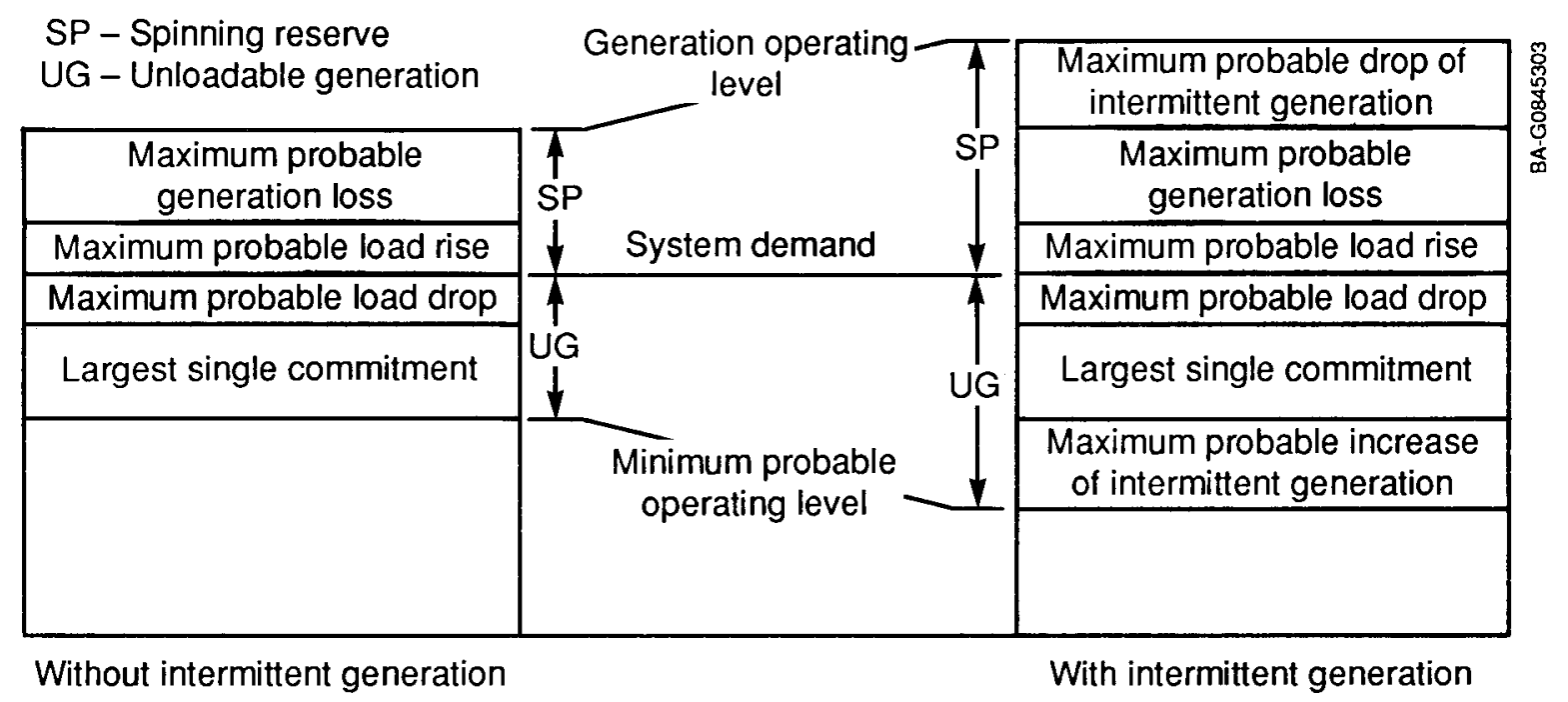

Source: Reddoch, Barnes, Lawler, and Skroski, 1982

Figure 3-2. Spinning reserve and unloadable generation requirement

Caution is needed when interpreting the spinning reserve and unloadable generation requirements for systems with intermittent generations from Figure 3-2. Although it is necessary to consider the maximum probable generation loss, the maximum probable load variations, and the maximum probable drop of intermittent generation when determining the level of spinning reserve and unloadable generation a system must carry, it is misleading to simply stack these items on top of one another to derive the spinning reserve and unloadable generation. For example, if system operators knew with great certainty that intermittent renewable output could be expected to continue for the next 10 minutes, there would be little impact on operating reserve requirements. Without proper knowledge of the probability of multiple events occurring simultaneously, simple addition, implied by the stacking of Figure 3-2, may overstate these requirements 
and thus may unintentionally put intermittent generations in a disadvantageous position compared with conventional generating technologies. The spinning reserve requirement for power with conventional generations is based on long-term operating experience, system load and generation characteristics, established mathematical rationale, and operator's judgment. Because intermittent generation technologies currently lack some of this information, utility planners and system operators tend to treat spinning reserve and unloadable generation for intermittent renewable resources conservatively and adopt the worst possible scenario.

\section{Unit Commitment and Economic Dispatch}

Unit commitment and economic dispatch of utility generators are based on economic principles. The operating costs of generators, along with the hourly and daily load forecasts, are used to determine the optimal generation mix in terms of production cost and system reliability. Based on hourly and daily load forecasts, the system control decides which generator to bring on line or take off line. For a given unit commitment plan, the economic dispatch determines the loading level of each unit, subject to the constraint of $\mathrm{ACE}$ limits and reserve requirements.

Utility system loads are temperature sensitive. With a knowledge of historical demand and available weather forecasts, utilities usually can predict their short-term demands fairly accurately; the system usually is operated in a state that would optimize system production cost and reliability. However, when the penetration level of intermittent generations in a system increases, the utilities' ability to forecast the net load (load minus intermittent generations) may not be as accurate. Unpredicted fluctuations of intermittent generation output may result in an excess or a shortage of on-line generation. Optimizing system production costs under such uncertainty may be difficult. Therefore, the uncertainty of predicting hourly intermittent generation output may create some doubt in the unit commitment strategy. Accurate weather forecasting, especially for specific intermittent generation locations within the utility service area, could help to resolve these problems. A recent study by Dutch researchers indicated that increasing the prediction accuracy of wind would increase the fuel savings of the power system with wind generations [22]. Their results showed that the savings increase was almost a linear function of wind prediction accuracy.

\subsubsection{Transmission System Operation}

The impact of intermittent generations on transmission system operation tends to be local. Problems will arise only when the penetration of intermittent generations reaches sufficiently high levels that their installed capacity begins to alter substantially the normal transmission system power flow pattern or to cause large voltage swings in the transmission system. A study by Jewell [23] shows that the penetration level of dispersed PV generation has to reach $30 \%$ of the total system load before transmission network power flow will change significantly.

Spreading PV or wind generations over wider areas to take advantage of the spatial diversity of renewable energy resources reduces total output fluctuations. This strategy puts less burden on the system regulating units but more burden on transmission links. If the power from intermittent generation in one utility's control area is not intended to serve the native load and has to be transmitted across utility control area boundaries, then a wheeling agreement with all the involved utilities must be enacted. Transferring large amounts of intermittent power across the transmission network over long distances will impact the normal system transmission operation. System transfer capability and loop flow are two considerations of system operators during wheeling operations. Another concern is system voltage instability. The availability of the additional transmission capacity to accommodate the intermittent generations and limitations on loop flow will affect the development of intermittent renewable generation. 
Introducing a large amount of fluctuating power into the utility transmission grid can result in unacceptable voltage flicker and other operational problems [24]. The flicker can be reduced by modifying the control system of wind turbines or by increasing the number of wind turbines in the cluster [25]. Some intermittent generation technologies also require reactive power support from the grid. The impact on the system voltage profile can be significant for a weak transmission grid. Wind energy development and the associated reactive power requirement over the Tehachapi Pass area north of Los Angeles have caused voltage problems for the relatively weak local $66 \mathrm{kV}$ transmission network. Southern California Edison Company sometimes has to request that the wind farm operators curtail wind turbine operations so that adequate voltage can be maintained around the wind farm area.

However, new technology and inverter design will enable the wind turbines to operate at either a lagging or a leading power factor, thus supplying reactive power to the transmission network, if required. This ability to behave like a static VAR compensator ${ }^{11}$ can be of great value to electric utilities. A better voltage profile and less transmission system losses can result from such reactive power support.

A generalized statement regarding the impact on the transmission operation is not possible, because each installation's impact on the grid has to be studied on a case-by-case basis. Unless the scope of a specific intermittent generation project is known, a detailed transmission study cannot be made, and the impact of such a project on the utility transmission grid is difficult to generalize.

\subsubsection{Distribution System Operation}

Major concerns of operating a utility distribution system are reliability, safety, service quality, and economics. The distribution system of an electric utility is installed to take bulk power from a transmission network, step down voltage to a safer level, and distribute the electricity to customers. Utilities plan and build distribution facilities to serve the load, not necessarily to accommodate intermittent generations connected to distribution systems. Consequently, most distribution system functions are designed to channel power flow in one direction only. The protection and voltage regulation equipment are designed and installed accordingly. Connecting many intermittent generations to the distribution system may reverse the direction of power flow and affect the normal operations of the distribution system. Harmonic currents injected into the distribution system by some renewable generation technologies may degrade service quality. Islanding of power conditioning systems or induction generators is a safety hazard. Detailed discussions of these hardware and design-related issues of distributed generation are included in Chapter 2.

Other operating concerns such as voltage profile, voltage flickers, and reactive power control and supply are also affected by the integration of intermittent generations into the distribution system. Curtice and Patton [39] studied the voltage and reactive power problems associated with the operation of small wind turbines on a distribution circuit. They found that wind generation would generally reduce voltage drop along a feeder circuit, but the voltage flicker on secondary circuits was a potential problem for wind turbines with induction generators. The flicker restricts installing wind turbines with induction generators on a distribution feeder that also serves other users. However, wind turbines with a synchronous generator and self-commutated inverter would not have this problem.

\footnotetext{
11 Also called a static VAR system. It uses high-speed solid-state electronic switching devices controlled by computers to continuously change the quantities of capacitors and reactors connected to the electric system. The purpose is to control the system voltage by varying and matching the system VAR requirement.
} 
Boardman et al. [26] developed a dispersed solar and wind system model to study the technical and economic impacts of distributing PV and wind generation within the electric distribution system. They examined the effects of distributed PV and wind generation on capital investments, reliability, O\&M costs, protection requirements, and communication and control requirements. Case studies using distribution system data of actual utilities showed that distributed small PV and wind generators were not likely to disrupt distribution protection coordination. The study also found voltage regulation with intermittent generation along the distribution feeders would become more complex, but acceptable limits could be maintained. In addition, the dispersed PV and wind generation devices were found to offer some investment savings by deferring the distribution capital investment.

EPRI [27] studied the impact of distributed wind generation systems. It found that distribution feeder voltage fluctuation would not be a limiting criterion for wind generation installation at utility distribution systems. Some reactive power compensation may be required, but carefully planned wind generations will lower utility distribution losses and defer substation capital improvement. Another EPRI report [28] examined the impacts that distributed PV systems might have on the distribution system. It reported that significant local impact might result from a large number of installations, but suggested the problems were solvable if proper planning and resources were available. The impact would be minimal at low penetration levels. Recent experiments with residential PV generations [29,30] confirmed that there were no serious distribution operation problems from distributed PV generation.

The ANSI/IEEE Std 1001-1988 [31] addresses the engineering concerns inherent in operating distributed generators in parallel with utility distribution systems. The guide includes comprehensive descriptions on proper interface construction techniques, operating procedures, and safety aspects of these generators. It provides a very good introduction and general overview of distributed generation applications. It also lists sources where utility engineers and operators can obtain more technical information on the construction requirements and operation of distributed generators.

\subsection{Studies of Intermittent Generation Penetrations}

Lee and Yamayee [32] published an often-cited early study of the impact of intermittent generation on utility systems. This study analyzed the additional load following and spinning reserve requirements and their economic penalties as a result of incorporating intermittent energy generation into conventional utility systems. The findings showed a linear relationship between the penetration level of intermittent energy generation and additional load following and spinning reserve requirements. The effect of intermittent energy generation penetration on system production costs, however, was found to be nonlinear. For a penetration level below $5 \%$ of system peak demand, total cost (production cost and fixed cost) decreases. Beyond 5\% penetration, the additional load following and spinning reserve requirements begin to alter the optimal generation mix significantly, greatly increasing system production cost. The simulation was done using an EPRI synthetic utility system. This study represented the most pessimistic approach to intermittent energy generation because of the conservative assumptions used in the simulations. It simulated the simultaneous loss of the largest unit, the maximum probable drop in intermittent generation, and the maximum probable increase in system load--all occurring simultaneously. In addition, the assumptions of spatial diversity for solar and wind resources for this study are not realistic. Based on the assumptions of the study, the load following and spinning reserve requirement penalties associated with intermittent energy generations could completely eliminate any energy and capacity credits from the intermittent generation at only a modest penetration level. Subsequent studies have indicated higher penetration limits of intermittent generation technologies.

The next two sections describe study results for specific penetration levels and potential impacts on system operations by PV and wind generation systems. 


\subsubsection{PV Generation Systems}

Several reports address the impact of a PV system on electric system operations.

\section{Anderson Study}

Anderson [33] completed a major study on the generation operations of electric systems with PV. This study examined the power system's ability to follow the combined load and output changes from a centralstation PV system ${ }^{12}$ under various utility loading and cloud patterns. A computer AGC simulation program simulated the operations of a power system with a $250 \mathrm{MW}$ central-station PV generation plant. Actual utility system loading data from two southwestern utilities, Arizona Public Service Company (APS) and the Salt River Project (SRP), were used in the computer simulations.

Special cloud models were developed to simulate the behavior of cumuliform clouds--dark clouds with welldefined edges. These clouds produce significant changes in PV generator output. Two patterns were considered. The first was a deterministic cloud pattern where a large cloud front moved past the PV generation array area at different speeds, covering and uncovering the PV array, resulting in different upand down-ramping rates of the PV generation output. The second pattern modeled stochastically scattered cloud conditions; PV generation output was continually and randomly changing in this mode.

System operations and AGC performance were monitored through the simulated ACE signals. Morning load pickup periods at different system loading levels were chosen to simulate the worst load fluctuations with which the system generators had to cope. Because normal utility AGC would adjust the generator output every 2-6 seconds to follow the load changes, the simulations used in this study were run with a step size of 0.5 second. Each simulation run was carried out for 30 minutes.

The results of these simulations show a wide range of PV penetration levels, from about $0.7 \%$ to $10.2 \%$ of the initial system load, before the systems violate the average ACE criterion. The worst case is during the summer peak season when system load increases and a cloud causes a sudden drop of the PV generation. The best case is during a fall load condition (load at $50 \%$ of the system peak level) with clouds moving away from PV panels and the PV generation output increasing. The study simulated different cloud speeds and some countermeasures to alleviate the effects of cloud movement. For example, with additional generators assigned to regulating duty to increase the system's ramping capability, the allowable PV penetration could increase to $16.3 \%$ for the best simulation condition (cloud speed at 5 meters/second) and increase to $1.5 \%$ under the worst simulation condition (cloud speed at 15 meters/second).

The stochastic cloud model simulations were run only for the fall load level of both APS and SRP (50\% of the peak load). In the simulation, the initial PV generation output was at $250 \mathrm{MW}$, which was $17 \%$ and $24 \%$ of the APS and SRP system loads, respectively. Results showed both systems performed much better than those under deterministic cloud conditions. In all cases, the average ACE was well below the allowable limits. The random output of the PV generation under the stochastic behavior of clouds appeared to the system control as random load variations. Although the output of PV generation changed randomly, it tended to vary around a mean value determined by the PV array size, cloud type, and the fraction of the sky coverage. The relatively slow thermal response of the coal-fired generators smoothed out most of the

\footnotetext{
${ }^{12}$ The literature is not clear on the classification of central-station PV system in terms of capacity, location, voltage level, etc. In this report, the term central-station PV system is a large-capacity PV system installed at a single site.
} 
combined load fluctuations, and the system operated satisfactorily. The author concluded that random PV generation behavior was not a serious problem for the power system.

Although the studies examined two utilities located in the southwest United States with a mostly coal-fired generation mix (no nuclear unit and limited hydro capacity), some general conclusions can be drawn from these results.

- The amount of PV generation that can be integrated into the utility power system without violating the established average ACE criterion varies widely, from $1 \%$ to $16 \%$ of system load. The determining factors are the amount of a utility's load fluctuation and the regulating capability of existing generating units. This observation indicates that the effect of PV generation on the power system is not uniform and case sensitive; hence, a general cause-effect conclusion cannot be drawn.

- With prudent generation dispatch and operating practice, a power system can generally accommodate PV generations up to 5\% of its system load in its generation mix. When PV generation exceeds $5 \%$ of the system load, the conventional generation control could have difficulty tracking the rapid PV output changes.

- Although high penetration levels of PV generation appeared to seriously violate the ACE criteria, corrective measures such as assigning more generating units to regulating duty or installing fastresponse combined-cycle generators are available. These measures are effective if carefully planned. The simulation results show higher penetration limits after adding a fast-response, combined-cycle generating unit to the existing generation mix. Assigning more existing generating units to regulating duty achieved the same result. Another method is to control the PV generation output under intermittent cloud coverage during periods of peak system demand when the utility has fewer generating units on standby and less on-line regulating capacity. However, these corrective measures may cause the system to deviate from its optimal operating condition, thus adversely affecting the economics of PV generation. The impact on the system operating cost was not addressed in the report.

Anderson's is the only major study that investigates the impact of central-station PV generation on power system AGC operations. It produces comprehensive and useful information on a power system's ability to accommodate intermittent generations. The study, however, does not address the network behavior during PV generation switching, nor does it consider the economics of system operation. Output fluctuation of a $\mathrm{PV}$ generator may cause voltage swings on the transmission network or require corrective actions from the system operators. The effect of voltage fluctuation needs to be studied.

Another shortcoming of Anderson's study is that results only apply to central-station PV generation. With a large amount of PV power concentrated in one site, its output is very susceptible to cloud movement and coverage. If PV generation consists of many smaller installations dispersed throughout a wider area, some of the limitations may be reached at a much higher penetration level. Therefore, the Anderson study needs to be extended to investigate the impact of a dispersed PV system.

Jewell Studies

Jewell studied the interactions among dispersed PV generations and how these generations affect electric utility systems. The studies establish quantitative relationships between the size of a utility service area through which the dispersed PV systems are installed and the maximum possible changes in PV generation during a certain time. In one report [23], Jewell used load flow studies to examine the effects of PV generation changes on an electric utility system. Actual electric system and loading data from the Public 
Service Company of Oklahoma (PSO) were used. A subsequent study [34] employed the EPRI BENCHMARK simulation program and actual load data from a large Kansas utility to assess the impact on utility generation dispatch and production cost.

Several cloud models were developed using actual meteorological data for both reports. The first study showed that the total percentage change in PV generation decreases as the area of dispersed PV systems increases, i.e., the farther apart the PV systems were, the less their output correlated. The worst-case cloud patterns turned out to be cumulus (fast-moving, well-defined clouds with clear sky between the clouds) and squall (a solid line of dark clouds moving across a clear sky). The squall line cloud pattern is similar to the deterministic cloud pattern simulated in the Anderson study. It causes complete loss of PV generation. The speed of the clouds and size of the dispersed PV system area determine how fast the complete loss occurs. The result shows that for a $10 \mathrm{~km}^{2}$ area, a squall line causes the loss of all PV generations within that area in 1.8 minutes. For an area of $1,000 \mathrm{~km}^{2}$, the time increases to 17.6 minutes, and for $100,000 \mathrm{~km}^{2}$, the time is 175.7 minutes. The effect of dispersing PV installations is very evident. Even the worst-case cloud pattern takes a longer time to affect a wide area.

The worst cumulus clouds, while causing less loss of PV generation than the squall line, might actually pose a more difficult problem for utilities because their changes are random and their effect on the PV output is much less predictable than that from a squall line. Jewell reports that for random cumulus clouds, the maximum PV output change for a 1-minute interval over a $10 \mathrm{~km}^{2}$ area is $15.9 \%$ of the total installed PV capacity in the area. When the area size increases to $1,000 \mathrm{~km}^{2}$ and beyond, the maximum change of PV output for normally occurring cumulus cloud patterns is only about $3 \%$ of the total installed PV capacity in this area. Geographical diversity causes the possible percentage loss of PV generation to decrease as the area of dispersed PV installation increases.

The load flow studies with PSO system data revealed that very large changes in line flows, including line flow reversals, occur on subtransmission and distribution systems when PV generation fluctuates under certain cloud patterns. Line flow reversals occur on subtransmission lines when the dispersed PV system penetration reaches $15 \%$ of the total system load. Such reversals would cause operational problems to an electric utility's protective equipment. At 30\% penetration, reversals occur on transmission tie lines. However, power flow reversals on transmission lines are not a problem for most utilities because transmission lines are designed to transfer power from either direction. It should be noted that these penetration limits were based on a utility's transmission and subtransmission system responses only. No considerations were given to the generator's ability to follow the combined PV output changes and load changes.

The Kansas study used actual solar irradiance data for southwest Kansas sites to simulate the fluctuation of PV generation. Its effects on a utility's production cost and ability to serve load were then investigated. Simulation was run on a 1-minute time increment. The simulation period was between 11:00 a.m. and 1:00 p.m., when peak PV output as well as the greatest possible variation in PV generation occurs. Ramping capability of the selected utility had a limit of $1 \%$ of system peak load per minute from its existing generation mix.

Study results of this selected utility system indicate that the amount of PV generation is limited by the ramp rate of conventional generators on the system. For central-station PV systems, the maximum allowable PV penetration is $1.3 \%$ for a $1 \%$-per-minute system ramping rate. Beyond this level, the on-line conventional generators may no longer be able to follow the combined PV output and system load changes, and unscheduled tie-line flows will occur. However, for dispersed PV systems, the same 1\% system ramp rate 
limit enables the utility system to cope with $6.3 \%$ of PV generation when the PV systems are installed over an area of $10 \mathrm{~km}^{2} .^{13}$

For a PV system dispersed throughout a $100 \mathrm{~km}^{2}$ area, the allowable penetration rises to $18.1 \%$, and for an area of $1,000 \mathrm{~km}^{2}$ or greater, the limit is $35.8 \%$. These higher limits, however, must be viewed with caution. Jewell has shown that a squall line can cause total loss of PV generation dispersed over a $1,000 \mathrm{~km}^{2}$ area in 17.6 minutes. This implies that the utility could lose $35.8 \%$ of its on-line capacity within this time frame. Such severe conditions require further study.

The results of the Jewell and Anderson studies are not directly comparable. The Anderson study investigated the PV penetration limit by simulating load-frequency control and economic dispatch capabilities of the electric system, whereas Jewell looked at the electric system's dispatch capability and load flow patterns. A typical utility AGC system performs load-frequency control every 2-6 seconds. The PV generation output is capable of changing up to 5\% fifteen times in 1 minute. The simulation time step used in the Jewell studies is too large to capture the responses of AGC under fast PV output variations.

Quantifying the spatial diversity of solar irradiance is a major contribution by Jewell. His simulations established the relationship between rates of PV output changes and the area size of dispersed PV installations. Jewell showed that a higher level of PV penetration is possible for dispersed PV systems. Similar studies should be conducted in other areas to verify that the rate of change of dispersed PV generation systems can indeed be made within the limits of the electric system operation. Future studies also should be aimed at developing models and simulating techniques that use standard meteorological and solar irradiance data to quantify the spatial diversity of solar irradiance for future PV system planning and installations.

\section{Chowdhury and Rahman Study}

To alleviate some of the problems identified in the Anderson and Jewell studies, Chowdhury and Rahman [35] suggested a rule-based dynamic dispatch algorithm to help utility operators choose optimal unit commitment and dispatch strategies when PV generation is operating. The new dynamic dispatch requires forecasts of PV generations at each dispatch interval. A Box-Jenkins time-series model provided such predictions [36]. The rule-based dynamic dispatch uses PV forecast information to commit and dispatch PV along with other conventional generations. For example, if PV generation is displacing a baseloaded unit, then PV generation is reduced to allow the baseloaded unit to operate at high efficiency. This study focused on the system operating cost using a simulation period of one day. Real-time AGC concern (load-frequency control) was not simulated; its behavior under the assumed PV generation output fluctuation was unknown. The authors did emphasize the important fact that the actual PV penetration level depends on the utility's load characteristics, generation mix, and location.

A case study with central-station PV generation was conducted. The solar irradiance data were chosen from a location in Virginia that represents typical weather in the southeastern United States; the load data were from a Virginia utility. The generation system used for the study, however, was derived from the EPRI synthetic utility system. Simulation time step was 30 seconds. The simulation results show a decreasing operating cost with increasing PV generation in the system until the installed PV capacity reaches $13.27 \%$ of the total system capacity. Beyond this point, measures to correct system operating problems (load following and spinning reserve) make it more expensive to continue operating a PV plant.

\footnotetext{
${ }^{13}$ In this case the maximum possible change of PV output is only $15.5 \%$ per minute under the worst cumulus cloud pattern. Thus, $1 \% \div 15.9 \%=6.3 \%$ of the utility's load.
} 


\section{Khallat and Rahman Study}

To overcome the output variability of a PV generation system, Khallat and Rahman [37] investigated the use of fuel cells to provide the operational support to central-station PV systems. A methodology for both capacity expansion planning and daily system operation was developed to assess PV generation in a utility system. The methodology was a two-stage process. In the planning stage, a limit on the PV system penetration level was determined using a negative load concept and equivalent loss-of-load expectation (LOLE). In the second stage, the operational consideration was examined and the level of fuel cells power plant support needed to maintain service quality in light of the PV output changes was determined. The second stage is an iteration process; fine tuning was necessary to determine the final feasible PV penetration level and fuel cells requirement.

A test case with load data from a utility in the southeastern United States and an EPRI southeastern synthetic generation system determined the applicability of the methodology. The simulation was conducted with a 3-minute time step for one day. The capacity credit for 1,000 MW of central-station PV generation (16.8\% of the peak system load) was found to be only $182 \mathrm{MW}$ for a peak day with high PV output fluctuations. An additional $88 \mathrm{MW}$ of fuel cells capacity was needed for this day to help conventional generating units cope with PV fluctuations. Beyond $16.8 \%$ of PV penetration, the operating cost savings start to decrease and the amount of needed fuel cells support exceeds the capacity credit allowed for PV generation.

According to this study, operating costs determine the final level of PV penetration. However, the study looked only at unit commitment and economic dispatch constraints of system operation. The loadfrequency control capability of the generation system was not simulated. Fuel cells offer additional operating benefits to the utility system such as VAR control, low emission, and reduced T\&D losses, but the study did not account for these benefits. Neither were the costs of fuel cells nor the PV system considered.

\section{Summary}

The penetration level of PV generation is not well defined in the literature. Some researchers quantify it as a percentage of total installed generation capacity; others quantify it as a percentage of system load. The methods of deriving these penetration limits are also diverse. Studies that focused on longer term operating concerns (e.g., transmission network load flows) tended to show higher penetration limit (Jewell), while a study that focused on shorter term operating concerns (e.g., load-frequency control) tended to give a much lower penetration limit (Anderson). Two studies used short-term production costs (Chowdhury and Khallat) to determine the allowable PV penetration level, but they considered only variable operating costs. Results of these studies seem to point to an upper penetration limit of PV generation of about $16 \%$ of the system load. This limit is usually set by the worst-case cloud pattern.

Two important points should be noted regarding these PV penetration limit studies. First, AGC simulation with a short time step generally gives a lower penetration level than the production cost simulation. The difference indicates a complicated relationship between AGC and intermittent generation; this relationship is not fully clear to researchers and requires further research. Second, the total economics of a PV system is ignored in the studies that use production cost to determine an allowable penetration level. Only fuel cost is considered. The capital cost of PV and the increased O\&M cost of conventional units due to increased regulating duties are not factored into the analyses. These costs may place additional limits on the PV penetration level. 
Several subjects should be included in future research:

- Verify solar irradiation spatial diversity with actual solar irradiance data from a wide range of different geographic locations

- Develop simulation techniques and models that use standard meteorological and solar irradiance data to quantify the solar irradiance spatial diversity

- Extend AGC study methodology (Anderson) to dispersed PV systems and examine how load following and ramping capability affect the feasible penetration limit

- Include realistic current and projected costs of an installed PV system in the production cost studies

- Include in the economic analyses T\&D benefits from a distributed PV system as suggested by some recent studies

- Investigate the feasibility of statistically forecasting short-term (10-minute) output of a PV generating plant.

\subsubsection{Wind Generation Systems}

Many studies have estimated the feasible penetration levels of wind generations. However, the term penetration level is not clearly defined by wind system researchers. Like PV studies, various methods were employed to determine the penetration levels, and the results strongly reflect the assumptions and input data used in the studies. Brief summaries and discussions of some of the studies follow. These studies are arranged in two groups: early studies (before 1986) and more recent studies (after 1986).

Early Studies (Before 1986)

A 1979 EPRI study [38] reported the impact and penetration analyses of wind generation for three actual utility systems. The evaluation was based on total production costs with and without wind power. Results showed feasible penetration levels ranging from very low to a high of around $15 \%$ under favorable wind conditions, utility characteristics, and economic framework. Although this study ignored the load following requirement and operating reserve constraints, it did illustrate that penetration level was a function of individual system characteristics and resource availability.

Curtice and Patton [39] used an AGC simulation program to assess the combined effects of load demand and wind generation output fluctuations on a utility's load-frequency control function. Second-by-second wind generation data from aggregate wind turbine systems were developed and treated as negative loads to characterize the short-term effects wind generations might have on system load. The result showed that if the output of each wind turbine was not correlated with output of other wind turbines, the aggregate power output would not significantly affect utility system generation regulation. However, a simultaneous power increase or decrease of aggregate wind turbine systems (such as caused by a storm front) will significantly change the utility's net system load and affect the system control performance. The study found that when installed wind generation exceeds $5 \%$ of the total system load, rapid increase and decrease in wind power output will produce increased tie-line flows and increased operating costs (mostly fuel) due to additional system regulation. 
Zaininger [40] studied the minute-to-minute ramping requirements, frequency excursions, and transient stability of an isolated electric system (Hawaiian Electric Company) to determine the impact of wind generation on a utility system. The results did not give direct wind generation penetration levels. The penetration levels were implied in terms of allowable combined changes of wind turbine cluster output and system load. The allowable combined wind output and load changes were in the range of $4 \%-5 \%$ of the system peak demand. The study method was extended to analyze the minute-to-minute ramping requirements of two typical interconnected utility systems with wind generations [41]. The results showed that allowable combined wind output and load changes could be higher if fast-response hydro units were available. Detailed system load profile and specific wind speed data are required to evaluate systemspecific penetration limits.

Aerospace Corp. [42] studied production costs on two utility systems using various amounts of wind generations. Penetration levels of wind generation were set by the researchers at $2.5 \%, 5 \%$, and $10 \%$ of the respective system's annual peak demand. Only production cost and the system loss-of-load probability (LOLP) were calculated. Operational issues such as load following, spinning reserve, and unloadable generation were not included in the analysis. This report showed that the value of wind generation (fuel savings and capacity values from replacing more expensive oil-fired generating capacity) declined $5 \%$ at the penetration level of $2.5 \%$, and $13 \%$ at the penetration level of $10 \%$.

One early study by Nielsen [43] analyzed the problems of integrating wind turbines into the Danish electric grid. Various wind generation penetration levels were simulated on the Danish system. Because of a high degree of combined heat and electricity production in the Danish system, unloadable generation limitation became very noticeable. The results showed that $12.1 \%$ of wind energy became surplus energy at $5 \%$ penetration (percentage of wind power to total system demand). The surplus energy increased to $21.6 \%$ when wind generation penetration increased to $15 \%$. No economic analyses were outlined in this report.

Schlueter et al. [44] has concentrated their studies on the impact of meteorological events (storm fronts, etc.) on large wind turbine arrays connected to an electric system. Their studies showed that infrequent meteorological events could cause serious operating problems for electric systems with wind energy generations if large amounts of installed wind generators could be affected by a single such event. It was suggested that the total output from a wind generation site that could be affected by a single storm front must be less than the electric power system's load following requirement for any 10-minute interval to comply with NERC-OC operating guidelines. In addition, the study suggested the maximum echelon penetration level within a wind turbine array is less than the typical power system response (ramping) rate capability (about $1 \%$ of the total installed system capacity). These constraints usually limited the total capacity of a single turbine array or multiple arrays, which could be affected by a single storm front, to about $5 \%$ of the total electric system generation capacity. A higher penetration level is possible if utilities modify the unit commitment and generation control strategies [45]. However, the proposed modification would require accurate "quarter-hour ahead" prediction of cyclic wind power variation and an accurate "hour ahead" prediction of a wind power variation trend.

Simburger and Cretcher [46] studied the load following impacts of a large wind farm on an interconnected electric utility system. Five hundred megawatts of wind generation was added to the 1979 Los Angeles Department of Water and Power system, and the AGC operations were simulated. The system had about 1,060 MW of hydro capacity; half of it was placed under AGC to provide the required ramping capability. Wind generation of $500 \mathrm{MW}$ represented $14.8 \%$ of the system's on-line capacity. The result showed that inadvertent tie-line flow increased from 10 to $20 \mathrm{MW}$ without wind power and to $150 \mathrm{MW}$ with wind power. Consequently, the NERC-OC area control error guidelines were violated. Ramping capability of 
conventional generators was the limiting factor. The authors suggested two strategies to mitigate the problem: (1) developing appropriate wind farm controls to level out the fluctuations of wind power output, and (2) adding a rapid-response generation source, such as gas turbines, to provide more ramping capability.

Bossanyi and Halliday [47] developed an hourly production cost simulation model to study the integration of wind energy into the British electric grid. Four types of generating plants were used to meet the electric demand: nuclear power baseload units, steam turbine intermediate units, gas turbine and pumped-storage hydro peaking units, and intermittent wind energy units. The model incorporated a simple look-ahead method to forecast available wind power for dispatching purposes. The results showed that wind power could supply $20 \%$ of Britain's annual electric demand without major difficulties. With wind power penetration at $14.3 \%$ of system demand, the operating penalties (efficiency reduction from partial loading of steam units and increased fuel cost from additional cycling duties) and discarded wind energy would reduce fuel savings by $6.8 \%$. Total fuel savings could be reduced by $23.6 \%$ when the wind penetration level reached $24.6 \%$. The authors suggested that the savings could be improved, particularly at high penetrations, by using a more realistic wind forecasting method. Impact on system load following capability was not considered.

Another comprehensive study examined integrating wind power into the TVA system [48]. The study focused on the short-term system operational issues. Researchers reported that if wind generation was treated as uncontrolled negative system load with assumed short-term wind power output variation, the impact on power system load frequency control might be enough to limit the penetration level of wind generation below $15 \%$ of the total system generation capacity. They also reported that excessive unloadable generation problems would require some modifications to the unit commitment and automatic control of generation procedures. The following strategies were suggested to accommodate higher wind power penetration:

- Develop stochastic algorithms for unit commitment and automatic control of generation to account for the intermittent and stochastic nature of wind generation systems

- Develop a pseudo cost function for wind generation reflecting intermittency of wind generation and dispatch wind generation in the same manner as hydro generation

- Develop and install a supervisory control and data acquisition (SCADA) system for wind farms.

Thomas et al. [49,50] proposed an AC/DC/AC linked wind power array and control strategy to limit the output power variations. An optimal level of wind generation output was determined in terms of mean wind speed and the relative production costs of the fast-response and baseload units. The results showed that wind power penetration as high as $16.75 \%$ might be economical for a system that gets $8 \%$ of its capacity from combustion turbines, $15 \%$ from combined-cycle turbines, $57 \%$ from coal units, and the remaining $20 \%$ from nuclear. The proposed $\mathrm{AC} / \mathrm{DC} / \mathrm{AC}$ interface provided better system protection and steady-state and dynamic stability. One of the significant advantages of this interface was the ability to control reactive power. The study showed that, with proper control, wind farms could enhance rather than degrade the system voltage profile. The same control was also useful for damping transient oscillations caused by system disturbances.

Recent Studies (After 1986)

A more recent study by Coelingh et al. [51] analyzed the operation of the Netherlands electric utility system with 1,000 MW of installed wind power. To reach 1,000 MW of installed capacity, wind turbines will be placed throughout the Netherlands, with the majority at coastal regions and off-shore. Actual 
meteorological and environmental data simulated the hourly output of the 1,000 MW wind generation, which represented $9 \%$ of the total installed capacity of the Netherlands system. The results indicated that it would be feasible to operate this electric system with that much wind generation. At this penetration level, the capacity credit for the 1,000 MW of installed wind generation was calculated at $184 \mathrm{MW}$. The study also found that the spatial diversity of wind velocity over the Netherlands made the variations of wind power output less severe and less frequent. For example, researchers observed that with this much installed wind capacity, hour-to-hour variations of total wind power output are never greater than $40 \%$ of installed capacity, while an hourly wind power output decrease of $30 \%-40 \%$ of installed capacity might occur only four times in 10 years.

The same conclusions were reached by Hans Georg Beyer et al. and Halberg in two other studies. Hans Georg Beyer et al. [52] used wind data from several North German sites. They found that the coherence in wind speed fluctuations was very low at high frequency from a large number of wind turbine sites dispersed over distances of some tens of kilometers. Wind farm power fluctuations with frequencies higher than $10^{-2}$ were in fact leveled out. Thus, in the analysis of wind power systems consisting of many wind turbines distributed over tens of kilometers, the output could be treated as smooth in time scales of several minutes. The low correlation of fluctuations in wind power over long distances, observed from these studies, gave hope that the negative impact of intermittent wind power on the operation of an electric power system might be less severe than previously thought. Halberg [53] simulated wind generation in the Dutch electric system using wind data recorded at six sites spread across the coastal area of the Netherlands. He concluded that although wide variations in wind power could be expected to occur for longer periods (several hours), the frequency of severe variations in power output per 1,000 MW of wind capacity appeared to be comparable with the frequency of forced outages of large thermal generation units.

Grubb [54] reported that, under favorable circumstances, it could be economical for wind energy alone to supply more than $50 \%$ of Britain's electricity demand on an integrated power-supply system without storage facilities. This penetration level of wind generations is much higher than the levels considered feasible by U.S. utilities. The author used a probabilistic production costing model with frequency and duration methods in a system reliability analysis to study the long-term generation expansion plan for the entire British power system. Wind resources for all of Great Britain were considered. To accommodate as much wind generation output as possible, the program permitted cycling of other on-line generating units, including nuclear power units. The minimum loading level for nuclear units was set at $40 \%$ of their maximum capacity with cost penalties. For wind power to achieve such a high penetration level in Britain, it was necessary to distribute many wind turbines over many feasible wind resource regions. The author argued that the output variations from the total installed wind power system would be small because of the spatial diversity of wind. The effect would be less variable wind generation. At such a high penetration, wind generation would begin to displace baseload generating units in the system. A similar effect was observed by an early study of wind generation impacts on the New York State power system [55].

The wind penetration level suggested by Grubb differed substantially from other previous studies. Grubb's study represented the most optimistic assessment of wind energy so far. However, these results reflected the simulation model, assumptions about wind diversity, other characteristics of the wind resources, and steam plant (both coal and nuclear) partial loading capabilities. Therefore, these results should be treated with caution. The simulation model used in the study was a generalized model for assessing the economic benefits from large-scale wind generation in the long term. Therefore, detailed operational impacts of wind generation on electric power systems could not be modeled in full. The criteria used to establish the amount of operating reserve needed for the system were not particularly stringent. The question of how much impact high penetration levels of wind generation had on power system short-interval control decisions (such as load-frequency control) remained unanswered. 


\section{Summary}

Studies indicate that wind generation has an even wider range of feasible penetration levels than PV generation - from $4 \%$ to $50 \%$ of the system load. As mentioned earlier, researchers have used different definitions for the term penetration level; the criteria used to determine the penetration limit also vary. One observation about the studies is that production cost simulation studies using hourly load and wind data tend to show higher penetration limits than those using AGC simulations with a shorter time step. Short-term system operating concerns such as load-frequency control and unloadable generation limitations cannot be modeled and simulated properly by either chronological or probabilistic production cost models. These models use only hourly load and wind data. Higher penetrations based on production cost simulations may have to be subject to AGC analysis to determine system operability. The study results also emphasize the point that penetration level is a function of utility load characteristics, generation and fuel mix, and resource availability.

There appears to be general agreement that a low penetration level (up to 5\% of the system load) of wind generation will not cause any appreciable problems to system operations. Actual utility experience concurs with this view. There are more than 7,000 wind turbines installed in Altamont Pass, California, with an installed capacity of $734 \mathrm{MW}$ (as of August 1989). This represents about 51\% of total installed wind generation capacity in the United States. During some late summer evenings, wind turbines were supplying about 7\% of Pacific Gas and Electric Company's (PG\&E) system load. During PG\&E's peak demand periods, wind turbines occasionally supplied about $5 \%$ of the system load. No system stability or operating problems have been reported by PG\&E [56].

Later studies seem to point to higher allowable penetrations than the earlier reports. This can be attributed to better knowledge of wind speed and its spatial and temporal correlations. Wind data collected worldwide over the past few years indicate that aggregate wind power output from a wind farm is less variable than previously thought. Some pessimistic assumptions of wind behavior, which result in projections of low wind penetration levels, have been shown to be unrealistic. Grubb studied the problem and tried to explain the wide difference in results obtained by different researchers [57]. He concludes that the difference in study assumptions can adequately explain the different results. Changing just a few basic parameters, particularly those relating to system operating reserve allocation, limits of thermal units partial loading, and wind diversity and predictability, can have a dramatic effect on the computed value of the wind energy output. Simplifying assumptions on these factors often leads to substantially overestimating operating penalties of wind generation at higher penetration levels.

Better models for converting wind-speed data to electric power are needed in future research. Future wind penetration studies should also include simulations of electric system AGC response using actual wind data. Analyses of actual wind-speed data have concluded that there is a high degree of spatial diversity in wind resources. Some early assumptions on wind-speed distribution and spatial correlation appear too simplistic and pessimistic. Exploiting spatial diversity of the wind resource may result in a higher allowable penetration limit.

As a final note, two isolated electric utilities on the islands of Hawaii and Maui (HELCO and MECO) actually issued wind penetration guidelines in 1988 to limit the amount of wind power in the utility grid during various system loading conditions. These guidelines limited the allowable wind power to roughly $4 \%$ of each utility's load for operational reasons: maintaining a stable grid, alleviating voltage fluctuations and flickers, and reducing frequency deviations. The $4 \%$ limit is based on results from privately funded research, which was not published. 


\subsection{Conclusions}

Literature shows wide differences in feasible penetration levels of intermittent generations in the electric system. For central-station PV systems, constraints on load-frequency control and system ramping rate limit the PV generation level to less than $10 \%$ of the system load. Penetration of dispersed PV systems could be higher, depending on the size of the area where the PV systems are installed. For instance, if PV systems are dispersed over an area of $1,000 \mathrm{~km}^{2}$ or more, total installed PV capacity could be at $35.8 \%$ of the system load.

Research shows that a feasible range of penetration levels for wind power generation is wider than for PV generation. Various studies show that wind power integrated in the electric system may supply from $4 \%$ to $50 \%$ of the system load. Load-frequency control and generator ramping rates limit the wind power penetration to $4 \%$ of the system load for an isolated electric system, whereas the same constraints would limit the wind penetration to $5 \%$ for an interconnected utility system. Fifty percent penetration was obtained using a probabilistic production cost model and by permitting cycling of all steam units (including nuclear units). Utilities in California and Hawaii are now getting actual operating experience with low penetration levels of wind generations.

The studies are strongly influenced by assumptions made on resource intermittency and system modeling. More recent studies usually suggest higher penetration limits than earlier studies. Analyses of actual wind data have proven that certain assumptions in the earlier studies regarding wind-speed variation and spatial diversity were too simplistic and too conservative; the negative impact of intermittent generation technologies on system operations were overstated. Wind speed can change rapidly, but these changes are found to be bounded and can be represented statistically. Power output from a wind farm actually fluctuates less than previously assumed; therefore, the electric system should be able to integrate more wind power into the system. Operational experiences and several recent studies with factual weather data indicate that hour-to-hour variations of distributed intermittent generation output are much less than early studies suggested. New studies and analyses are needed to find out under realistic weather conditions what the system load following and operating reserve requirements should be when intermittent generation is added.

One suggestion for utilities to overcome the penetration limit set by infrequent worst case weather phenomena is to have NERC-OC establish different operating criteria for large penetrations of intermittent generations. ACE caused by intermittent generation may not be much different from the ACE induced from a large load change that frequently is caused by large fluctuating industrial loads.

Most of the published penetration limits are determined by the worst-case weather conditions. Such worstcase conditions only happen infrequently. An examination of actual weather data to determine how often those conditions occur appears necessary. Such probability information provides the basis for judging the expected impact of the worst-case condition and comparing its severity with other known system contingencies. No component in the electric system is perfectly reliable. Risk is acceptable to utilities so long as the probability of such risk is reasonably low. If utilities can be reasonably assured what the risk will be, proper design and operational changes can be made to deal with such occurrences.

Finally, attempting to establish penetration limits for intermittent renewable energy technologies with today's understanding of those technologies and the current electric systems may not be fair to the intermittent renewable energy technologies. Incorporation of renewable energy technologies will occur 
gradually over time, as economic and environmental concerns continually change. During this time, significant technology improvement will have major effects on the renewable technologies and the electric systems. Advanced design and new material and our ability to forecast them would enable us to better utilize the intermittent renewable energy resources. There may be some new technologies in the electric utility industry that would change the planning and operations of the electric systems. The Flexible AC Transmission System (FACTS) concepts pursued by EPRI is an example that could have a fundamental impact on the future electric systems. Similar advancement in control and communication technologies would eliminate or alleviate many of the issues facing the distributed utility concept today. Ongoing evolutions in utility systems are parallel to the development of renewable energy technologies, but they will certainly affect the utilities' ability to integrate intermittent renewable energy technologies into their systems. Concentrating on finding feasible penetration levels with today's knowledge and system structure may not be a worthy research topic in the near future. Instead, the effort should be directed toward finding feasible technical solutions to facilitate the integration of intermittent renewable energy technologies.

Short-term wind speed and solar irradiance forecasting capabilities are of real value to utility system operations. They will ease the load following, operating reserve, and economic dispatch requirements of integrating intermittent energy resources into utility systems. Currently, this capability is limited. Research activities to address this need should be placed high on future research agenda.

\subsection{References}

1. Elgerd, O.I., Electric Energy Systems Theory: An Introduction, McGraw-Hill Book Company. 1971.

2. Lachs, W.R., "Voltage Collapse in EHV Power Systems," paper presented at the IEEE PES Winter Meeting, New York, NY. A 78 057-2. January 29-February 3, 1978.

3. Lachs, W.R., "Dynamic Study of an Extreme System Reactive Power Deficit," IEEE Transactions on Power Apparatus and Systems, Vol. PAS-104, No. 9, September 1985. pp. 2420-2426.

4. Lachs, W.R., "insecure System Reactive Power Balance Analysis and Counter Measures," IEEE Transactions on Power Apparatus and Systems, Vol. PAS-104, No. 9. September 1985. pp. 24132419.

5. Schlueter, R.A., Voltage Stability and Security Assessment, EPRI EL-5967. Final Report. August 1988.

6. Graf, K.M., et al., Dynamic Simulation of Voltage Collapse Process in EHV Power Systems, EPRI EL-6183, Final Report. January 1989.

7. Chiang, H.D., et al., "On Voltage Collapse in Electric Power Systems," IEEE Transactions on Power Systems, Vol. 5, No. 2. May 1990. pp. 601-611.

8. Begovic, M.M., Phadke, A.G., "Dynamic Simulation of Voltage Collapse," paper presented at the IEEE Power Industry Computer Application Conference, Seattle, Washington. May 1-5, 1989.

9. Flatabø, N., Ognedal, R., Carlsen, T., "Voltage Stability Condition in a Power Transmission System Calculated by Sensitivity Methods," IEEE Transactions on Power Systems, Vol. 5, No. 4. November 1990. pp. 1286-1293. 
10. DeMarco, C.L., Overbye, T.J., "An Energy Based Security Measure for Assessing Vulnerability to Voltage Collapse," IEEE Transactions on Power Systems, Vol. 5, No. 2. May 1990. pp. 419-427.

11. Chow, J.-C., Fischl, R., Yan, H., "On the evaluation of Voltage Collapse Criteria," paper presented at the IEEE Power Industry Computer Application Conference, Seattle, Washington. May 1-5, 1989.

12. Begovic, M.M., Phadke, A.G., "Voltage Stability Assessment Through Measurement of a Reduced State Vector," IEEE Transactions on Power Systems, Vol. 5, No. 1. February 1990. pp. 198-203.

13. Wasynczuk, O., "Dynamic Behavior of a Class of Photovoltaic Power Systems," IEEE Transactions on Power Apparatus and Systems, Vol. PAS-102, No. 9. September 1983. pp. 3031-3037.

14. Wasynczuk, O., "Integration of Dispersed PV Generation into Utility Distribution Systems: Stability, Integration and Fault Tolerance," Proceedings 19th Intersociety Energy Conversion Engineering Conference, Vol. 4. August 1984. pp. 2145-2151.

15. Hinrichsen, J.I. et al., Dynamic of Single and Multi-Wind Energy Conversion Plants Supplying Electric Utility Systems, Report DOE/NASA/-13401, NASA CR-165156. June 1980.

16. Hilson, D.W., Sadanandan, N.D., et al., "Impact Assessment of Wind Generation on the Operation of A Power System," IEEE Transactions on Power Apparatus and Systems, Vol. PAS-102, No. 9. September 1983. pp. 2905-2911.

17. Herrera, J.I., Lawler, J.S., Reddoch, T.W., Sullivan, R.L., "Status Report on Utility Interconnection Issues for Wind Power Generation," DOE/NASA/4105-3. June 1986.

18. Chan, S.M., Curtice, D., Chang, S.-K., Methods for Wind Turbine Dynamic Analysis, EPRI AP-3259. Final Report. October 1983.

19. Thomas, R.J., Phadke, A.G., Pottle, C., "Operational Characteristics of A Large Wind-Farm UtilitySystem with A Controllable AC/DC/AC Interface," IEEE Transaction on Power Systems, Vol. 3, No. 1. February 1988.

20. Smith, J.C., "Utility Integration of Photovoltaic Systems, EPRI RP-3179, Task 1 Overview," prepared for US-EC Workshop, Madrid, Spain. September 1990.

21. Cohn, N., Control of Generation and Power Flow on Interconnected Power Systems, Second Edition. John Wiley \& Son, Inc., New York. 1971.

22. European Wind Power Integration Study - The Dutch Contribution. CEC DG XII. Contract No. JOUR-0029-NL (CH). Final Report. April 1992.

23. Jewell, W.T., "The Effects of Moving Cloud Shadows on Electric Utilities with Dispersed Solar Photovoltaic Generation," Ph.D. Thesis. Oklahoma State University. December 1986.

24. Thomas, R.J., "An Integration Methodology for Large Wind-Energy conversion Systems," Final Report, DOE/RA/50664-1. June 1986.

25. Thomas, R.J., et al. Ibid. 
26. Boardman, R.W., Tatton, R., Curtice, D.H., Impact of Dispersed Solar and Wind Systems on Electric Distribution Planning and Operation, Final Report. ORNL/Sub-7662/1, Oak Ridge National Laboratory. February 1981.

27. Electric Power Research Institute, "Assessment of Distributed Wind Power Systems," Final Report, EPRI AP-2882. February 1983.

28. Electric Power Research Institute, "Assessment of Distributed Photovoltaic Electric Power Systems," Final Report, EPRI AP-2687. October 1982.

29. Gulachenski, E., et al. "Current and Voltage Harmonic Measurements and Modeling at the Gardner Photovoltaic Project," IEEE Transactions on Power Delivery, Vol. 4. January 1989. pp. 800-809.

30. Kern, E.C., et al. "Cloud Effects on Distributed Photovoltaic Generation: Slow Transients at the Gardner, Massachusetts Photovoltaic Experiment," IEEE Transactions on Energy Conversion. June 1989. pp. 184-190.

31. ANSI/IEEE Std 1001-1988, IEEE Guide for Interfacing Dispersed Storage and Generation Facilities with Electric Utility Systems.

32. Lee, S.T., Yamayee, Z.A., "Load Following and Spinning Reserve Penalties for Intermittent Generation," IEEE Transaction on Power Apparatus and Systems, Vol. PAS-100, No. 3. March 1981. pp.1203-1211.

33. Anderson, P.M., "The Effect of Photovoltaic Power Generation on Utility Operation," Final Report SAND84-7000. February 1984.

34. Jewell, W.T., Unruh, T.D., "Limits on Cloud-induced Fluctuation in Photovoltaic Generation," IEEE Transactions on Energy Conversion, Vol. 5, No. 1. March 1990. pp. 8-14.

35. Chowdhury, B.H., and Rahman, S., "Is Central Station Photovoltaic Power Dispatchable?," 88 WM 233-9. January 31 - February 5, 1988.

36. Chowdhury, B.H., Rahman, S., "Forecasting Sub-hourly Global Solar Irradiance for Prediction of Photovoltaic Output," Proceedings 19th IEEE Photovoltaics Specialists Conference, New Orleans, Louisiana. May 1987.

37. Khallat, M.A., Rahman, S., "A Model for Capacity Credit Evaluation of Grid-Connected Photovoltaic Systems with Fuel Cell Support," IEEE Transactions on Power Systems, Vol. 3, No. 3. August 1988. pp. 1270-1276.

38. Electric Power Research Institute, "Requirements Assessment of Wind Power Plants in Electric Utility Systems," Volume 2, EPRI ER-978. Final Report. January 1979.

39. Curtice, D., Patton, J., Operations of Small Wind Turbines on a Distribution System, Systems Control, Inc. August 1980.

40. Zaininger, H.W., Wind Power Generation Dynamic Impacts on Electric Utility Systems, EPRI AP1614, Final Report. November 1980. 
41. Zaininger, H.W., Bell, D.J., "Potential Dynamic Impacts of Wind Turbines on Utility System," IEEE Transactions on Power Apparatus and Systems, Vol. PAS-100, No. 12. December 1981. pp. 48214829.

42. Aerospace Corp., Electric Utility Value Analysis for Wind Energy Conversion System, SERI/TR98336-1A. Solar Energy Research Institute. April 1982.

43. Nielsen, P., "Problems of Interconnecting Aerogenerators to the Grid," Solar Energy R\&D in the European Community, Series G, Volume 1 Wind Energy. Proceedings of the EC Contractors' Meeting, Brussels, Belgium. Edited by W. Palz \& W. Schnell. November 23-24, 1982. pp.151-157.

44. Schlueter, R.A., Park, G.L., et al., "Simulation and Assessment of Wind Array Variations Based on Simultaneous Wind Speed Measurements," IEEE Transactions on Power Apparatus and Systems, Vol. PAS-103, No. 5. May 1984. pp.1008-1016.

45. Schlueter, R.A., Park, G.L., Reddoch, T.W., Barnes, P.R., Lawler, J.S., "A Modified Unit Commitment and Generation Control for Utilities with Large Wind Generation Penetrations," IEEE Transactions on Power Apparatus and Systems, Vol. PAS-104, No. 7. July 1985. pp.1630-1636.

46. Simburger, E.J., Cretcher, C.K., "Load Following Impacts of a Large Wind Farm on an Interconnected Electric Utility System," IEEE Transaction on Power Apparatus and Systems, Vol. PAS-102, No. 3. March 1983. pp. 687-692.

47. Bossanyi, E.A., Halliday, J.A., "Recent Developments and Results of the Reading/RAL Grid Simulation Model," Proceedings of the Fifth BWEA Wind Energy Conference, Reading, Great Britain. March 1983. pp. 62-74.

48. "TVA/DOE Analysis of the Operation of An Electric Power System with and without Wind Generation, Volume III: Simulated Operations of TVA Power System with Wind Generation," Final Report, TVA. March 1985.

49. Thomas, R.J., An Integration Methodology for Large Wind-Energy Conversion Systems, Final Report. DOE/RA/50664-1. Cornell University, Ithaca, New York. June 1986.

50. Shi, An-Jen, Thorp J., Thomas, R., "An AC/DC/AC Interface Control Strategy to Improve Wind Energy Economics," IEEE Transactions on Power Apparatus and Systems, Vol. PAS-104, No. 12. December 1985.

51. Coelingh, J.P., Van Der Ree, B.G.C., Van Wijk, A.J.M., "The Hourly Variability in Energy Production of 1000 MW Wind Power in the Netherlands," Proceedings of European Wind Energy Conference. July 1989.

52. Beyer, Hans Georg, Luther, J., Steinberger-Willms, R., "Power Fluctuations from Geographically Diverse, Grid Coupled Wind Energy Conversion Systems," Proceedings of European Wind Energy Conference. July 1989.

53. Halberg, N., "Wind Energy Research Activities of the Dutch Electric Generation Board," paper presented at the EC Wind Conference. September 1990. 
54. Grubb, M.J., "The Integration and Analysis of Intermittent Source on Electricity Supply Systems," Ph.D. Thesis, Kings College, University of Cambridge. 1987.

55. Kinloch, D.H., Wicks, F.E., Becker, M., "Potential and Impacts of Wind Electric Generation Upon Electric Power System," IEEE Transactions on Power Apparatus and Systems, Vol. PAS 99, No. 4. July/August 1980. pp. 1328.

56. Smith, D.R. and Ilyin, M.A., "Wind Energy Evaluation by PG\&E," Pacific Gas and Electric Research and Development, San Roman, California. 1990.

57. Grubb, M.J., "The Economic Value of Wind Energy at High Power System Penetrations: An Analysis of Models, Sensitivities and Assumptions," Wind Engineering, Vol. 12, No. 1. 1988. pp. 1-26. 


\subsection{Planning Factors}

Planning for electric utilities is a complex and time-consuming optimization process in which utilities aim to minimize the total cost of electric services [1]. Some decision variables in this process are projected future demands, new facilities required and their costs, fuels and their costs, and utility financial stability (debt accumulation and service, cash flow, etc.). Traditionally, utility planning and decision-making are carried out in well-defined steps. A variety of planning tools and models are available that served electric utilities reasonably well until the mid-1970s.

The traditional utility planning process also helped shape the vertically integrated structure of today's electric utilities. Until the early 1970s, most electric utilities experienced constant high growth of demand. Technical advances in generation facilities made the economies of scale a matter of fact in the utility business. There was always a need for new generation capacity, and the next generation plant that the utility brought on line always had a lower marginal production cost than the existing system's average production cost. Utilities earned a fixed return on their investment allowed by the regulatory process and could confidently plan and build new generation plants to meet the ever-increasing demand [2].

This load growth pattern changed in the mid-1970s, becoming unstable and less predictable. Generation technologies appeared to have reached the limits of the economies of scale. Production costs of new generation plants were not necessarily lower than the average cost of the existing system. Furthermore, the cost overrun and construction delay of some of the nuclear power plants had put utilities under numerous public and regulatory prudence audits and reviews. The planning results as well as the planning assumptions and methodologies of the utilities were challenged. These public scrutinies of utility planning activities sometimes resulted in financial distress to the utilities. As a result, electric utilities have been undergoing some noticeable changes since the 1970s. Partial deregulation of electricity generation and the emergence of independent power producers are two most significant developments. Other changes in the utility industry include greater demand of access to utilities' transmission systems and competition for retail and wholesale customers. Electric utilities are forced to respond to those changes.

Today, much of the traditional utility planning process is still in place, but the elements of risk and uncertainty are now heavily considered. Environmental restrictions, siting and licensing difficulties, regulatory delays, public involvement in the utility planning process, and uncertain future load growth have prompted utilities to evaluate their decisions for a range of future uncertainties and take steps to minimize future risks. Power supply options are no longer the only alternatives considered by utilities in meeting new demands. Demand-side management (DSM) options have been given equal consideration or even higher priority over supply-side options by utilities during the planning process. There is now a need to include a much wider variety of resources during the planning process. Furthermore, many states and utilities have used competitive bidding to select future generation capacity. Under this approach, part of the utility generation expansion process becomes a proposal evaluation process in which considerations of usual utility cost and reliability are expanded to cover the experience and performance of some non-utility entities.

Intermittent renewable energy technologies do not fare well compared to their potentials under current utility planning processes. The barriers that intermittent renewable energy technologies face in the planning processes are analyzed in this chapter. 


\subsection{Evolution of Utility Planning Process}

Utility planning involves developing and evaluating technically and economically feasible plans that require capital intensive facilities. It aims to identify the most cost-effective plan to meet a utility's future demands at an appropriate service quality. Planning for electric utilities is generally carried out in three steps: (1) forecasting demand and supply requirements, (2) analyzing alternatives, and (3) selecting the plan. Utilities use the same basic steps to plan all facilities, although significant variations exist in planning different sectors (generation, transmission, distribution, etc.) of utilities.

Demand forecasting is the first step in the planning process. The forecasting methodologies vary from simple trending of historic demands to the use of very sophisticated econometric models. Generation and transmission facilities usually take a long time to construct and complete; therefore, the load forecasting is normally carried out well into the future. The utility's total capacity requirement is determined by considering both load forecast and reserve requirements. Comparing the total requirements to the available capacity, which includes firm capacity purchase and retirement of old units, establishes the amount and timing of any new capacity requirement. Many models ranging from simple reserve margin calculations to sophisticated LOLE ${ }^{14}$ computations are available for this purpose.

After the demand and required supply are decided, the next step in the planning process is to identify and evaluate comparable alternatives that can satisfy future demand and supply requirements. First, a screening method is developed to eliminate certain alternatives that are not likely to provide the necessary economy and service quality. The screening analysis generally examines factors such as resource applicability and duty cycle requirement. Detailed economic analyses usually are not performed at this stage. The results from screening analysis then become the basis for detailed analyses to evaluate each plan's capital requirement, fuel requirement, operating costs, system reliability, and environmental compatibility. The production costing program combines the estimated capital cost, the associated fuel, and O\&M costs into a power cost projection for each plan. The total system reliability of alternative plans is examined according to some generally accepted guidelines and methodologies to ensure comparable service quality. Various computer-based models are used to evaluate these factors.

The last step is the ranking and selection of alternative plans. Certain weighting factors are assigned to different attributes of the alternative plans based on the utility's preference, experience, regulatory rules, perceived value and risk, environmental impact, and other factors so that a ranking order of all the alternative plans can be decided. Other criteria such as fuel diversity and regulatory approval are also considered in the selection of the final plan.

Utility planning is an iterative process. Electric demand is price sensitive; the price of electricity relative to other energy sources will influence the electricity usage. Customers may decide to increase electricity usage if its price is lower than other energy sources. Otherwise, customers may decide to adopt conservation measures or switch to competing energy sources. Utilities will assess rate impacts of various plans on load forecasting and reexamine the load projection. This, in turn, may affect the selection of expansion alternatives in the planning process.

There are usually specific technical, economic, and financial objectives to be met in the selection criteria. The objectives are stated in the early stage of the planning process; the final plan is expected to meet these

\footnotetext{
${ }^{14}$ Loss-of-load probability (LOLP) is an index representing the probability of a generation shortage. The expectation of this shortage over a specified time period is the loss-of-load expectation (LOLE). LOLE is the proper name because its calculation is the result of a mathematical operation known as "expected value."
} 
objectives. If it does not, the process will be repeated with greater emphasis placed on certain characteristics of alternate options that are related to the desired objectives. This step is similar to the pricedemand feedback loop discussed earlier. Some utility objectives include technical reliability, operating flexibility, environmental impact, technology and resource diversity, financial feasibility, ownership option, maximization of earnings, minimization of revenue requirement, etc.

Since the 1970s, several major developments in the electric utility industry have impacted the planning process. These include overcapacity situations in some parts of the country; cancellation, delay, and cost overrun of nuclear power plants; fuel and load forecast uncertainties; and the development of non-utility generators. Different planning approaches have been tried: DSM options are considered equally or even given higher priority; utilities begin to evaluate the impacts of their decisions under a range of projected future situations; emphasis is placed on shorter term analyses and effects, and plans that involve unproven technologies and operating practices or do not show benefits within a short time are delayed or eliminated; utilities attempt to develop a range of load projections rather than a single load forecast to cover expected high and low growth scenarios.

Risk assessment has become a prime consideration in the planning process in the volatile regulatory and operating environments. Risk assessment examines the ability of a plan to adapt to potential variations in future events. Selected plans must conform to the utility's willingness to accept the associated risk of potential future outcomes.

Traditional reliability planning criteria for electric systems are based on engineering judgment and operating experience. For a power supply system, the generally accepted reliability criterion is a LOLE of one day in 10 years; for a transmission and distribution system, most utilities set a limit on average outage time per customer per year. These planning criteria are designed to establish a minimum acceptable level of reliability (or maximum level of risk). However, the reliability criteria ignore economics because they do not account for the cost of providing a given level of service reliability, nor do they account for the value of reliability service to customers. In general, system reliability targets give little recognition to customer preference regarding service reliability and outage cost, which may vary substantially.

An emerging approach to system reliability planning is to consider both the reliability "worth" and its cost. PG\&E developed a value of service (VOS) methodology [3] to determine the optimal level of system reliability for a utility and its customers. The VOS methodology measures the reliability worth in terms of customer preference and outage costs. The basic approach in estimating VOS is to use customers' responses to postulated outage scenarios to measure the outage cost. The VOS information is incorporated into the planning process, and the total cost (supply cost and customer outage cost) is minimized. Under this concept, capacity addition or system improvement would be added only when the marginal cost of capacity or improvement is equal to the expected marginal benefit from its use.

\subsubsection{Least-Cost Utility Planning}

As the analysis perspective has broadened in the utility planning process, new terms describe the resource expansion planning ${ }^{15}$ process in which demand-side options are explicit alternatives to generation supply options. This paradigm has been called least-cost planning. This term derives from a study by Roger Sant in 1979 [4]. Like most other broad generic labels, it has sometimes come to mean different things to different audiences. The traditional utility demand-side activities had been marketing new loads by

\footnotetext{
15 Generation expansion planning was the traditional term. Now it is preferable to call it resource expansion planning because demand-side management options are routinely considered by utilities.
} 
promoting electric appliances (refrigerators, air conditioners, electric water heaters, etc.), all-electric homes, or electric industrial processes. In regions where average costs are higher than incremental costs because of excess capacity or low fuel prices or both, marketing programs to increase sales are still being promoted as cost-reducing strategies.

Least-cost planning is a process that considers both supply- and demand-side options in planning to meet utilities' future demands. Demands for electric service can be met by increasing the supply of electricity or by reducing demand (e.g., improve end-use efficiency or substitute an alternative energy resource). The risk and cost of investing in a new generation plant, along with public pressure, has prompted utilities to evaluate the impacts of demand control and demand reduction programs in the planning process. The concept that the individual customer class or end-use electricity demand is not fixed and can be altered by a variety of means adds a new dimension to traditional utility planning and operation.

Utility plans are seldom "ideal" because there are major uncertainties in the forecast of future demands, as well as in economic factors (cost escalation, general inflation, interest rate, etc.), and environmental and regulatory impacts. Utilities have realized that more sophisticated forecasting methods are not the cure for the problem. Unpredictable events, not forecasting methods, frequently made the underlying assumptions inappropriate. Learning from this, the least-cost planning process explicitly considers uncertainties and risks and strives to minimize the impact of adverse future events.

Several states currently require utilities to adopt least-cost planning that looks at both supply- and demandside options. The U.S. Congress recognized the importance of environmental factors by giving conservation resources a $10 \%$ bonus in economic evaluations in the Pacific Northwest Electric Power Planning and Conservation Act (Regional Power Act 1980). Thus, energy-efficient resources that cost up to 10\% more than the conventional supply alternatives can be acquired [5].

Many DSM options, as well as innovative planning methodologies to analyze them, are available. Vast experience has been accumulated over the past decade. Evaluating demand and supply options on an equal basis requires a broader perspective than that previously needed for traditional supply-side-only planning studies. The planning methods and models used to carry out the analyses now require additional features to analyze DSM options. The new emphasis on the integration of supply- and demand-side options requires more data. The quality of data needed also has significantly increased. This has made the planning process even more complicated and involved. Utilities are now retrofitting the traditional process with new sets of objectives and algorithms that make it more compatible with today's planning requirements.

\subsubsection{Integrated Resources Planning}

Integrated resource planning (IRP) is yet another evolving planning process for electric utilities, and regulatory commissions to consistently assess a variety of supply and demand resources to meet customer electricity demand at the lowest economic and social cost. Like least-cost planning, IRP considers both supply and demand resource options in the process, but with a more broadened approach to utility planning.

One of the driving forces behind IRP is the greater recognition of various stakeholder perspectives in the planning process. In order for a plan to be acceptable and successful, concerns of utilities, customers, and regulators have to be balanced. The impacts of any DSM program on customers and customer acceptance of such a program must be analyzed. The risks and uncertainties, both real and perceived, of different resource options need to be compared. The scope of the utility planning process needs to be broadened to include more diversified resource options - renewable technologies, DSM programs, T\&D options, or even electricity pricing as a resource - and to facilitate more public involvement in the planning process. 
One of the barriers to a utility using the IRP process is the utility rate-making process. Utilities are required to evaluate supply and demand resources on an equal basis. However, the traditional method of setting electric rates discourages utilities from making optimal use of DSM options, especially energy-efficiency measures. Under the rate-making principle used in most states, utilities' revenues increase when electricity sales increase. Implementing energy-efficiency measures decreases utilities' revenues and profits without proper compensation to utility shareholders. There are also concerns about potential rate increases caused by spreading fixed costs over fewer sales and the consequent detrimental effect on utilities' competitiveness in the market. IRP is striving to achieve a regulatory and rate-making practice that eliminates these disincentives for utilities.

IRP expands the economic criteria upon which plans are assessed. In a traditional supply plan, revenues required by a utility from its customers include the costs of production, delivery, and capital recovery. IRP recognizes that the process must be broadened to include the total customer costs of electric service. For example, environmental and social factors, such as air quality, water quality, land use, etc., of a particular plan also must be equally assessed. Such a broadened approach also could encompass possible regional economic benefits associated with electricity generation and use, and could include other incomedistribution effects of different plans.

An extension of the IRP process further optimizes the total cost of providing services. Not only are supplyand demand-side alternatives considered in the planning processes, but transmission, distribution, and storage options are included in the optimizing processes as well. A different term sometimes is used to describe the process: integrated cost of services planning.

IRP as a planning and regulatory process can greatly reduce the uncertainties and risks faced by both utilities and regulatory commissions. These benefits are the result of considering a wide range of resource options and public involvement during the planning and regulatory approval process. IRP can thus benefit all stakeholders in the process; i.e., acquisition of resources that meet customer electricity demands in ways that are cost-effective, environmentally benign, and publicly acceptable.

A number of technical and institutional issues exist, and they need further research and development. Hirst and Goldman [6] list the following research and development priorities for IRP: alternative regulatory procedures to eliminate disincentives that discourage utilities from implementing IRP; inclusion of environmental effects and other social factors in resource planning; expansion of technology transfer activities among regulatory commissions and utilities; and development of new methodologies to assess the cost-effectiveness of various resource options. Several research projects currently are examining these issues.

\subsection{Planning for Intermittent Renewable Technologies}

Intermittent energy resources do not fit well into current planning tools and processes. Most planning tools and processes are developed for the traditional electric utility structure, and they focus on economic factors of electric systems. Certain attributes of renewable resources offer important societal values, but many of those attributes are not explicitly considered in the current utility planning process. The unique operating characteristics of the intermittent renewable technologies also cause difficulties in evaluating intermittent energy resources against conventional options. 
For a given demand forecast, a resource supply planning process strives to determine the needed capacity to meet demand at the lowest possible cost and with acceptable reliability and service quality. The term reliability has a wide range of meanings and is interpreted differently by different parties. Electric utilities usually consider two aspects of system reliability: system adequacy and system security. Adequacy relates to the availability of sufficient facilities or capacities to satisfy the demand. It is therefore associated with steady-state conditions of the electric system. Security relates to the ability of the system to respond to disturbances associated with the loss of major facilities and other external causes; it is associated with system dynamic and transient behavior.

The generally used system reliability indices are reserve margin, LOLE, loss-of-energy expectation (LOEE), and frequency and duration (F\&D) index. All but reserve margin are probabilistic measures of the system adequacy. Reserve margin is the generation reserve capacity expressed as a percentage of weathernormalized expected peak load. ${ }^{16}$ It is a static measurement of the system capacity adequacy and does not consider plant and fuel availabilities. LOLE is normally expressed in terms of days per year and indicates the expected number of days in a year in which the projected load exceeds the available generation capacity. It does not give the severity of the generation deficiency, nor does it give any information on the frequency or duration of the deficiency. LOEE is a more appealing index because it gives the expected energy that will not be served by the available generation capacity and thus indicates the severity of the generation deficiency. The F\&D criterion is an extension of the LOLE index, that also gives information on how often the expected generation deficiency will occur and how long it will last. The F\&D index is not as widely used in generation planning as the LOLE index. Despite the advantages of the probabilistic reliability indices, deterministic reserve margin is still widely used in the utility industry for generation planning. Literature [7] and computer models are available for utility planners to evaluate and apply those probabilistic indices.

Planning criteria for system reliability are specified by NERC and nine regional reliability councils. Nevertheless, differences in the probabilistic methods and interpretation of the reliability guidelines make direct comparison of system reliability indices difficult. The assessment of system reliability is subject to an individual utility's experience and preference. The most common LOLE criterion is the familiar one day in ten years [8]. However, a recent survey of the utility industry [9] indicated considerable variations in the interpretation of LOLE and the method of calculation among utilities. For example, the load model specifications used in LOLE calculations vary widely; some utilities use daily peaks whereas others use hourly peaks. Some utilities employ all 8,760 hours in a year to obtain a load duration curve (LDC) for the LOLE calculations. Others may look only at the peak month or peak week. Some utilities define a loss-ofload event in LOLE calculations assuming an isolated system, while others account for the emergency support capability of the interconnected system. Problems in comparing LOLE criteria among utilities can also arise from differences in specifying what constitutes a loss-of-load event. For some utilities, interruptible loads, voltage reduction, or public appeals for voluntary load reduction do not constitute a lossof-load event, while they do for other utilities. Even the simple calculation of reserve margin is subject to a variety of interpretations. For instance, interruptible load and emergency load management may be included in the internal peak demand, or they may be treated as supply options.

Different interpretations and practices regarding system reliability measurement will have a significant impact on the valuation of intermittent renewable technologies in the planning process. If all 8,760 hours are considered in determining the system reliability index, contributions from intermittent renewable technologies to system reliability will be greater than if a method was used that only considered peak-week or peak-month load and resource data. However, the industry has not established a standardized method.

\footnotetext{
${ }^{16}$ Reserve margin $(\mathrm{RM})=(\mathrm{C}-\mathrm{L}) / \mathrm{L}$, where $\mathrm{C}=$ total installed capacity and $\mathrm{L}=$ expected peak load.
} 
Probabilistic production cost modeling and simulation programs are used to evaluate the economics of alternative generation supply options. Most production cost models consider fuel and other operational constraints in the process. The system load is represented by an LDC formed from hourly load data. The operation of the power system is simulated by convolving the generation unit outage onto the LDC. Fixed cost and other operational parameters of the generation units are input data; the program then calculates the power production cost for the given load and generation mix. The optimum generation expansion plan incorporates the resulting power production costs for different generation alternatives along with capital costs in dynamic programming algorithms or other optimization routines.

Different generation expansion options are assessed in terms of their capacity and energy values. The energy value is usually the cost of providing the energy with an alternative expansion plan. The capacity value is the value of improved reliability (expressed in LOLE) that the resource expansion plan provides to the system. Capacity value is realized through deferment of future capacity additions. Calculating the capacity value is based on the effective load carrying capacity (ELCC) of the particular resource expansion option. Garver [10] defined the ELCC of a resource as the amount of constant load increase the system could carry while maintaining the original system LOLE. The ELCC of a resource can be determined by calculating the LOLE without the resource and then with it.

Another approach can be used for the last step of the calculation. Instead of increasing the load to bring the LOLE down to the original value, perfectly reliable capacity can be added to the original system (without a new resource) until the reliability measurement reaches the same value as with the new resource. This results in a firm capacity equivalent for the resource. Depending on how load increases and firm capacity additions are treated in the models, the ELCC and firm capacity equivalent can have the same or slightly different values. Many researchers and utility planners use the term "capacity credit" for both ELCC and firm capacity equivalent.

\subsubsection{Valuation of Intermittent Renewable Generation Technologies}

Most of the value of the intermittent renewable technologies is derived from the low incremental cost of energy, which can displace higher-cost energy sources. Because of their low fuel and maintenance costs (e.g., wind and PV systems), renewable generations usually will be dispatched first by the utility economic dispatch program based on the short-term incremental operating cost. Therefore, utilities operate intermittent renewable generation plants whenever they are available to maximize economic value. There is one potential problem with this mode of operating intermittent renewable generators. If most intermittent generation occurs during periods of minimum system demand, the utility system operators may have to decrease the output of baseload generating units to accommodate all available power from intermittent renewables. Displacing baseload generation will decrease the value of intermittent energy. If the intermittent generations can produce energy during periods of system peak demand, they can displace more expensive power sources, and their value will be higher. However, the output of intermittent generations is subject to natural meteorological conditions over which utilities have no control. These factors cause difficulties in estimating the value of intermittent generation.

The capacity value of intermittent renewable technologies is often overlooked. Some utilities contend that, because PV and wind generation output depend on uncontrolled resources and cannot be used to meet the system demand on command, no capacity value or credit can be given unless there is adequate energy storage. This implies that if intermittent renewable generation options are adopted, utilities have to make available other "firm capacities" to back up the intermittent renewables in order to maintain the same 
reliability. However, reliability analyses have shown that intermittent renewable generation does contribute to the system reliability and can be used to reduce the capacity requirement of the utility system. Unlike conventional generators, the capacity value of intermittent renewable energy strongly depends on the correlation between the utility load and the pattern of resource availability.

The energy value of intermittent renewable generation is derived from displacing more costly fuels. The degree of coincidence between the output of intermittent generation and utility peak demands will affect the energy value of intermittent renewables. The calculation is relatively straightforward. Incremental costs of the power generated under the existing generation mix are first determined for periods when intermittent renewable generations are producing output, then the value of intermittent renewable generated energy is calculated with simple mathematics. Chinery and Wood [11,12] proposed such a method to estimate the value of PV generation for a utility system.

Capacity value of intermittent renewable technologies can be calculated by the same procedure used for conventional generation technologies. System reliability indices before and after the addition of intermittent renewable technologies are determined, then the ELCC of intermittent generation is calculated. The value of ELCC is derived from the cost (in $\$ / \mathrm{kW}$ or $\$ / \mathrm{MW}$ ) of an alternative resource plan that provides the same ELCC. However, the intermittencies of renewable energy complicate the process. The output of intermittent renewable technologies are random variables with known statistical properties such as mean and variance derived from local climate data. One common approach is to treat the intermittent generations as "negative loads" in the probabilistic modeling and simulation programs $[13,14,15]$. The concept of negative load is simple, and treatment in the model is straightforward. A chronological output of the renewable energy resource is first developed, and that amount is subtracted from the utility hourly load to form a modified LDC. The program then convolves the unit outages with the modified LDC and calculates the reliability indices and power production cost. The drawback of this approach is that the renewable energy output is treated as a deterministic event although it is actually stochastic.

Slight variations of this method exist. Mean output of intermittent renewable generation can be used to develop a series of chronological output. Bossanyi and Halliday [16] used the output probabilistic distribution function and a random draw to determine the output at each interval to account for the intrinsic output fluctuations.

Another way to handle renewable energy generation in the probabilistic simulation of production costs is by treating both the output of the renewable energy generation and system demand as random variables and representing their dependencies by a joint probability distribution. The probability distribution for the modified load is then converted into a load duration curve [17,18,19], and the modified LDC is used in subsequent calculations.

However, outputs of intermittent renewable technologies are not completely random in relation to utility demand. For example, utilities with summer peaking demand (caused by air-conditioning loads) often experience maximum demand during sunny summer afternoons; solar radiation in most places is also higher during this time. Electric demand and wind speed are high during the winter in northern Europe. This relationship has prompted examination of the correlation between intermittent renewable energy output and utility system peak. The capacity values of PV and wind generations have been calculated based on their expected output during periods of utility system peak demand. 


\section{Capacity Credit of Wind Generation}

Several factors play an important role in establishing capacity credit of wind energy systems. The timing of wind plant output relative to the utility demand profile is critical. If wind plant output does not coincide with utility peak loads, the wind energy system will have a low capacity credit. A second factor influencing capacity credit is penetration level. As seen later in this section, there is a noticeable saturation effect in capacity credit when the penetration level of wind power increases.

Smith and Ilyin $[20,21]$ have performed ELCC computations on installed wind power in California for PG\&E. An experimental 2.5 MW MOD-2 unit (now discontinued) located at Solano County, California, achieved an ELCC of $74 \%$ of its rated capacity in 1987. The ELCC of wind turbines installed at Altamont Pass, California, showed large year-to-year variations, reaching $22 \%$ of the total installed capacity (name plate rating) in 1987 but only 14\% in 1988. If the ELCC is calculated against the actual maximum output of wind farms during the year instead of total installed capacity to account for any non-operational and overrated wind turbines, the ELCC value at Altamont wind farms would increase to about $40 \%$ in 1987 and $20 \%$ in 1988. Using the same formula, the ELCC value at Solano County would increase to $80 \%$ in 1987. The seasonal wind patterns at both the Solano County MOD-2 site and Altamont Pass are highly regular, and the available wind energy at both sites correlates with PG\&E's seasonal load well; i.e., winds at both sites are much stronger in the summer when the demand on the PG\&E system is higher. However, the daily wind pattern at Solano County tends to peak, producing maximum power during the PG\&E peak load hours (3:00 - 4:00 p.m. PDT). The daily wind pattern at Altamont Pass tends to produce a maximum output after PG\&E's peak load hours. Differences in wind patterns at Solano County and Altamont Pass cause the variations in wind power capacity value. These results indicate clearly that the capacity value of intermittent renewable energy resources depends on the utility system load pattern and is site specific.

Several early studies examined the ELCC of wind power systems in an actual utility environment. Flaim and Hock [22] summarize the results in Figure 4-1. Two important observations can be made from the figure. First, the ELCC varies widely among different utilities, ranging from 5\% to almost $50 \%$. Second, as the wind energy system penetration increases, the ELCC drops quickly to a constant level. This means that the incremental ELCC value from each successive addition of wind power generation becomes smaller and smaller and approaches zero at a sufficiently high penetration level. Because each wind generator produces only during certain hours, more wind generators will produce more power during those hours and minimize the effect of generator outage. The net system loads during those hours will become less, and the LOLE during those hours will diminish. However, even as the number of wind generators continues to increase, new peak loads emerge at other times when the wind speed is low or there is no wind at all. These new peak loads determine the capacity requirement of the system regardless of wind penetration. Dispersing wind turbines over a wide area will reduce the rate of decrease of the ELCC but will not completely eliminate the phenomenon.

Halberg [23] reported that capacity credit of a wind energy system at low penetration would be approximately equal to the installed wind power capacity multiplied by its average yearly capacity factor. ${ }^{17}$ At higher penetration, the wind power capacity credit will reach an asymptotic value, which is a function of wind energy availability and existing system generation mix. In the case of the Dutch electric system, the capacity credit starts from $26 \%$ at a low penetration level to $7 \%$ at a high penetration level (31\% of the installed capacity). Coelingh et al. [24] found that for 1,000 MW of wind power (representing $9 \%$ of the total system load) in the Netherlands system, the calculated capacity credit would be $184 \mathrm{MW}$. Their calculations also showed the saturation effect of capacity credit.

\footnotetext{
17 The capacity factor of a generator is the ratio of its average output to its maximum output over a specified period.
} 


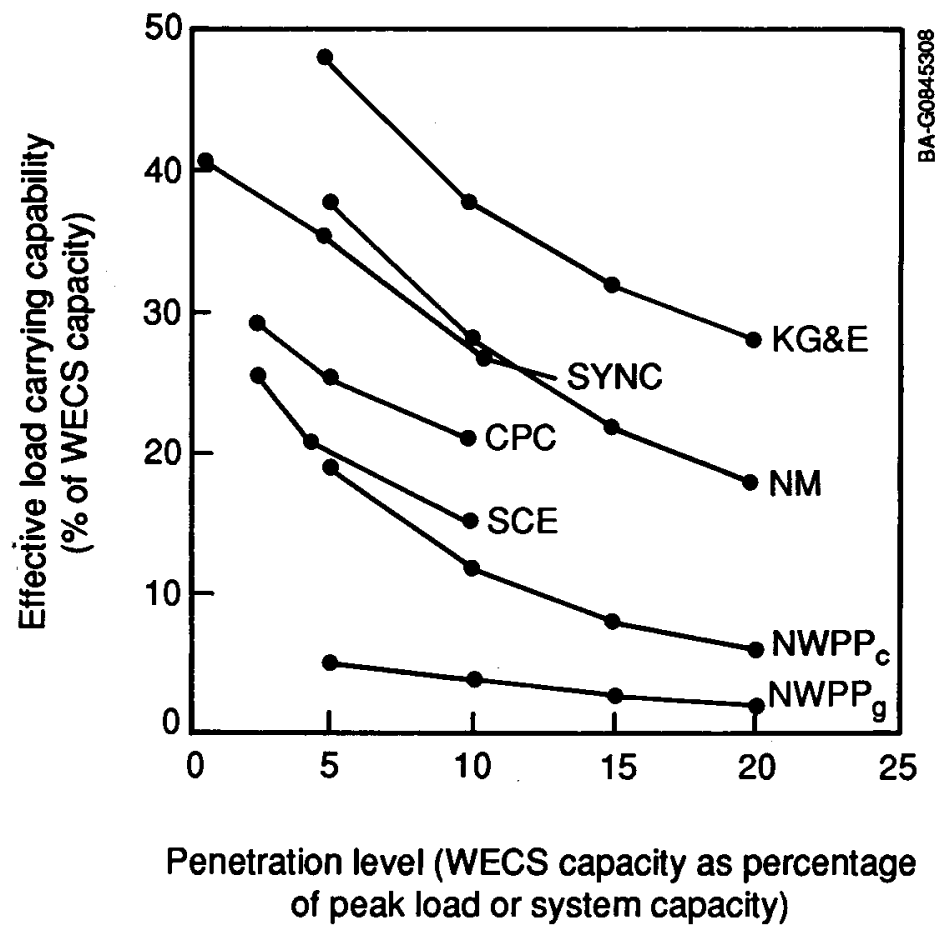

Source: Flaim and Hock, 1984

Figure 4-1. Wind generation ELCC as a function of penetration level

Overall, there is wide variation in the capacity credit that can be realized with wind energy systems. Existing generation mix, load profile, and most importantly, the correlation between wind speed and utility load all affect the capacity credit.

\section{Capacity Credit of PV Generation}

Hoff $[25,26]$ analyzed the output of the Carrisa, California, PV plant and PG\&E system load and found the PV plant had a high capacity factor during PG\&E's peak demand period. The capacity credit of the Carrisa PV plant was calculated to be $79 \%$ of its installed capacity. Perez [27] investigated the load matching potential of PV generation for the Consolidated Edison load and reported that the capacity credit for 100 MW of PV generation could reach $62 \%$ of installed capacity. A noticeable saturation effect in capacity credit was also evident. For $500 \mathrm{MW}$ of PV generation, the capacity credit will be only $50 \%$ of the installed capacity. Figure 4-2 shows the results of Perez' study.

A similar PV capacity credit was found in an earlier study using 1981 irradiation data from central New Jersey and load data from Public Service Electric and Gas Company [28]. The results are shown in Figure 4-3. It is interesting to note that, although total irradiation in New Jersey is significantly less than in California, the PV capacity credit does not show the same degree of difference. The capacity credit decreases with the increasing penetration level, but at a slower rate. 


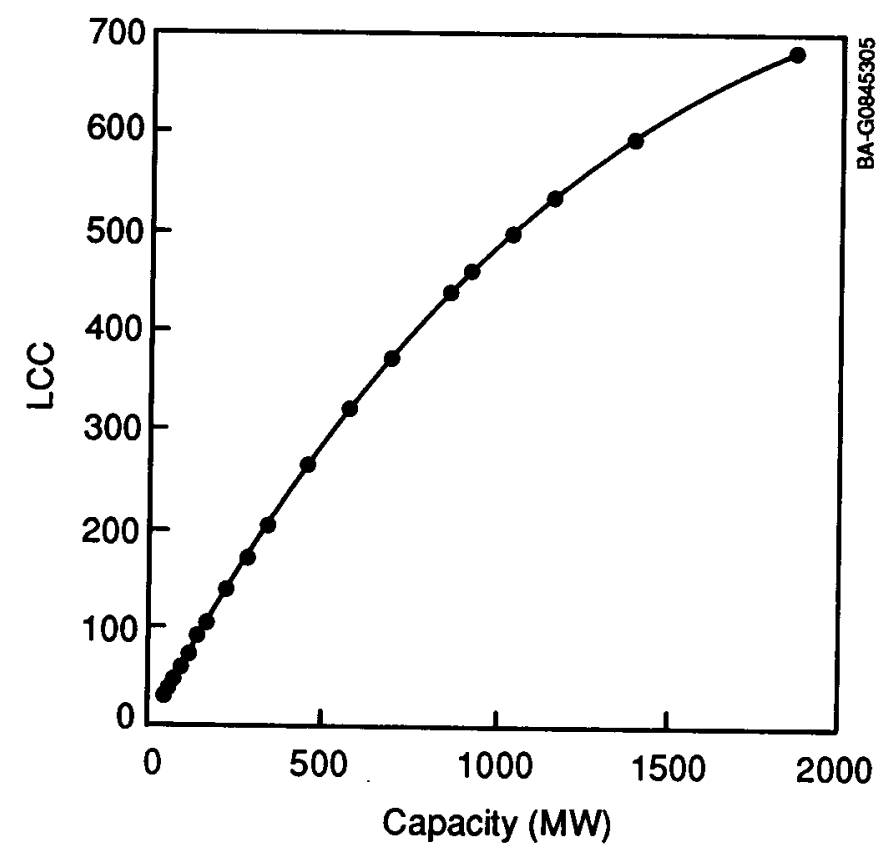

Source: Perez, 1989

Figure 4-2. LCC of installed PV capacity

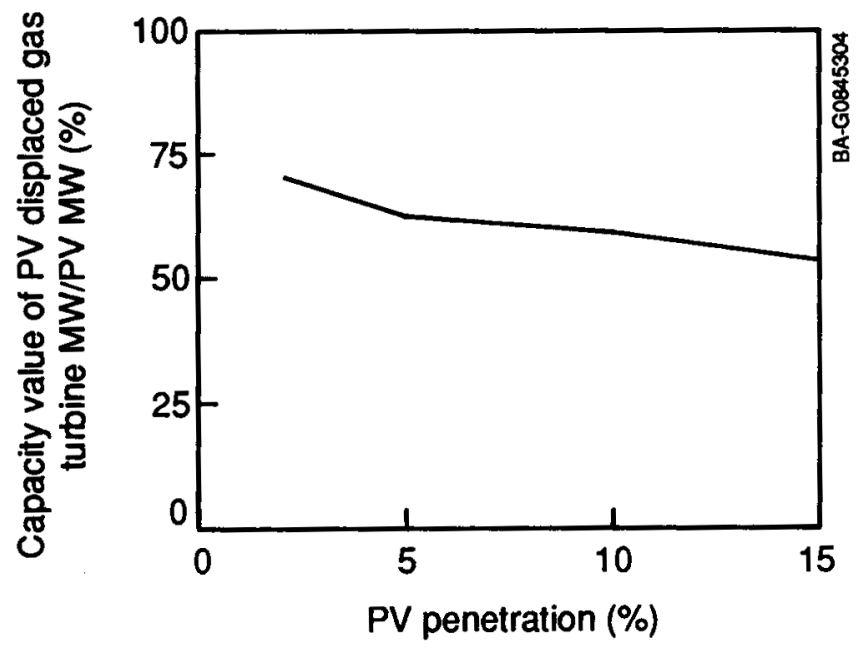

Source: Ku, et al., 1983

Figure 4-3. PV capacity values as a function of penetration level 
Study results show the capacity credit of PV generation is generally higher than that of the wind energy system. This is a consequence of a better irradiance-demand correlation: human activities tend to follow the sunlight cycle. Residential PV installations in the New England area have shown that approximately $60 \%$ of the total daily output from PV systems is supplied during the utility peak period when the utility system load is equal to or greater than $95 \%$ of the maximum load reached during the day [29].

\section{Transmission and Distribution Benefits}

Recent work by PG\&E has identified the additional value of intermittent renewable energy technologies when placed close to the load. Besides simple energy and capacity value, strategically located PV generation, under proper conditions, can offer additional benefits in terms of local T\&D support, service reliability improvement, and line loss reduction. Rueger and Manzoni [30] reported that the added benefits can double the PV generation value derived from energy and the capacity credit alone. Under these conditions, PV may be cost competitive with other conventional generation technologies.

PV generation, with its inherent modular design, fits the distributed application well. Capacity can be added in small increments to match the local load requirement. Shugar [31] reported that a PV generation facility connected to a utility distribution grid can theoretically relieve the thermal overload of the substation transformer and distribution feeder. Additional value from those distributed benefits can make this option more economical than the traditional approach of upgrading the substation transformer and the feeder circuit.

These results point to an important alternate path for integrating intermittent renewable technologies into utility systems. If the added value of intermittent renewable technologies can offset their cost, acceptance by utilities may be accelerated. Utilities are starting to recognize the potential of these benefits. However, results from the studies are utility- and technology-specific, and they are derived from ad hoc analytic procedures. Utilities need to develop a unified approach and methodology to assess the cost-effectiveness of these options.

\section{Storage Considerations}

Electric utilities have considered using energy storage systems as a load-leveling device. Pumped-storage hydro has long been established as the primary type of energy storage plant for electric utilities, and its operations and economics are well understood. The technical feasibility of battery storage systems for electric utilities has been demonstrated [32]. Compressed air and other types of energy storage systems are also being investigated for electric utility applications. In addition to system load leveling, energy storage systems reduce operating costs and improve the operating flexibility of electric power systems because they are capable of providing nonspinning reserve for the utility system.

The combination of intermittent energy technologies and energy storage systems has the potential of reducing output fluctuations. A properly sized energy storage system can supplement intermittent energy resources by providing firm capacities during periods of cloudy or calm weather. However, this combination also increase the cost of intermittent renewable energy resources to electric utilities. Some early studies with actual utility system data have shown that storage could increase the capacity value to utilities of renewable energy generations [33,34], but the high cost of energy storage systems assumed in these studies did not make the combined renewable/storage system economically feasible. Energy storage technologies can offer utilities considerably more benefits than can the usual peaking and load management services. EPRI studies [35,36] indicated that the dynamic operating benefits of energy storage systems such as spinning reserve and load following can be substantial. However, these benefits were not considered in the early studies. 
Superconductive magnetic energy storage (SMES) systems with high roundtrip efficiency $(>92 \%)$ and fast dynamic response can be a better choice to regulate the fluctuations of renewable energy technologies [37]. However, the SMES technology is still in the development stage and the eventual installed cost of such a system is unknown.

Integration of large grid-connected intermittent renewable energy technologies with existing hydropower systems represents another opportunity to increase the values of both systems. Hydropower with a storage reservoir may complement intermittent renewable resources by overriding their natural energy output fluctuations, making them more compatible with normal utility operations. Using a hydropower system as energy storage for renewable energy resources may also result in transmission savings. The existing transmission lines at the hydropower facilities can be utilized to accommodate the additional power output from the renewable resources. Transmission facilities built exclusively for either hydropower or renewable resources tend to be relatively expensive because of their low load factors. Modification of hydropower operations to complement renewable energy resources could result in fewer power output fluctuations and a higher load factor of the transmission facilities. One such study [38] examined a combined wind-solarhydro system in terms of system reliability. The conclusion was that very small generation reserves would be needed because of the energy storage capabilities of the hydro facilities.

The Bureau of Reclamation [39] reported on the operational and financial feasibility of a wind/hydroelectric energy project in Medicine Bow, Wyoming. Researchers studied integrating a wind farm with $100 \mathrm{MW}$ of installed capacity into the Colorado River Storage Project (CRSP). This project has eight hydropower plants with an installed capacity of 1,487 MW. Various combinations of low-, normal-, and high-water years and projected wind energy were simulated to determine acceptability and potential impacts of the proposed project. The results showed that wind energy can be integrated into a hydropower system without significant adverse hydrologic impacts. Hightower [40] proposed a solar thermal/hydropower integration project and showed the same operational feasibility. Because of federal budget constraints, no actions were taken after these studies.

Although some assumptions made in these reports regarding future trends, such as oil price and load growth, are no longer valid, the concept of integrating intermittent renewable energy technologies into existing hydropower systems is still sound. The existing hydropower systems with reservoirs probably represent the most convenient and economical energy storage systems presently available for intermittent renewable energy technologies. Recently, the Hawaii Natural Energy Institute started a research program at its Wind Energy Storage Test facility on the island of Hawaii to study using a pumped hydro storage system with renewable energy generators [41]. Results of this program should provide more insight about the synergistic relationship between intermittent renewable generation and hydro generation.

\subsubsection{Considerations of Externalities}

Environmental effects of various supply options differ significantly. Renewable energy technologies such as PV and wind are much less environmentally intrusive than conventional fossil-fueled power plants. There are no emissions and no waste products during operations. Failure to consider these external factors in the planning process often leads to plans that are socially suboptimal because many resource options entail significant societal costs. Proper accounting of how and where society pays these costs will improve the competitiveness of renewable energy resources relative to other resource options and lead to wider acceptance of renewable energy.

Regulators and utilities have just begun to recognize these attributes and have designed means to valuate them during planning phases. The New England Electric Company has begun to consider environmental 
externalities in its long-range planning process. The Wisconsin Public Service Commission adopted an approach similar to the Pacific Northwest Electric Regional Power Act, which gave conservation a 15\% credit relative to fossil-fueled plants. The New York Public Service Commission approved utility proposals for competitive bidding of new power supplies that would assign environmental factors $15 \%-20 \%$ of the total weight used to rank proposals [42]. Without such means to evaluate total societal costs of both conventional and renewable technologies, current renewable technologies are not cost competitive enough to make a significant contribution in meeting the nation's energy demand.

Evaluation of externalities is a complex and sometimes subjective process that involves sophisticated technological and economic investigations. It often leads to different interpretations of results. External factors are not considered in most of the current planning models and processes. More research is required to identify those factors and incorporate them into the utility planning processes.

\subsubsection{Transmission Planning}

The function of the electric transmission system is to move power from the generation plants to various loads. Most utilities use deterministic criteria for designing and planning their transmission systems. These transmission systems are usually planned and constructed so that the more probable contingencies (also called single or first contingencies) can be withstood without any loss of load, and the less probable contingencies (multiple contingencies) can be sustained with a probable loss of load but without uncontrolled cascading interruptions. The system is designed not to exceed equipment emergency ratings during these contingencies. Typically, utility system planners study only selected double contingencies that are credible.

The first contingencies that the transmission system needs to withstand without losing any load include the loss of one bulk transmission line - or more than one line if they are on the same right-of-way or on the same tower- or the loss of one major generator or a bulk transmission substation. The multiple contingencies involve possible loss of some load or localized generation instability resulting from the loss of two bulk transmission lines, or a fault at a major generator bus causing the loss of all generating units on that bus. To guard against these contingency conditions, tie lines with neighboring utilities are planned and built to ensure adequate capacity for emergency power transfer.

Transmission planning typically determines what new facilities are required as well as when they are needed to meet the system reliability criteria for a projected system peak demand and anticipated generation mix. A sequence of load flow, short-circuit, and stability studies are performed to examine the system behavior under selected contingencies. The selection criteria vary but contingencies usually correspond to "reasonably probable" conditions. The planners' experience and their knowledge of the system are also important factors in selecting the contingency cases. Stoll [43] describes the long-term transmission planning processes.

The generation mix and load level are generally considered known in traditional transmission studies. Even with a known level of generation, there is a need to study a large number of contingency cases. For example, for first contingencies only, i.e., a condition involving the loss of a single system element, N-1 different cases must be studies, where $\mathrm{N}$ is the total number of system elements. For a modern interconnected utility system, $\mathrm{N}$ is very large and so are the number of probable contingency cases. When intermittent generation technologies are included in system planning, the assumption of known generation level is no longer valid because the output of the intermittent generation fluctuates. There are few formal methods of determining the distribution of line flows on major transmission lines as a result of the intermittent generations. Planners must manually set the output level of intermittent generations and then proceed with load flow simulations of various contingency cases. This process has to be repeated for each 
anticipated level of intermittent generations. When the penetration of intermittent generation technologies is low, simulation deficiency of current models may not be significant. However, for moderately high penetrations, the shortfalls of the current simulation process will increase transmission study difficulties and the time required to perform such studies.

In addition to the increased number of system conditions to be analyzed, the reactive power requirement of many intermittent renewable generation technologies calls for accurate modeling and simulation of both real and reactive power effects. System voltage fluctuation caused by the intermittent injections of a large amount of power into the transmission grid is another factor to be evaluated by the planners. The protection scheme of the transmission system also will be affected by the fluctuating nature of the intermittent renewable generation technologies. Sizing, locating, and coordinating protection hardware are strongly influenced by how the intermittent generation is deployed in the grid (e.g., dispersed versus centralized). The problems associated with system voltage regulation and reactive power compensation will require more analyses to resolve. Although these problems can be analyzed and resolved on an ad hoc basis, there is no comprehensive transmission planning methodology available to planners to address the concerns of integrating intermittent renewable generation technologies into the utility grid.

At the current stage of renewable energy technology development, the emphasis has been on reducing the energy production cost to make such technologies competitive with the conventional generation technologies. Transmission issues and their costs have not yet played a significant role in the commercial development of renewable energy technologies because sufficient sites with good resource density and relatively easy access to existing transmission systems have been available for development. As the penetration of the renewable technologies increases, however, accessible sites will become scarce, and transmission availability and cost can be expected to become very important issues.

\subsubsection{Distribution Planning}

Resource availability and the modular design of some intermittent renewable generation technologies make them equally suitable to be integrated into the utility system at either the transmission or distribution level. However, electric utilities plan and construct distribution systems to take power from a higher voltage transmission system and distribute that power to customers. Accommodating distributed generations at distribution lines was not a concern prior to the emergence of distributed generation technologies.

As with transmission and generation planning, distribution planning process starts with load forecasting. The spatial distribution of load plays a more significant role in distribution planning than in generation planning. Distribution system planners and designers have to know not only load demands and times, but also the specific locations of these demands because distribution systems are built to serve only these loads in a specific geographic area.

Connecting intermittent generation at distribution lines will have a direct impact on the distribution system. The unidirectional power flow and the passive nature of the distribution system may be no longer valid. Distribution planners need to know how much power would be generated by the intermittent generation and when it would be generated in order to predict distribution equipment loading. Other protection and safety issues also can arise. Careful planning is the first step toward solving these problems.

Existing distribution planning tools are not adequate to handle these problems. The possibilities of a distributed generator being connected to the distribution lines is usually ignored during the distribution planning process. While a small amount of intermittent renewable generations can be accommodated by 
most utility distribution systems, higher penetration levels could have serious consequences. Few researchers have investigated the distribution planning issues related to interconnection of intermittent generation at the distribution level. Two studies [44] and [45] examined the impacts of dispersed intermittent generation devices on distribution planning and developed methods to evaluate these impacts on utility distribution system planning and operation.

Utilities are not yet expecting large-scale interconnections of intermittent energy generators in their distribution systems. Consequently, utilities are not planning their distribution systems to facilitate the connection of intermittent power generation. A solution to this problem is not easy because it would require a fundamental change in the utility planning philosophy. Instead of considering generation, transmission, and distribution planning as separate activities, utilities need to take a unified approach toward system planning. One such example was mentioned earlier in this section: locating intermittent generators at the utility distribution system as a means to defer system upgrades. This option can have a number of additional advantages over traditional options for distribution system improvement. However, conventional distribution planning methodologies will not consider using distributed generation as an option. Neither are the necessary planning tools available for planners and engineers to fully evaluate distributed generation options. Further development of planning methodologies that will enable utility distribution planners to include distributed generation options during normal planning activities is required.

\subsubsection{Other Corporate and Strategic Concerns}

Planning at the corporate level deals primarily with more fundamental strategy issues associated with resource expansion plans. The company's long- and medium-term goals are important considerations, and are not limited to financial factors. Resource and technology diversification, long-term fuel availability and price stability, environmental impacts, and operational flexibility are all important factors in corporate decision making. The goals are to meet the expected demand, minimize risks, and maintain long-term corporate survivability.

When intermittent renewable technologies are considered, these same factors will be used to judge their viability. Major concerns during this phase of the planning process include:

- Rate impact and financial viability -- Utilities need to study the impact on future revenue requirements. How sensitive is the plan's economic feasibility to financial parameters? How will investors perceive intermittent renewable technologies and how will these technologies affect the corporation's ability to raise the required capital?

- Technology uncertainty and risk -- Utilities need to know if there are additional risks involved in selecting intermittent renewable technologies as resources. Are the technologies mature? Can industry supply the technology and support it in the future? What kind of guarantee should the utilities seek and obtain regarding new technologies?

- Regulatory treatment -- Utilities need to know if the regulatory process will treat intermittent renewable technologies favorably for an expansion plan. Will a favorable treatment of renewable technologies by the regulatory body also help the transmission and distribution siting and permitting process? Will these technologies be treated differently if a third-party owns the intermittent renewable resources?

An important goal in the utility decision-making process is to achieve a diversified supply mix. This includes both resource and technology diversity. Risk associated with each individual resource and technology is independent of a utility's decision, but by including a variety of resources and technologies in their generation mix, utilities can limit the impact that any single source has on their systems' overall risk. 
Operational flexibility is another important factor. Conventional generators can be scheduled to meet the plant maintenance schedule and other operating requirements. Operating flexibility also enables utilities to engage in opportunistic exchanges and take advantage of the market condition. Intermittent renewable generation technologies lack this operational flexibility. If additional capacity is needed at night, for example, a PV power plant cannot deliver. This inherent limitation may have contributed to the reluctance of utilities to integrate intermittent renewable technologies on a large scale.

Many utilities also have taken a low-risk posture aimed at deferring capital-intensive commitments that take long lead times to complete. Because of major uncertainties about fuel availability and price and future loads, many utilities are deferring or avoiding any long lead-time and high capital-cost commitment. This risk-aversion attitude makes utilities reluctant to adopt new power-supply alternatives, such as intermittent renewable technologies with unproven reliability and little operating experience. The economic constraints imposed by public regulatory bodies or utilities themselves to keep current rates as low as possible also impede the development of intermittent renewable energy technologies. Current renewable technologies are capital intensive but have very low annual operating costs. Thus, the emphasis on near-term economic factors during the corporate planning and decision-making processes tends not to favor including renewable technologies in a utility's expansion plan. Most utilities are taking a more traditional approach toward renewable technologies - passively watching development and planning to react at some future time when the technologies are considered mature.

\subsection{Issues Affecting Intermittent Renewable Technology Planning}

Several factors have limited the ability of utilities to evaluate intermittent renewable technology options during the resource planning process. The two most important constraints are inadequate planning models and unavailability of necessary data. Lack of current information about technology improvements also biases utilities' attitudes toward renewable technologies. Another critical factor that may have impeded the utilities' acceptance of intermittent renewable generations is the nondispatchability of these technologies. Utilities put a higher value on a capacity that can be dispatched.

\subsubsection{Operating Flexibility}

Utilities plan and optimize their generation mix to achieve a range of objectives. One of them is the operating flexibility of their generation facilities. As mentioned in section 4.2.5, utilities depend on power plant dispatchability to meet the generator maintenance schedule requirements and to take advantage of market conditions. Conventional generators can provide this operating flexibility. For example, utilities may baseload an intermediate unit or operate a peaking unit during off-peak hours to satisfy various system operational requirements. These benefits may not be easily quantified, but they are real concerns for utilities in the planning process. Intermittent renewable generation technologies do not have this flexibility because their output is generally not dispatchable.

\subsubsection{Planning Models for Intermittent Renewable Technologies}

Two different but related modeling requirements for intermittent renewable technologies are important to utilities during the planning phase. One type of model converts the meteorological data into electricity output. Utilities need this model to predict the available output of a particular renewable energy plant or compare the performance of different designs. The other type is a utility planning model that can incorporate intermittent renewable technologies in the resource expansion planning process and evaluate them against other conventional supply- and demand-side management technologies. 
SERI [46] listed some of the currently available computer models for renewable energy resources. A variety of models with various input data requirements are available for PV power systems, ranging from simple first-order approximations of PV system output to complex, circuit-level simulations. In general, these models use a deterministic approach for simulating PV system performance. Model performance is generally satisfactory. Rahman and Chowdhury [47] examined 12 such PV performance models and ranked them based on their ability to predict electricity output with typically available meteorological data (global irradiation, ambient temperature, and wind speed). Output from a wind generation plant is usually estimated from available meteorological data and the wind turbine power conversion curve supplied by the wind turbine manufacturer. Difficulty may arise when estimating the output of a wind farm that consists of tens or hundreds of wind turbines. The common practice is to apply an empirical reduction factor to account for the wake effect of downwind turbines. Future research may be necessary to develop a better model to predict wind farm output.

Utilities have access to many different planning models, from spreadsheet models for simple economic analysis of expansion options to large simulation programs of complex system operations. Some models are capable of evaluating both supply- and demand-side resource options, utility decision analyses, and optimization under specified constraints. Some examples of typical models in this category include PROMOD III, MIDAS, and EGEAS. They usually contain several separate modules for screening options, production costing analyses, resource optimization, financial and rate analyses, and risk and decision analyses. Most of the available models are complex and require considerable resources and effort to use. Keeping these models up-to-date requires dedicated support from the utility to collect and process data. Experienced utility planners are needed to operate the model and to analyze and interpret the results.

Most of the existing planning models are not developed specifically with the integration of intermittent renewable technologies in mind, although some of them can incorporate intermittent technologies. Many early studies treat the output from intermittent renewable technologies as a negative load. A LDC derived from the net load (total system demand minus intermittent generation output) is convolved with the generator outage to calculate system production costs. The LDC method is preferred because of its computational efficiency. Some researchers indicate that a chronological simulation method to calculate production costs better accounts for the stochastic nature of intermittent generation technologies. However, this is true only if statistically meaningful meteorological data are available to make a chronological prediction of the available intermittent resources.

The value of intermittent renewable generation is usually obtained by calculating total production cost and capital requirement without, and then with, intermittent renewable generations while maintaining the same level of system reliability (usually measured in terms of system LOLE). However, research shows that intermittent renewables have other attributes that can increase their value to the utility systems more than their capacity and energy value alone. Current planning models usually do not account for such attributes, and thus put intermittent renewable technologies at a disadvantage during the evaluation process. Planning models that do recognize special characteristics and attributes of intermittent renewable technologies are needed to help these technologies gain acceptance in resource expansion plans.

\subsubsection{Data Requirements and Availability}

Another factor that may hamper a utility's efforts to include intermittent renewable technologies in its resource expansion planning process is the lack of data and information. There are two main reasons for this lack of information. First, there have been only a limited number of successful implementations of intermittent renewable technologies in utility systems. Second, many utilities and regulators are not fully aware that intermittent renewable technologies have made significant progress during the last few years. 
Many utility planners have outdated information about the performance and cost of renewable energy systems that has contributed to a less favorable attitude toward renewable energy among some utilities. Collecting and disseminating accurate information about utility operating experiences and current cost and performance of renewable energy technologies are important steps in developing these technologies in the utility sector.

Availability of renewable resource data is also a problem for utilities. Conventional planning methodology can be adopted to evaluate renewable energy options, but much more data are required. For planning purposes, utilities need data on plant cost and performance, projected O\&M costs, fuel availability and cost, and other economic variables (cost of money, tax rates, etc.). To include renewable energy technologies in the generation planning process, utilities will need additional climate data such as wind speed, frequency distribution, solar irradiation, and temperatures at selected locations to assess the renewable resources. Unfortunately, area or site-specific wind speed and solar irradiation information is generally not available to utilities.

Efforts to address this problem are under way. For example, a method has been developed for remote sensing of the necessary solar irradiation data from geostationary satellite images of cloud coverage over very wide areas [48]. A test case in New York state showed that the data accuracy using this technique is comparable to the accuracy of data extrapolated from a network of ground stations $95 \mathrm{~km}$ apart. If further tests show that this technique can be applied to a wide variety of geographic regions, remote sensing can be extremely useful in providing adequate data for screening solar options in the planning process.

\subsection{Conclusions}

Several problems related to planning for intermittent renewable energy generation have been identified; some of these problems are technical and others are institutional.

Perhaps the most significant long-term problem for intermittent renewable generations is the noticeable saturation effect in capacity credit as the penetration level increases. The saturation effect also points to other complexities in evaluating intermittent generation technology options during the planning process: resource inhomogeneity and the output correlation between different sites. Output of conventional generators generally is independent of their locations and each other. In contrast, the output and value of intermittent renewable generation technologies depend on the density of natural energy flow and are site specific. A conventional generating unit has identical capacity value regardless of its geographic location, and the incremental load carrying capacity of the next conventional unit increases. As more and more conventional units are added to the system, the load carrying capacity of additional units approaches its rated output, and the system LOLE can be made arbitrarily small.

However, intermittent renewable generations are characterized by a decreasing incremental load carrying capability. For a given resource availability, e.g., total solar irradiation in southern California, continually increasing the amount of solar generation will not reduce the system LOLE to an arbitrarily small value. The diurnal nature of solar irradiation limits the solar contribution to system LOLE regardless of the amount of installed solar generation capacity. This implies that other factor such as the correlation between utility loads and resource availability, may limit the penetration level of intermittent renewable generation in the utility system besides operational limitations.

Furthermore, output from one intermittent renewable generator is closely related to that at other sites. Therefore, additions of intermittent capacity cannot be considered independently from existing or other 
planned installation of intermittent generation capacities. Effective evaluation of intermittent renewable resources must consider such correlations and their impact on generation systems. Analyzing spatial and time correlations of intermittent renewable resources and load/resource correlations remains an important resource assessment task.

The intermittent renewable generation's lack of operational flexibility is also of concern to utilities. A high penetration of intermittent generation may make it difficult for utilities to schedule generator maintenance. Transmission limitations may also restrict large-scale development of intermittent renewable energy systems. Further studies are needed to address these issues.

Current planning models and methodologies do not consider all of the attributes of intermittent renewable technologies; neither are all societal costs associated with conventional technologies properly evaluated. These deficiencies have impeded the development of intermittent renewable technologies in the utility sector. Without proper evaluation of total costs and benefits, current planning methodologies will put intermittent renewable technologies at a disadvantage.

Finally, utilities may need to take a unified approach toward system planning. The traditionally separate generation, transmission, and distribution planning processes may no longer be adequate in the current changing environment. New tools and new ideas are needed. Collaborative efforts among utilities and research organizations in developing those tools and ideas are essential. Ongoing efforts toward integrated resource planning should encourage utilities to adopt more intermittent renewable technologies.

\subsection{References}

1. New Electric Power Technologies. Office of Technology Assessment. July 1985.

2. Hirsh, R.F., Technology and Transformation in the American Electric Utility Industry, Cambridge University Press, New York. 1989.

3. Burns, S., Gross, G., "Value of Service Reliability," IEEE Transactions on Power Systems, Vol. 5, No. 3. August 1990. pp. 825-834.

4. Sant, R.W., The Least-Cost Energy Strategy - Minimizing Consumer Costs Through Competition, The Energy Productivity Center, Mellon Institute, Arlington, Virginia. 1979.

5. Bull, M., "Bonneville's Least Cost Planning," IEEE Transaction on Power Systems, Vol. 4, No. 1. January 1989. pp. 300-304.

6. Hirst, E., Goldman, C., "Key Issues in Integrated Resource Planning for Electric Utilities," IEEE Transactions on Power Systems, Vol. 5, No. 4. November 1990. pp. 1105-1111.

7. Applied Reliability Assessment in Electric Power Systems, Edited by Roy Billinton, Ronald N. Allan, Luigi Salvaderi, IEEE Press. 1991.

8. North American Electric Reliability Council, Overview of Planning Reliability Criteria of the Regional Reliability Councils of NERC. April 1988.

9. Sanghvi, A.P., Balu, N.J., Lauby, M.G., "Power System Reliability Planning Practices in North America," IEEE Transactions on Power Systems, Vol. 6, No. 4. November 1991. pp. 1485-1492. 
10. Garver, L.L., "Effective Load Carrying Capability of Generating Units," IEEE Transactions on Power Apparatus and Systems, Vol. PAS-85, No. 8. August 1966.

11. Chinery, G.T., Wood, J.M., "Estimating the Value of Photovoltaics to Electric Power Systems," Proceedings of the 18th IEEE Photovoltaic Specialists Conference, Las Vegas, Nevada. October 1985.

12. Chinery, G.T., Wood, J.M., Larson, A.L., "The Case for Photovoltaics in the Tennessee Valley," Proceedings of the 19th IEEE Photovoltaic Specialists Conference, New Orleans, Louisiana. May 1987.

13. Day, J.T., Malone, M.J., "Electric Utility Modeling Extensions to Evaluate Solar Plants," IEEE Transactions on Power Apparatus and Systems, Vol. PAS-101, No.1. January 1982. pp. 120-126.

14. Harper, J.R., Percival, C.D., Solar Electric Technologies: Methods of Electric Utility Value Analysis. SERI/TR-214-1362. Solar Energy Research Institute, Golden, Colorado. May 1982.

15. Percival, C.D., Harper, J.R., Electric Utility Value Determination for Wind Energy, Volume I: A Methodology. SERI/TR-732-604R. Solar Energy Research Institute, Golden, Colorado. January 1982.

16. Bossanyi, E.A., and Halliday, J.A., Ibid.

17. Caramanis, M.C., Tabors, R.D., Nochur, K.S., Schweppe, F.C., "The Introduction of NonDispatchable Technologies as Decision Variables in Long-Term Generation Expansion Models," IEEE Transactions on Power Apparatus and Systems, Vol. PAS-101, No. 8. August 1982. pp. 26582667.

18. Caramanis, M.C., "Analysis of Non-Dispatchable Options in the Generation Expansion Plan," IEEE Transactions on Power Apparatus and Systems, Vol. PAS-102, No. 7. July 1983. pp. 2098-2103.

19. Electric Generation Expansion Analysis System (EGEAS), EPRI EL-2561, Volume 1, Project 1529-1, Final Report. August 1982.

20. Smith, D.R. and Ilyin, M.A., "Wind Energy Evaluation by PG\&E," Pacific Gas and Electric Research and Development, San Ramon, California. 1990.

21. Smith, D.R., "Wind Energy Resource Potential and the Hourly Fit of Wind Energy to Utility Loads in Northern California," paper presented at 1990 AWEA Conference, Washington, D.C. September 1990.

22. Flaim, T., Hock, S., Wind Energy Systems for Electric Utilities: A Synthesis of Value Studies, SERI/TR-211-2318. Solar Energy Research Institute. May 1984.

23. Halberg, N., Ibid.

24. Coelingh, J.P., B.G.C. van der Ree, A.J.M. van Wijk, Ibid. 
25. Hoff, T., "The Value of Photovoltaics: A Utility Perspective," Proceedings of the 19th IEEE PV Specialists Conference, New Orleans, Louisiana. May 1987. pp. 1145-1149.

26. Hoff, T., Iannucci, J.J., "Siting PV Plants: A Value Based Approach," Proceedings of the 20th IEEE Photovoltaic Specialists Conference. September 1988. pp. 1056-1061.

27. Perez, R., Berkheiser III, W., Stewart, R., Kapner, M., Stillman, G., "Photovoltaic Load Matching Potential for Metropolitan Utilities and Large Commercial Users in the Northeastern U.S.," Proceedings of the 9th European PV Conference, Freiburg, FRG. 1989. pp. 903-907.

28. $\mathrm{Ku}, \mathrm{W} . S .$, Nour, N.E., et al., "Economic Evaluation of Photovoltaic Generation Application in A Large Electric Utility System," IEEE Transactions on Power Apparatus and Systems, Vol. PAS-102, No. 8. August 1983. pp. 2811-2816.

29. Bzura, J.J., "The New England Electric Photovoltaic Systems Research and Demonstration Project," IEEE Transactions on Energy Conversion, Vol. 5, No. 2. June 1990. pp. 284-289.

30. Rueger, G.M., Manzoni, G., "Utility Planning and Operational Implications of Photovoltaic Power Systems," Pacific Gas \& Electric Company, San Roman, California. 1991.

31. Shugar, Daniel S., "Photovoltaics in The Distribution System: The Evaluation of System and Distributed Benefits," 21st IEEE Photovoltaic Specialist Conference, Kissimmee, Florida. May 1990.

32. Electric Power Research Institute, Demonstration Test of a 500-kW Peak-Shaving Load-Acid Battery Energy Storage System, Final Report, EPRI AP-4841. September 1986.

33. Assessment of Distributed Photovoltaic Electric Power Systems, Summary Report, EPRI AP-2687SY. October 1982.

34. Assessment of Distributed Wind Power Systems, Summary Report, EPRI AP-2882-SY. February 1983.

35. Decision Focus Incorporate, Dynamic Operating Benefits of Energy Storage, EPRI AP-4875. Final Report. Electric Power Research Institute. October 1986.

36. Zaininger, H.W., Benefits of Battery Storage as Spinning Reserve: Quantitative Analysis, EPRI AP5327. Final Report. Electric Power Research Institute. July 1987.

37. Tam, K.W., Kumar, P., Foreman, M., "Enhancing the Utilization of Photovoltaic Power Generation by Superconductive Magnetic Energy Storage," IEEE Transactions on Energy Conversion, Vol. 4, No. 3. September 1989. pp. 314-321.

38. A. Traça de Almeida, et al., "Source Reliability in a Combined Wind-Solar-Hydro System," IEEE Transactions on Power Apparatus and Systems, Vol. PAS-102, No. 6. June 1983. pp. 1515-1520.

39. Bureau of Reclamation, Wind-Hydroelectric Energy Project, Wyoming, Feasibility Report. June 1981. 
40. Hightower, S.J., "Solar/Hydro Integration Study," presented at the Department of Energy Large Solar Central Receiver Systems Semiannual Meeting, Williamsburg, Virginia. September 1979.

41. Wind Energy Weekly. September 2, 1991. pp.3-4.

42. Reeder, M., "Competitive Bidding for Electricity Supplies: Utility Responsibility and the Intervention of the Regulator," presented at the 1989 IEEE Power Engineering Society Winter Meeting, New York, New York. February 1989.

43. Stoll, H.G., Least-Cost Electric Utility Planning, John Wiley \& Sons, New York, New York. 1989.

44. Boardman, R.W., Tatton, R., Curtice, D.H., Impact of Dispersed Solar and Wind Systems on Electric Distribution Planning and Operation. Final Report, ORNL/Sub-7662/1. Oak Ridge National Laboratory. February 1981.

45. Ma, F.S., Curtice, D.H., "Distribution Planning and Operations with Intermittent Power Production," IEEE Transactions on Power Apparatus and Systems, Vol. Pas-101, No. 8. August 1982. pp. 29312940.

46. Solar Energy Research Institute. Solar Energy Computer Models Directory. SERI/SP-271-2589. August 1985.

47. Rahman, S, Chowdhury, B.H., "Simulation of Photovoltaic Power Systems and Their Performance Prediction," IEEE Transactions on Energy Conversion, Vol. 3, No. 3. September 1988. pp. 440-446.

48. Perez, R., et al., "Meeting Utility Load Requirements with Photovoltaics--Resource Assessment Logistics," ISES World Congress, Denver, Colorado. August 1991. 


\subsection{Implications for Intermittent Renewables}

Many technical concerns associated with the interconnection of intermittent renewable energy technologies and electric utility systems have been raised. However, the literature reviewed in this report does not indicate any unsolvable technical problems. Most importantly, this study has found that several commonly held perceptions regarding integration of intermittent renewable energy technologies into utility systems are not valid. Technology advancement and operating experience have enabled utilities to address most of these concerns. The following list summarizes the findings.

- Contrary to common perceptions that interconnections of intermittent renewable energy technologies and utility systems are problematic and costly and that major issues regarding harmonics, protection, and safety remain, the study has found that hardware and system design advances have eliminated most of interface concerns. Furthermore, the cost of hardware is going down.

- The arguments that intermittency causes large economic penalties for utilities and integration of intermittent renewable energy technologies is feasible only at a very low penetration level are overly pessimistic. These views resulted from early studies with very conservative assumptions; more recent studies have shown that the effects are less severe than originally believed. Study results and actual operating experience have shown that cost penalties do not occur at low to moderate penetration levels and higher penetration levels are feasible.

- The common views that intermittent renewable energy technologies provide only replacement energy to the utility systems with no capacity value and that they require significantly lower costs to be competitive in the utility industry are misleading. Studies have shown that intermittent renewable energy technologies can have capacity values and are competitive today in many situations. Renewable technologies were at a disadvantage because their unique attributes and characteristics were not always considered in the conventional planning process.

Assessing the impacts of renewable energy on electric system operations has been difficult because renewable resources and the existing utility generation mix differ significantly across regions. No standard or generally accepted methodology has been developed. Researchers typically analyze the impact of intermittent renewable energy technologies and the feasible penetration levels in a power system based on two aspects of utility operations: production costs and system regulation requirements. Analyses based on production cost simulations compare the value of displaced energy and capacity of conventional generating plants to the cost of renewable energy technologies. Analyses based on system regulation requirements focus on a system's ability to maintain frequency and to provide necessary operating reserve when renewable energy generations are added to the power system.

Although the study results are derived from different analytic techniques and are not directly comparable, some general conclusions can be drawn. Many studies conclude that the existing electric system can accommodate wind generation supplying up to $10 \%$ of the system load without significant negative effects. Experience from wind farm operations in California shows that the electric system can operate normally when wind generation is supplying $8 \%$ of the system demand (during off-peak hours). Research also has shown that $50 \%$ penetration of wind generation is feasible. A penetration level higher than $10 \%$ may require improved short-term weather forecasting and a proper generator control strategy. Studies completed in the late 1970s and early 1980s usually gave low penetration limits and high economic penalties. Research performed in the late 1980s indicated that higher penetration levels were feasible. Better understanding of wind-speed distributions and spatial diversity contributed to the higher limits. 
Small-scale PV systems have demonstrated technical feasibility and economic competitiveness in standalone applications over remote areas where utility grid service is not available. Simulations and actual operating experience have shown that harmonics, equipment protection, voltage regulation, and personnel safety problems associated with distributed PV generations do not appear to be as severe as earlier anticipated. Researchers have shown a wide range of feasible PV penetrations in utility systems (5\%-17\%), depending on the existing generation mix and utility load characteristics. With careful planning and some modifications of existing work procedures, one utility has managed to integrate distributed PV systems into one feeder circuit equal to $50 \%$ of that feeder's capacity. Studies indicate that improvement in short-term weather forecasting can facilitate higher penetration levels.

It should be noted that penetration limits from many studies are economic rather than technical limits. Studies generally show that adding combined-cycle generating units or other fast-response generating units allows utility systems to accommodate a higher level of intermittent renewable energy technologies. However, the additional operational costs may be greater than the added value of additional intermittent renewable energy technologies. As the cost of renewable energy technologies continues to decline, this mitigation measure will certainly increase the penetration level of intermittent renewables.

Storage can increase the value to utilities of intermittent energy generations, but studies do not always indicate that adding storage to intermittent renewable generation is a viable option. While energy storage systems can enhance the operating flexibility of a utility system, they should be considered based on the overall utility system operation and not just for intermittent renewable generations. Integrating renewable energy technologies with existing hydropower systems has the potential of increasing the values of both. Fast-response and storage capabilities associated with hydropower systems can compensate for the intermittency of renewable energy and make renewable energy more attractive to electric utility operations.

Even a penetration level of $10 \%$ of the installed utility capacity represents a tremendous opportunity for intermittent renewable energy technologies. Current installations of wind and PV generation capacities are far below this level. It appears that there is no near-term technical impediment to utilities' integration of intermittent renewable resources. However, other economic and institutional concerns may limit the market penetration.

\subsection{Limiting Factors}

As discussed in previous sections, there are no significant interfacing or operating barriers to integrating intermittent renewable technologies into utility systems, especially at low penetration levels. However, current installations of intermittent renewable generating plants in utility systems are far less than the feasible level indicated by research results or actual utility operating experience. Several key factors can limit significant penetration of intermittent renewable energy technologies into the utility systems.

\subsubsection{Economic Factors}

Although it was not assessed in this report, the cost of renewable energy technologies was identified as one of the most important factors affecting the utilities' decision to adopt renewable technologies. Remarkable progress has been made over the last decade in reducing the cost of intermittent renewable energy technologies, but still more is needed. Renewable technologies must be able to compete against the utility's least-cost alternative for supplying electricity in order to be accepted. Current costs of many renewable technologies are not yet sufficiently competitive for utilities in all regions to accept these technologies. 
Using conventional economic analyses, planning criteria, and current costs, many renewable energy technologies cannot generate electricity at a cost that is competitive with other conventional generating technologies. But certain attributes of renewable technologies make them more desirable to society than conventional fossil-fuel based generating technologies. Many renewable energy technologies do not generate waste products, nor do they emit $\mathrm{CO}_{2}, \mathrm{SO}_{2}$, or $\mathrm{NO}_{\mathrm{x}}$. They have short construction lead times, and their O\&M costs are low. A major uncertainty is eliminated from the economic analysis process because of their zero fuel costs. These attributes should have a value to society. Standard utility analysis with its emphasis on $\$ / \mathrm{kW}$, however, does not properly value these additional benefits and thus underestimates the potential contribution from renewable technologies. In order for renewable energy technologies to make significant contributions toward meeting the nation's energy demand, these benefits must be recognized and given proper credit in the evaluation process.

Another factor that may negatively impact the cost of intermittent renewable technologies is the transmission cost. Transmission cost will be associated with every resource expansion plan. The burden may be disproportionally heavy for intermittent renewable technologies because significant developable wind and solar resources generally occur at the peripheries of the utility systems where the transmission links to the load centers are weak. The development of utility-scale renewable energy systems inevitably leads to the significant requirement of transmission facilities for integrating these new resources into the bulk utility transmission systems. One preliminary study has identified the transmission cost as one of the major barriers for large scale development of wind resources over the Northwest.

\subsubsection{Institutional Factors}

Few utilities have actual operating experience with unconventional technologies. A significant amount of grid operating experience with renewable technologies has been accumulated over the last 10 years by several utilities. However, information about these utility experiences is not widely available to utilities and regulatory bodies. Therefore, many utilities are unaware of recent technology and performance improvements of intermittent renewable generations. Lack of experience and information are two critical factors that hamper the electric utilities' decision to employ renewable energy technologies. Many utilities still regard renewable energy technologies as "uncertain" and perceive major technical and financial uncertainties as well as other risks associated with such technologies.

Some power pools have established a reserve margin requirement for their member utilities, and there are formal criteria for rating and reporting generator capacities to calculate the reserve margins. Member utilities have contractual obligations to maintain the required reserve margin based on these rating and reporting criteria. For example, some power pools require member utilities to periodically operate any generators that are included in the reserve margin calculations and to hold the output at rated capacity for a specified duration (e.g., 4 hours). PV and wind power have different operating characteristics and may not fit these criteria.

Utilities also are concerned about the inability to control the intermittent renewable generations. Conventional generating units can be dispatched to meet the system maintenance schedule and other operational requirements. Intermittent renewable generation technologies lack this operating flexibility. Many electric utilities consider choosing renewable energy technologies to meet their future demand to be too great a risk. It is unclear which aspects of these concerns are real and which reflect the attitude of utilities toward new technologies in general. 


\subsubsection{Regulatory Factors}

The current planning process and analytic methods do a reasonably good job of evaluating and ranking conventional types of energy resources. However, they generally fail to recognize many unique attributes and operating characteristics of intermittent renewable energy technologies. Furthermore, the value of renewable energy systems as a distributed supply option or a demand-side management alternative is not properly credited.

Existing regulatory practices also may be unintentionally biased against renewable energy options. Ratemaking processes that do not reflect the operating characteristics and positive attributes of renewable energy systems need to be modified. Renewable energy technologies often entail high capital costs and low operating costs with no future escalation of fuel costs. Electric utilities selecting an expansion plan with renewable energy technologies will face a heavy financial burden trying to recover the high capital investment during earlier years of the plan, but will benefit from the low risk of future rate escalation. Under current financial constraints and regulatory policies, there are no incentives for electric utilities to commit to such capital-intensive technologies, which the utilities also may consider to be unproven.

Competitive bidding procedures to acquire new capacity for electric utilities is rapidly becoming the preferred or required mechanism in the utility industry. Many bidding solicitations do not properly account for such factors as environmental and fuel-diversity benefits that are important attributes of renewables. Bidding solicitations that emphasize price and operational characteristics (e.g., dispatchability) will put intermittent renewable technologies at a disadvantage.

\subsubsection{Technical Factors}

Electric utilities have a great amount of knowledge and experience with planning and operating conventional power supply technologies. Planning models and procedures to evaluate the conventional generation technologies are readily available and most electric utility planners feel confident using them. Comprehensive and regulator-approved models capable of evaluating renewable energy technologies are few, and data requirements are very specific. Electric utilities often either lack the necessary information or do not feel comfortable using these models.

Lack of planning tools for utilities to evaluate the cost and impact of intermittent renewable technologies has hampered efforts of some utilities and utility commissions to include intermittent renewable technologies in their resource planning processes. Some existing models have been adapted to handle nondispatchable resources, but a uniform planning methodology to account for the stochastic nature of the intermittent renewable resources is not available. Input data availability is another obstacle. Long-term, site-specific wind resource and solar radiation data that enable utilities to conduct a detailed analysis of the renewable energy generation are often lacking.

So far, the majority of intermittent renewable generation plants connected to utility systems are Qualifying Facilities (QFs) under the Public Utilities Regulatory Policies Act (PURPA). Utilities have used these generation plants to displace higher cost energy sources, but do not plan for the intermittent capacities to meet the system demand. If the intermittent renewable generation plants do not perform as expected, utilities can fall back on existing capacities to serve their load. Under these circumstances, deficiencies in the planning models and data used for evaluation may not pose serious problems. However, model and data accuracy will become very critical if utilities plan to install intermittent renewable generation plants to dependably satisfy new capacity as well as energy requirements. Utilities must have reasonable assurance that new capacity will perform as planned. Current planning models and methodologies for intermittent renewable technologies do not provide such a confidence level for utilities. 


\subsection{Remaining Issues}

Renewable energy technologies can become significant contributors to the nation's energy supply only with the full support of electric utilities. It is therefore imperative that electric utilities develop a thorough understanding of all the costs and benefits associated with renewable energy technologies. Gaps in knowledge or partial understanding of specific topic areas prove to be barriers to utilities' adoption of intermittent renewable energy technologies in their capacity expansion plans.

As renewable technologies develop and mature, many technical limitations will be resolved and the cost of these technologies will decrease. However, as discussed in the previous section, technical and economic factors, while important, are not the only barriers to the development of intermittent renewable energy technologies. Utilities have other concerns that must be addressed and resolved before large-scale development of intermittent renewable energy technologies can take place.

The following is a prioritized list of issue topics that would benefit from further resolution. The first four issues are generally near-term and address topics that have an immediate impact on utilities' decision to integrate intermittent renewable technologies. The last two issues are long-term and generally deal with topics that will increase in importance as penetration of intermittent renewables reaches or is expected to reach a much higher level. The long-term issues should be addressed within the next ten years.

\section{Utility Planning Models and Methodologies}

The lack of standard planning models and methodologies for utilities to plan and value intermittent renewable technologies requires immediate attention. Today, electric utilities do not always include renewable energy technologies in their planning process because standard techniques for evaluating them are not readily available. Studies have shown that renewable technologies located at carefully chosen sites can significantly change their cost/benefit economics. Environmental and fuel-diversity benefits are also important attributes of renewable technologies. Traditional planning models do not consider these benefits, nor other externalities of power production and consumption. Improved planning models that properly evaluate the benefits and costs of all generation technologies will facilitate the integration of renewable energy technologies by utilities.

\section{Institutional Issues}

Institutional issues such as regulation and utility decision-making processes may impede the development and integration of intermittent renewable technologies. Identifying these institutional obstacles and developing proper remedies to eliminate them are important near-term strategies. Identifying the obstacles will require learning about the decision-making processes of various stakeholders in the utility arena, as well as independent developers. Remedies can then be determined through future discussions and collaborative research activities with utilities and state and federal regulatory agencies.

\section{Resource Assessment}

Utilities need resource data specific to their service territories in order to evaluate the potential contributions of those resources to their systems and design an appropriate development strategy. Generalized resource data often do not contain detailed information necessary for utility resource planning. Analyzing long-term, detailed resource data for their statistical properties may help utilities to develop short-term as well as long-term forecasting capabilities for intermittent renewable resources. The results also can be used to derive quantitative information regarding resource spatial and temporal 
diversities. All this information is important for utilities developing plans to integrate intermittent renewable resources.

4. Implementation Issues

Interfacing the intermittent renewable energy technologies with existing utility transmission and distribution systems is a critical issue facing intermittent renewables. Despite significant progress in the past decade in our understanding of the interface problems and hardware performance, standard designs and study procedures are not yet available. Interfacing costs are still too high, especially for small intermittent renewable energy projects. Transmission access and cost are real concerns to the largescale development of renewable energy, and they could be a major barrier in the future.

\section{Operational Studies}

Many integration studies appeared to establish some hard limits on intermittent renewable energy penetration, sometimes without proper recognition of exactly what mechanisms are responsible for these limits. Some of the studies used very conservative assumptions about the resources and system capabilities or simplified models to simulate the system behavior at different penetration levels of intermittent renewable resources. These approaches may be adequate if the penetration level is low, but the results for medium and high penetration scenarios may not reflect actual system response. Further investigation of operating issues may be needed to answer the questions on optimal penetration levels. This topic is a long-term issue because medium to high penetration levels are currently a long-run option.

6. Mitigation Techniques

Issues discussed under topic five above deal with identifying potential operational limits associated with the intermittent generations, but do not explore opportunities to mitigate the effects. For example, combined-cycle plants can be used to supplement the load following capability of a system with a high level of penetration of intermittent generation. Various energy storage technologies can also be employed for the same purpose. A combination of existing hydropower facilities and renewable energy technologies is another feasible option that needs further examination. Earlier studies have shown that these measures can be valuable tools that will enable utilities to integrate intermittent renewable energy resources into their systems at higher penetration levels. 


\subsection{Bibliography}

\section{Pre-1978}

California Institute of Technology. The Cost of Energy From Utility-Owned Solar Electric Systems, A Required Revenue Methodology for ERDA//EPRI Evaluations. ERDA/JPL-1012-7613. June 1976.

Cohn, N., Control of Generation and Power Flow on Interconnected Power Systems, Second Edition. John Wiley \& Son, Inc., New York. 1971.

Fuchs, E.F., "Evaluation of the Power Quality Standards Recommended by European Committees."

Elgerd, O.I., Electric Energy Systems Theory: An Introduction, McGraw-Hill Book Company. New York. 1971.

Garver, L.L., "Effective Load Carrying Capability of Generating Units," IEEE Transactions on Power Apparatus and Systems, Vol. PAS-85, No. 8. August 1966. pp. 910-919.

IEEE Working Group, "MW Response of Fossil Fueled Steam Units," IEEE Transactions on Power Apparatus and Systems, Vol. PAS-92, No. 3. March 1973. pp. 455-463.

PVUSA Information Brochures, PVUSA Project Management Office, 3400 Crow Canyon Road, San Ramon, California.

Zaininger, H.W., Cycling Ability of Large Generating Units Workshop. EPRI WS-77-50. Electric Power Research Institute. November 1-2, 1977.

1978

Davitian, H., Wind Power and Electric Utilities: A Review of the Problems and Prospects. BNL 50849. UC-60. Brookhaven National Laboratory. April 1978.

Electric Power Research Institute, Requirements Assessment of Photovoltaic Power Plants in Electric Utility Systems, EPRI ER-685, Technical Report, Vol. 2. June 1978.

General Electric Space Division. System Dynamics of Multi-Unit Wind Energy Conversion Systems Application, Final Report, DSE-2332-T2. February 1978.

Justus, C.G., Mikhail, A.S. "Energy Statistics for Large Wind Turbine Arrays," Wind Engineering. Vol 2, No. 4. 1978. pp. 184-202.

Kahn, E.C., Reliability Planning in Distributed Electric Energy Systems. LBL-7877. Lawrence Berkeley Laboratory. 1978.

Lachs, W.R., "Voltage Collapse in EHV Power Systems," paper presented at the IEEE PES Winter Meeting, New York, NY. A 78 057-2. January 29-February 3, 1978.

\section{9}

Dodge, D.M., Stafford, J.V., Small Wind Turbine Systems 1979, A Workshop on R\&D Requirements and Utility Interface/Institutional Issues. Boulder, Colorado. Rockwell International. February 27-March 1. 1979. 
General Electric Company. Requirements Assessment of Wind Power Plants in Electric Utility Systems. Volume 2, Final Report, EPRI ER-978. January 1979.

Hightower, S.J., "Solar/Hydro Integration Study," presented at the Department of Energy Large Solar Central Receiver Systems Semiannual Meeting, Williamsburg, Virginia. September 1979.

JBF Scientific Corporation. Wind Energy Systems Application to Regional Utilities, Volume 1. May 1979.

JBF Scientific Corporation. Wind Energy Systems Application to Regional Utilities, Executive Summary. DOE/ET/20063-T1(Exec. Summ.) June 1979.

Kahn, E., "The Compatibility of Wind and Solar Technology with Conventional Energy Systems," Annual Review Energy. 1979.

Lindley, C.A., Melton, W.C., Electric Utility Application of Wind Energy Conversion Systems on the Island of Oahu," ATR-78(7598)-2. Department of Energy. February 1979.

Sant, R.W., The Least-Cost Energy Strategy - Minimizing Consumer Costs Through Competition, The Energy Productivity Center, Mellon Institute, Arlington, Virginia. 1979.

\section{0}

Bahrami, K., Stallkamp, J., Walton, A., Dispersed Storage and Generation Case Studies. JPL Publication 79-98. Jet Propulsion Laboratory. March 1980.

Bawn, W.E., Guerrero, J.V., "Utility Concerns about Interconnected Small Wind Energy Conversion Systems," Technical Memorandum. Rocky Flats Wind Systems Program. TM-IP-81-2. November 1980.

Bonneville Power Administration. Wind Energy Integration Study. August 1980.

Eichler, C.H., Hayes, T.P., Matthews, M.M., Wilraker, V.F., Photovoltaic Utility/Customer Interface Study, Final Report. SAND80-7061. Sandia National Laboratories. December 1980.

Fegan, G.R., Percival, C.D., Problems in the Integration of Intermittent Sources into Utility Production Costing Models. SERI/TP-351-546. Solar Energy Research Institute. January 1980.

Hinrichsen, J.I. et al., Dynamic of Single and Multi-Wind Energy Conversion Plants Supplying Electric Utility Systems, Report DOE/NASA/-13401, NASA CR-165156. June 1980.

Kinloch, D.H., Wicks, F. E., et al., "Potential and Impacts of Wind Electric Generators Upon Electric Power Systems," IEEE PES Winter Meeting. New York, New York. February 1980.

Miles, W.T., Ma, F.S., "Electric System Impacts of Dispersed Energy Technologies," Proceedings of the National Conference on Renewable Energy Technologies. Honolulu, Hawaii. December 1980.

Schenk, K.F., Chan, S., Uko, P., Rau, N.S., "Evaluation of Production Costs and Capacity Credits of a Wind Energy Conversion System Supplying an Electric Utility," Proceedings 3rd Miami International Conference on Energy Sources. 1980.

Thomas, R.J., Thorp, J.S., "Integration Problems with Large Wind Energy Conversion Systems," Proceedings of the Eighth Annual Allerton Conference on Communication, Control and Computing. 1980. pp. 8-10. 
VanKuiken, J.C., Buehring, W.A., Huber, C.C., Hub, K.A., Reliability, Energy, and Cost Effects of WindPowered Generation Integrated with a Conventional Generating System. ANL/AA-17. Argonne National Laboratory. January 1980.

Zaininger, H.W., Wind Power Generation Dynamic Impacts on Electric Utility Systems, Final Report. Electric Power Research Institute. EPRI AP-1614. November 1980.

\section{1}

ANSI/IEEE Std 519-1981. IEEE Guide for Harmonic Control and Reactive Compensation of Static Power Converters.

Belt, R.M., "Utility Scale Application of Wind Turbines," IEEE Region 6 Conference on Electrical Engineering Applications in the Pacific. Honolulu, Hawaii. April 1981.

Boardman, R.W., Tatton, R., Curtice, D.H., Impact of Dispersed Solar and Wind Systems on Electric Distribution Planning and Operation. Final Report, ORNL/Sub-7662/1. Oak Ridge National Laboratory. February 1981.

Bureau of Reclamation, "Wind-Hydroelectric Energy Project, Wyoming," Feasibility Report, June 1981.

Conner, T.J., The Value of Photovoltaic Power Plants to a Municipal Sunbelt Utility. ATR-81-6828-01IND, The Aerospace Corporation. September 1981.

Curtice, D., Patton, J., Operations of Small Wind Turbines on a Distribution System, Systems Control, Inc. DE-AC04-76DP03533. March 1981.

Curtice, D., Patton, J., "Small Wind Turbines Operating in Utility Distribution Systems," Proceedings of the 1981 Wind Energy Technology Conference, DOE/NBM-2021241. 1981.

Day, J.T., Malone, M.J., Powell, R.W., Laughton, M.A., "Modeling the Electric Utility Impact of Solar Electric Technologies," Power Systems Computation Conference, Lausanne, Switzerland. July 1981. pp. 104-105.

DeDuck, P.F., Neal, R.W., Zaininger, H.W., "Assessment of the Effects of Distributed Photovoltaic Systems on Utility Subtransmission and Distribution Networks," Fifteenth IEEE Photovoltaic Specialist Conference1981. Kissimmee, Florida. May 1981.

Flaim, T., Considine, T.J., Witholder, R., Edesess, M.. Economic Assessments of Intermittent GridConnected Solar Electric Technologies: A Review of Methods. SERI/TR-353-474, Solar Energy Research institute. September 1981.

Hassan, M., et al., Distributed Photovoltaic Systems: Utility Interface Issues and Their Present Status. DOE/ET/20356-3. Jet Propulsion Laboratory. September 1981.

JBF Scientific Corporation. WECS Value for Southern California Edison Company. Draft Report. January 1981.

JBF Scientific Corporation. Methodology for Determining the Value of Wind Energy Conversion Systems for Specific Utility Systems. SERI/TR-98336-2. Solar Energy Research Institute. September 1981.

Lee, S.T., Yamayee, Z.A., "Load Following and Spinning Reserve Penalties for Intermittent Generation," IEEE Transaction on Power Apparatus and Systems, Vol. PAS-100, No. 3. March 1981. pp.1203-1211. 
Miles, W.T., Patmore, J., "System Reliability Implications of Distributed Power Sources in the Electric Grid," Proceedings of New Energy Conservation Technologies and Their Commercialization Conference. Berlin, Germany. April 1981.

Moffat, A.M., "System Technical Questions in Integrating Renewable Energy Sources into Small Systems," Colloquium on Integration of Renewable Energy Sources in Existing Networks. London, England. November 1981

Patton, J.B., Iqbal, S., Small Power Production Interconnection Issues and Costs. DOE/NBM-401075. February 1981.

Percival, D., Harper, J., "Value Analysis of Wind Energy Systems to Electric Utilities," January 1981.

Wasynezuk, O., Man, D.T., Sullivan, J.P., "Dynamic Behavior of a Class of Wind Turbine Generators During Random Wind Fluctuations," IEEE Transaction Power Apparatus and Systems, Vol. PAS-100, No. 6. June 1981. pp. 2837-2845.

Zaininger, H.W., "Potential Dynamic Impacts of Wind Turbine on Utility Systems," IEEE Transactions on Power Apparatus and Systems, Vol. PAS-100, No. 12. December 1981. pp. 4821-4829.

\section{2}

Aerospace Corp., Electric Utility Value Analysis for Wind Energy Conversion Systems, SERI/TR-98336-1A. Solar Energy Research Institute. April 1982.

Bechtel Group, Inc., Photovoltaic Balance-of-System Assessment. Final Report, EPRI AP-2474. Electric Power Research Institute. June 1982.

Bingley, D.W., "Wind System Utility Intertie with Inverters/Frequency Changers," Proceedings Wind Energy Expo'82 and National Conference, AWEA. Amarillo, Texas. October 1982.

Bossanyi, E.A., "Probabilities of Sudden Drop in Power from a Wind Turbine Cluster," Fourth International Symposium on Wind Energy Systems. September 1982.

Campen, G.L., Results of the Harmonics Measurement Program at the John F. Long Photovoltaic House. ORNL-5834, Oak Ridge National Laboratory. March 1982.

Caramanis, M.C., Tabors, R.D., Nochur, K.S., Schweppe, F.C., "The Introduction of Non-Dispatchable Technologies as Decision Variables in Long-Term Generation Expansion Models', IEEE Transactions on Power Apparatus and Systems, Vol. PAS-101, No. 8. August 1982. pp. 2658-2667.

Chu, D., Fitzer, J., Key, T., "Utility Interface Issues for Grid-Connected Photovoltaic Systems," 16th IEEE Photovoltaics Specialists Conference, San Diego, California. September 1982.

Daozhi Xia, Heydt, G.T., "Harmonic Power Flow Studies Part I - Formulation and Solution," IEEE Transactions on Power Apparatus and Systems, Vol. PAS-101, No. 6. June 1982. pp. 1257-1265.

Das, R.L., Klein, J.W., Macie, T.W., Distributed Photovoltaic Systems: Utility Interface Issues and Their Present Status. JPL-PUBL-82-63, DE83 003165. Jet Propulsion Laboratory. September 1982.

Day, J.T., Malone, M.J., "Electric Utility Modeling Extensions to Evaluate Solar Plants," IEEE Transactions on Power Apparatus and Systems, Vol. PAS-101, No. 1. January 1982. pp. 120-126.

Dodge, D.M., Porpotage, J.L., Bawn, W.E., Jr., Guerrero, J.V. Small Wind Systems Field Evaluation, Volume III. Utility Issues. Final Report. DE84 006919. DOE Rocky Flats. July 1982. 
Electric Generation Expansion Analysis System (EGEAS), EPRI EL-2561, Volume 1, Project 1529-1, Final Report. August 1982.

Harper, J.R., Percival, C.D., Solar Electric Technologies: Methods of Electric Utility Value Analysis. SERI/TR-214-1362. Solar Energy Research Institute, Golden, Colorado. May 1982.

House, L.W., Wind and Solar Electricity Producing Technologies Impact on Electric Utilities, AD-54 WST. California Energy Commission. September 1982.

Janssen, A.J., "A Frequency and Duration Method for the Evaluation of Wind Integration," 1982 Meeting of Experts of Annex III a Integration of Wind Power into National Electricity Supply Systems. June 1982.

JBF Scientific Corporation. Assessment of Distributed Photovoltaic Electric Power Systems, Final Report, EPRI AP-2687. Electric Power Research Institute. October 1982.

Jones, G.J., Bonk, G.J., Thomas, M.G., "Future Contingencies and Photovoltaic System Worth," 16th IEEE Photovoltaics Specialists Conference, San Diego, California. September 1982.

Kinloch, D.H., et al., " Impacts of Solar Heating Options Upon Electric Power Systems," IEEE Transactions on Power Apparatus and Systems, Vol. PAS-101, No. 6. June 1982. pp. 1271-1280.

Longrigg, P., "D.C.-To-A.C. Inverters for Photovoltaics," January 1982.

Ma, F.S., Curtice, D.H., "Distribution Planning and Operations with Intermittent Power Production," IEEE Transactions on Power Apparatus and Systems, Vol. Pas-101, No. 8. August 1982. pp. 2931-2940.

Moyle, R., Chernoff, H., Patton, J. Schweizer, T., "Grid-Connected Distributed Solar Power Systems," Proceedings 16th IEEE Photovoltaics Specialists Conference, San Diego, California. September 1982. pp. 1172-1175.

Moyle, R., Chernoff, H., Schweizer, T., "Assessment of Distributed Solar Power Systems: Issues and Impacts," Proceedings IEEE 16th Photovoltaics Specialists Conference, San Diego, California. November 1982. pp. 1172-1176.

Neal, R.W., DeBucj, P.F., Marshall, R.N., Assessment of Distributed Photovoltaic Electric Power Systems, Summary Report, EPRI AP-2687-SY. October 1982.

Nielsen, P., "Problems of Interconnecting Aerogenerators to the Grid," Solar Energy R\&D in the European Community, Series G, Volume 1 Wind Energy. Proceedings of the EC Contractors' Meeting, Brussels, Belgium. Edited by W. Palz \& W. Schnell. November 1982. pp. 151-157.

Oplinger, J.L., "Economics of Large Wind Turbine Generators," Proceedings of the Ninth Energy Technology conference. Washington, D.C. June 1982. pp. 1525-1536.

Park, G.L., Zastrow, O.W. "Interconnection Issues Concerning Consumer-Owned Wind Electric Generators," IEEE Transactions on Power Apparatus and Systems, Vol. PAS-101, No. 7. July 1982. pp. $2375-2382$.

Patton, J.B., Curtice, D., "Analysis of Utility Protection Problems Associated with Small Wind Turbine Interconnections," IEEE Transactions on Power Apparatus and Systems, Vol. PAS-101, No. 10. October 1982. pp. 3957-3966.

Percival, C.D., Harper, J.R., Electric Utility Value Determination for Wind Energy Volume 1 and Volume 2. SERI/TR-732-604R. Solar Energy Research Institute. January 1982. 
Proceedings: Research Needs for the Effective Integration of New Technologies into the Electric Utility. CONF-820772. July 1982.

Reddoch, T.W., Barnes, P.R., Lawler, J.S., Skroski, J.C., "Strategies for Minimizing Operational Impacts of Large Wind Turbine Arrays on Automatic Generation Control Systems," Journal of Solar Energy Engineering. Vol. 104. May 1982.

Schulz, R.P., "Impact of New Technology Generation and Storage Processes on Power System Stability and Operability," Proceedings Research Needs for the Effective Integration of New Technologies into the Electric Utility, CONF-820772. Edited by Michael A. Kuliasha and Thomas W. Reddoch, Oak Ridge National Laboratory. June 1982.

Science Applications, Inc., Assessment of Distributed Solar Power Systems: Issues and Impacts. Final Report. EPRI AP-2636. Electric Power Research Institute. November 1982.

Stafford, R.W., Park, G.L., "Technical Problems of WECS Interconnection," Rural Wind Energy Workshop. June 1982.

Sullivan, R.L., Flaim, T., Percival, D., WECS Value Analysis: A Comparative Assessment of Four Methods. SERI/TR-211-1563. Solar Energy Research Institute. March 1982.

Systems Control, Inc., The Effect of Distributed Power Systems on Customer Service Reliability. EPRI EL2549. Electric Power Research Institute. August 1982.

Tabors, R.D., White, D.C., "Solar Energy/Utility Interface: The Technical Issues," Energy. Vol. 7, No. 1. January 1982. pp. 39-48.

Wegley, H.L., "The Development and Evaluation of Wind Forecasts for Wind Energy Applications," Proceedings of the 9th Conference on Weather Forecasting and Analysis. Boston, Massachusetts. June 28July $1,1982$.

\section{3}

A. Traça de Almeida, Martins, A., Jesus, H., Climaco, J., "Source Reliability in a Combined Wind-SolarHydro System," IEEE Transactions on Power Apparatus and Systems. Vol. PAS-102, No. 6. June 1983. pp. 1515-1520.

Balcerak, J.C., "Wind System--Utility Interaction Issues," 10th Meeting of Experts--Utility and Operational Experiences and Issues from Major Wind Installations, Palo Atlo, California. October 1983.

Bossanyi, E.A., Halliday, J.A., "Recent Developments and Results of the Reading/RAL Grid Simulation Model," Proceedings of the Fifth BWEA Wind Energy Conference, Reading, Great Britain. March 1983. pp. 62-74.

Caramanis, M.C., "Analysis of Non-Dispatchable Options in the Generation Expansion Plan," IEEE Transactions on Power Apparatus and Systems, Vol. PAS-102, No. 7. July 1983. pp. 2098-2103.

Carroll, D.P., et al., Dynamic Simulation of Dispersed Grid-Connected Photovoltaic Power Systems: Task 1-Modeling and Control. SAND-83-7018. November 1983.

Chan, S.M., Curtice, D., Chang, S.-K, Methods for Wind Turbine Dynamic Analysis, Final Report, EPRI AP-3259. October 1983. 
Chan, S.M., Powell, J.C., Yoshimura, M.,Curtice, D.H., "Operations Requirements of Utilities with Wind Power Generation," IEEE Transactions on Power Apparatus and Systems, Vol. PAS-102, No. 9. September 1983. pp. 2853-2860.

Curtice, D., Patton, J.B., Interconnecting DC-Energy Systems: Response to Technical Issues. Final Report, AP/EM-3124. Electric Power Research Institute. June 1983.

Curtice, D.H., Reddoch, T.W., "Assessment of Load Frequency Control Impacts Caused by Small Wind Turbines," IEEE Transactions on Power Apparatus and Systems, Vol. PAS-102, No. 1. January 1983. pp. 162-170.

Dixon, J.C., Lowe, R.J., "Operating Reserve, Utility Size and Power Variance," Proceedings of the Fifth BWEA Wind Energy Conference, Reading, UK. March 1983.

Dub, W., Pape, H., Implementing Agreement for a Programme of Research and Development on Wind Energy Conversion Systems. International Energy Agency IEA. Juel-Spez-195. March 1983.

Dub, W., Pape, H., Integration of Wind Power into National Electricity Supply Systems. Implementing Agreement for a Programme of Research and Development on Wind Energy Conversion Systems. March 1983.

Dugan, R.C., Computer Simulation Harmonics Study: Analysis of the Effects on Two Distribution Feeders of Harmonics Produced by the Proposed John F. Long 100-house Photovoltaic Development. ORNL/Sub81/95011/1. Oak Ridge National Laboratory. August 1983.

Dugan, R.C., Jewell, W.T., Roesler, D.J., "Harmonics and Reactive Power From Line-Commutated Inverters in Proposed Photovoltaic Subdivision," IEEE Transactions on Power Apparatus and Systems, Vol. PAS-102, No. 9. September 1983. pp. 3205-3211.

Electric Power Research Institute. EPRI Conference Proceedings: Solar and Wind Power--1982 Status and Outlook. EPRI AP-2884-SR. February 1983.

Electric Power Research Institute, Interconnecting DC-Energy Systems: Response to Technical Issues. EPRI AP/EM-3124. June 1983.

General Electric Company, Assessment of Distributed Wind Power Systems, Summary Report, EPRI AP2882-SY. February 1983.

Goldenblatt, M.K., Wegley, H.L., Miller, A.H., Analysis of the Effects of Integrating Wind Turbines into a Conventional Utility: A Case Study. PNL-3962 Rev. UC-60. Pacific Northwest Laboratory. March 1983.

Hilson, D.W., Sadanandan, N.D., et al., "Impact Assessment of Wind Generation on the Operation of A Power System," IEEE Transactions on Power Apparatus and Systems, Vol. PAS-102, No. 9. September 1983.

Key, T.S., "Evaluation of Grid-Connected Inverter Power Systems: The Utility Interface," IEEE/IAS Glass Industry Committee Meeting. Mexico City, Mexico. October 1983.

Kirkham, H., Klein, J., "Dispersed Storage and Generation Impacts on Energy Management Systems," IEEE Transactions on Power Apparatus and Systems, Vol. PAS-102, No. 2. February 1983. pp. 339-344.

$\mathrm{Ku}$, W.S., Nour, N.E., et al., "Economic Evaluation of Photovoltaic Generation Applications in a Large Electric Utility System," IEEE Transactions on Power Apparatus and Systems. Vol. PAS-102, No. 8. August 1983. pp. 2811-2816. 
Longrigg, P., "Effects on Electrical Distribution Networks of Dispersed Power Generation at High Levels of Connection Penetration," SERI/TP-214-2008. Paper presented at the 18th IECEC, Orlando, Florida. August 1983.

Møeller, J., "Wind Power in the Danish Electricity Supply System," 10th Meeting of Experts - Utility and Operational Experiences and Issues from Major Wind Installations. October 1983.

Murdoch, A., Winkelman, J.R., Javid, S.H., Barton, R.S., "Control Design and Performance Analysis of a 6 MW Wind Turbine-Generator," IEEE Transactions on Power Apparatus and Systems, Vol. PAS-102, No. 5. May 1983. pp. 1340-1347.

Ofry, E., Braunstein, A., "The Loss of Power Supply Probability as a Technique for Designing Stand-Alone Solar Electrical (Photovoltaic) Systems," IEEE Transactions on Power Apparatus and Systems, Vol. PAS102, No. 5. May 1983. pp. 1171-1175.

Reddoch, T.W., Rizy, D.T., "Electric Utility Intertie Issues for Small, Dispersed Power Sources," EPRI Conference Proceedings: Solar and Wind Power--1982 Status and Outlook, August 25-27, 1982. Providence, Rhode Island. EPRI AP-2884-SR. February 1983. pp. 4-71 to 4-78.

Russell, P., "Using the Electric Utility for Storage," The Solar Electric Magazine, Photovoltaics. January 1983.

Schlueter, R.A., et al., "Modification of Power System Operation for Significant Wind Generation Penetration," IEEE Transaction on Power Apparatus and Systems, Vol. PAS-102, No. 1. January 1983. pp.153-161.

Schlueter, R.A., Park, G.L., Lotfalian, M., Shayanfar, H., Dorsey, J., "Modification of Power System Operation for Significant Wind Generation Penetration," IEEE Transactions on Power Apparatus and Systems, Vol. PAS-102, No. 1. January 1983. pp. 153-161.

Schulte, R.P., Bradley, D.E., "Problems Associated with Generator Load Following in System Operation," IEEE Transaction on Power Apparatus Systems, Vol. PAS-102, No. 6. June 1983. pp. 1566-1569.

Simburger, E.J., Cretcher, C.K., et al. "Load Following Impacts of A Large Wind Farm on An Interconnected Electric Utility System," IEEE Transactions on Power Apparatus and Systems, Vol. PAS102, No. 3. March 1983. pp. 687-692.

Tamura, Y., Mori, H., Iwamoto, S., "Relationship Between Voltage Instability and Multiple Load Flow Solutions in Electric Power Systems," IEEE Transactions on Power Apparatus and Systems, Vol. PAS-102, No. 5. May 1983. pp. 1115-1125.

U.S. Department of Energy. Systems Research Program Report. DOE/CE-0046. August 1983.

Wasynczuk, O., "Dynamic Behavior of a Class of Photovoltaic Power Systems," IEEE Transactions on Power Apparatus and Systems, Vol. PAS-102, No. 9. September 1983. pp. 3031-3037.

Yamayee, Z. A., Ma, F.S., "Effect of Size and Location of Conventional and Intermittent Generation on System Reliability," Electrical Power \& Energy Systems, Vol. 5, No. 2. April 1983. pp. 94-100.

Zaininger, H.W., Bell, D.J., Investigate Alternative Interconnection Strategies for Arrays of Wind-Turbine Generations, Final Report, ORNL/SUB-82/69604/1. Oak Ridge National Laboratory. July 1983.

Zaininger, H.W., Bell, D.J., "Economic and Reliability Assessment of Alternative Wind Turbine Array//Utility System Interconnection Strategies," Proceedings Sixth Biennial Wind Energy Conference and Workshop, Minneapolis/St. Paul, Minnesota. June 1983. 
Anderson, P.M., The Effect of Photovoltaic Power Generation on Utility Operation, Final Report. SAND84-7000. February 1984.

Ballard, L.J., Swansborough, R.H. Recommended Practices for Wind Turbine Testing and Evaluation--7. Quality of Power. Single Grid-Connected WECS. 1984.

Bose, A., Anderson, P.M., "Impact of New Energy Technologies on Generation Scheduling," IEEE Transactions on Power Apparatus and Systems, Vol. PAS-103, No. 1. January 1984. pp. 66-71.

Cokkinides, G., Banta, L., Birdwell, G., Meliopoulos, A. P., Vachtsevanos, G., "Investigation of Utility Interface Problems of Photovoltaic Systems Experimental and Simulation Studies," Proceedings 17th IEEE Photovoltaic Specialists Conference, Orlando, Florida. May 1984.

Curtice, D., Bowe, T. R., Iqbal, S., Dapkus, W. D., Rizy, D.T., Cost/Risk Tradeoffs of Alternate Protection Schemes for Small Power Sources Connected to the Electric Distribution Systems. ORNL/Sub/81-16957/1. Oak Ridge National Laboratory. 1984.

Curtice, D., et al., Protection and Safety of Electric Distribution Systems with Dispersed Storage and Generation Devices, ORNL/Sub/80-7974-1. Oak Ridge National Laboratory. April 1984.

Dugan, R.C., Thomas, S.A., Rizy,D.T., "Integrating Dispersed Storage and Generation (DSG) with an Automated Distribution System," IEEE Transactions on Power Apparatus and Systems, Vol. PAS-103, No. 6. June 1984. pp. 1142-1146.

Flaim, T., Hock, S., Wind Energy Systems for Electric Utilities: A Synthesis of Value Studies. SERI/TR-2112318. Solar Energy Research Institute. May 1984.

Firstman, S.I., Vachtsevanos, G.J., "Distributed Photovoltaic Systems: Addressing the Utility Interface Issues," Fifth E.C. Photovoltaic Solar Energy Conference, Kavouri (Athens), Greece, October 1984.

Gellings, C.W., Stovall, J.P., Quade, A.W., Taylor, R.W., "Generation System Impacts of Storage Heating and Storage Water Heating," IEEE Transactions on Power Apparatus, Vol. PAS-103, No. 6. June 1984. pp.1439-1446.

Guess, R.H., Turnbull, F.G., Martzioff, F.D., "Central Station Advanced Power Conditioning Technology, Utility Interface, and Performance," 19th Intersociety Energy Conversion Engineering Conference. August 1984.

Healey, H.M., Birdwell, G.L., "Photovoltaic Systems Interconnection Requirements from the Utility Perspective," 17th IEEE Photovoltaic Specialists Conference, Orlando, Florida. May 1984.

Katzman, M.T., Solar Wind Energy: An Economic Evaluation of Current and Future Technologies. Bowman and Allanheld; Totowa, New Jersey. 1984.

Kirkham, H., Das, R., "Effects of Voltage Control in Utility Interactive Dispersed Storage and Generation Systems," IEEE Transactions on Power Apparatus and Systems, Vol. PAS-103, No. 8. August 1984. pp. $2277-2282$.

Klein, J., Koerner, T., Rippel, W., Kalbach, J., "Requirements for a Transformerless Power Conditioning Subsystem," IEEE Transaction on Power Apparatus and Systems, Vol. PAS-103, No. 8. August 1984. pp. 2269-2276. 
Leung, K.S., Stronach, A.F., "Integration of Wind Turbine Generators into Small Diesel Based Systems," Proceedings Energy Options: The Role of Alternatives in the World Scene. London, England. April 1984.

Lundtveit, T., "Safety Requirements for Power Conditioning Units for use in Residential Photovoltaic Power Systems," Proceedings 17th IEEE Photovoltaics Specialists Conference-1984, 1984. pp. 653-657.

McCabe, T.F. Analysis of Wind Energy Systems for Selected Electric Utilities. SERI/STR-211-2379. Solar Energy Research Institute. July 1984.

Michel, G., "Utility Concerns with the Additions of Photovoltaics to the Distribution System," Fifth Project Integration Meeting, Albuquerque, New Mexico. February 1984.

Michigan State University, "Improved Models for Increasing Wind Penetration, Economics and Operating Reliability," April 1984.

Park, G.L., Schlueter, R.A., "Interfacing Fluctuating Energy Sources to Utility Networks," 1984.

Rahman, S., Chowdhury, B.H., "Effects of Clusters on the Electric Power from Windfarms," IEEE Transaction on Power Apparatus and Systems, Vol. PAS-103, No. 8. August 1984. pp. 2158-2165.

Rizy, D.T., Jewell, W.T., "Power Quality and Protection of Electric Distribution Systems with Small, Dispersed Generation Devices," Southwestern Symposium on System Theory. March 1984.

Rizy, D.T., Jewell, W.T., Stovall, J.P., Operational and Design Considerations for Electric Distribution Systems with Dispersed Storage and Generation (DSG). ORNL/CON-134. Oak Ridge National Laboratory. September 1984.

Schlueter, R.A., Park, G.L., Sigari, G., Costi, T., Improved Models for Increasing Wind Penetration, Economics and Operating Reliability. Final Report. DOE/NBM-1077. April 1984.

Schlueter, R.A., Park, G.L., et al., "Simulation and Assessment of Wind Array Power Variations Based on Simultaneous Wind Speed Measurements," IEEE Transactions on Power Apparatus and Systems, Vol. PAS-103, No. 5. May 1984. pp.1008-1016.

Takeda, Y., Hashimoto, E., Hayashi, T., Takigawa, K., "Utility Interface Problems of Distributed PV System," Proceedings 17th IEEE Photovoltaic Specialists Conference, Orlando, Florida. May 1984. pp. 541-546.

Tausch, H.J., Collaros, G.J., "Interaction of Residential Photovoltaic Systems with Utility Power Waveforms," 17th IEEE Photovoltaic Specialists Conference. Orlando, Florida. May 1984.

Thomas, M.G., Stevens, J.W., Jones, G.J., Anderson, P.L., "The Effect of Photovoltaic Systems on Utility Operations," 17th IEEE Photovoltaic Specialists Conference. Orlando, Florida. May 1984.

Wang, Xifan, Dai, H.Z., Thomas, R.J., "Reliability Modeling of Large Wind Farms and Associated Electric Utility Interface Systems," IEEE Transactions on Power Apparatus and Systems, Vol. PAS-103, No. 3. March 1984. pp. 569-575.

Wasynczuk, O., "Integration of Dispersed PV Generation into Utility Distribution Systems: Stability, Interaction and Fault Tolerance," Proceedings Intersociety Energy Conversion Engineering Conference, San Francisco, California. August 1984. pp. 2145-2151.

Wilreker, V.F., Stiller, P.H., Scott, G.W., Kruse, V.J., Smith, R.F., Wind Turbine Generator Interaction with Conventional Diesel Generators on Block Island, Rhode Island. Volume 1. Executive Summary. DOE/NASA-0354-1. National Aeronautics and Space Administration. February 1984. 
Yamayee, Z.A., "Modeling Intermittent Generation (IG) in a Monte-Carlo Regional System Analysis Model," IEEE Transactions on Power Apparatus and Systems, Vol. PAS-103, No. 1. January 1984. pp. 174-182.

\section{5}

Bouwmeester, R.J.B., Schlueter, R.A., Park, G. L., "Simulation and Assessment of Power Variations From Wind Arrays During Local Storms," Journal of Wind Engineering and Industrial Aerodynamics, 21. September 1985. pp.207-221.

Bunting, D.P., Ney, E.J., Jardine, G.M., "An Experiment in Multi-Source Islanding Including Photovoltaics," INTERSOL '85 Solar Energy--The Diverse Solution. June 1985.

Chalmers, S.M., Anderson, P.M., Vogt, P.L., et al., "The Effect of Photovoltaic Power Generation on Utility Operation," IEEE Transactions on Power Apparatus and Systems, Vol. PAS-104, No. 3. March 1985. pp. 524-530.

Chinery, G.T., Wood, J.M., "Estimating the Value of Photovoltaics to Electric Power Systems," Proceedings of the 18th IEEE Photovoltaic Specialists Conference, Las Vegas, Nevada. October 1985.

Chinery, G.T., Wood, J.M., "TVA's Photovoltaic Activities," IEEE Transactions on Power Apparatus and Systems. Vol. PAS-104, No. 8. August 1985. pp. 1998-2005.

David, A.K., "Incorporation of Large Stochastic Sources in the Power System," IEE Proceedings, Vol. 132, Pt. C, No. 4. July 1985. pp. 161-171.

Herrera, J.E., Reddoch, T.W., Lawler, J.S., Utility Issues and their Relationship to Design Requirements for Electric Variable Speed Generating Technology. Draft Report. Solar Energy Research Institute. October 1985.

Javid, S.H., Reddoch, T.W. et al., "A Method for Determining How to Operate and Control Wind Turbine Arrays in Utility Systems," IEEE Transactions on Power Apparatus and Systems, Vol. PAS-104, No. 6. June 1985. pp. 1335-1341.

Jewell, W., Ramakumar, R., "Insolation Model for Simulation of an Electric Utility with High Penetration of Dispersed Photovoltaic Generation," INTERSOL 85. Proceedings of the Ninth Biennial Congress of the ISES, Volume 3. June 1985. pp. 1635-1639.

Lachs, W.R., "Dynamic Study of an Extreme System Reactive Power Deficit," IEEE Transactions on Power Apparatus and Systems, Vol. PAS-104, No. 9. September 1985. pp. 2420-2426.

Lachs, W.R., "Insecure System Reactive Power Balance Analysis and Counter Measures," IEEE Transactions on Power Apparatus and Systems, Vol. PAS-104, No. 9. September 1985. pp. 2413-2419.

Longrigg, P., Buell, E.H., et al., Research Recommendations for AC Interfacing Between Electric Utility Transmission and Distribution Systems and Wind, Photovoltaics, and OTEC Energy Systems, SERI/TR216-2400. Solar Energy Research Laboratory. March 1985.

New Electric Power Technologies. Office of Technology Assessment. July 1985.

Patapoff, N.W., Jr., "Photovoltaic Power Plants in Utility Interactive Operations," Proceedings of the 20th Intersociety Energy Conversion Engineering Conference. August 1985. 
Patapoff, N.W., Jr., Mattijetz, D.R., "Utility Interconnection Experience with an Operating Central Station MW-Sized Photovoltaic Plant," IEEE Transactions on Power Apparatus and Systems, Vol. PAS-104, No. 8. August 1985. pp. 2020-2024.

R. Lynette \& Associates, Inc., Wind Turbine Operation and Maintenance Experience. Final Report, EPRI AP-3735. Electric Power Research Institute. February 1985.

Schlueter, R.A., Park, G.L., Reddoch, T.W., Barnes, P.R., Lawler, J.S., "A Modified Unit Commitment and Generation Control for Utilities with Large Wind Generation Penetrations," IEEE Transactions on Power Apparatus and Systems, Vol. PAS-104, No. 7. July 1985. pp.1630-1636.

Schlueter, R.A.,, Sigari, G.,, Costi, T., Effect of Accuracy of Wind Power Prediction on Power System Operator. Final Report. NASA-CR-176300. NASA Lewis Research Center. June 1985.

Science Applications International Corporation, Early Market Potential for Utility Applications of Wind Turbines. Final Report, EPRI AP-4077. Electric Power Research Institute. August 1985.

Shi, An-Jen, Thorp J., Thomas, R., "An AC/DC/AC Interface Control Strategy to Improve Wind Energy Economics," IEEE Transactions on Power Apparatus and Systems, Vol. PAS-104, No. 12. December 1985.

Solar Energy Research Institute. Solar Energy Computer Models Directory. SERI/SP-271-2589. August 1985.

Tennessee Valley Authority, TVA/DOE Analysis of the Operation of An Electric Power System with and without Wind Generation, Volume III: Simulated Operations of TVA Power System with Wind Generation, Final Report. TVA. March 1985.

Wallace, D.B. "PV Power Conditioner Harmonics," Proceedings of the Joint ASME-ASES Solar Energy Conference. Knoxville, Tennessee. March 1985.

Wasynczuk, O., et al., Dynamic Simulation of Dispersed, Grid-Connected Photovoltaic Power Systems. SAND83-7019. Sandia National Laboratories. March 1985.

\section{6}

ANSI/IEEE Std 242-1986. IEEE Recommended Practice for Protection and Coordination of Industrial and Commercial Power Systems. 1986.

ANSI/IEEE Std 928-1986. IEEE Recommended Criteria for Terrestrial Photovoltaic Power Systems. 1986.

Bulawka, A., Krauthamer, S., Das, R., "Power Conditioning Subsystems for Photovoltaic Central-Station Power Plants: State-of-the-Art and Advanced Technology," IEEE Transactions on Energy Conversion. Vol. EC-1, No. 1. March 1986. pp. 47-53.

Decision Focus Incorporated., Dynamic Operating Benefits of Energy Storage. Final Report, EPRI AP4875. Electric Power Research Institute. October 1986.

Electric Power Research Institute, Demonstration Test of a 500-kW Peak-Shaving Load-Acid Battery Energy Storage System, Final Report, EPRI AP-4841. September 1986.

Feero, W., Gish, W., "Overvoltages Caused by DSG Operation: Synchronous and Induction Generators," IEEE Transactions on Power Delivery, Vol. PWRD-1, No. 1. January 1986. pp. 258-264. 
Fitzer, J., Dillon, W.E., Ramesh, S., Shen, T.H., Impact of Residential Utility Interactive Photovoltaic Power Systems on the Utility, SAND-84-7008. Sandia National Laboratories. September 1986.

Herrera, J.I., Lawler, J.S., Reddoch, T.W., Sullivan, R.L., Status Report on Utility Interconnection Issues for Wind Power Generation, DOE/NASA/4105-3. June 1986

Khallat, M.A., Rahman, S., "A Probabilistic Approach to Photovoltaic Generator Performance Prediction," IEEE Transactions on Energy Conversion, Vol. EC-1, No. 3. September 1986. pp. 34-40.

Leonard, S.L., "Photovoltaic Power Generation for Utilities: The Implications of Some Recent Projects and Design Studies," IEEE Transactions on Energy Conversion, Vol. EC-1, No. 2. June 1986. pp. 61-67.

Menicucci, D.F., Fernandez, J.P., Estimates of Available Solar Radiation and Photovoltaic Energy Production for Various Tilted and Tracking Surfaces Throughout the US based on PVFORM, a Computerized Performance Model. SAND85-2775. Sandia National Laboratories. August 1986.

Nielsen, P., "Grid Integration of Wind Turbines," Wind Energy Research and Technological Development in Demark. Danish Ministry of Energy, Copenhagen, Denmark. 1986. pp. 37-41.

Oei, T.D., "Estimation of the Fuel Savings by Wind Energy Integration into Small Diesel Power Grids," Wind Energy Conversion 1986 - Proceedings of the 8th British Wind Energy Association Conference, Cambridge, UK. March 1986.

Power Math Associates, Inc. Automatic Generation Control Simulation User's Guide. SAND86-7044. Sandia National Laboratories. December 1986.

Ranade, S.J., "Harmonic Characteristics and Impact of Utility-Interactive Photovoltaic Prototypes on the NUSU Distribution Feeder," IEEE Transactions on Power Systems, Vol. PWRD-1, No. 2. April 1986. pp. 121-128.

R. Lynette \& Associates, Inc., Utility Considerations for Wind Energy Purchase Agreements. Final Report, EPRI AP-4591. Electric Power Research Institute. June 1986.

Schlueter, R.A., Sigari, G., Costi, A., "Wind Array Power Prediction for Improved Operating Economics and Reliability," IEEE Transactions on Power Systems, Vol. PWRS-1, No. 1. February 1986. pp. 137-142.

Steitz \& Associates. Proceedings: Workshop on Prospects and Requirements for Geographic Expansion of Wind Power Usage. EPRI AP-4794, Final Report. Electric Power Research Institute. November 1986.

Thomas, R.J., An Integration Methodology for Large Wind-Energy conversion Systems, Final Report, DOE/RA/50664-1. June 1986.

Tsukamoto, K., Tanaka, K., "Photovoltaic Power System Interconnected with Utility," American Power Conference. April 1986.

\section{7}

Alonso, A.M., Burgos, J.C., :Solving the Transient Network Connection of Asynchronous Generators by a Static Switch $\mu \mathrm{P}$ Controlled," Proceedings of the Mediterranean Electrotechnical Conference. Rome, Italy. March 1987.

ANSI/IEEE Std 937-1987. IEEE Recommended Practice for Installation and Maintenance of Lead-Acid Batteries for Photovoltaic (PV) Systems. 1987. 
Chan, S., Cheng, S., Curtice, D., Integrating Dispersed Storage and Generation into Power System Control, Final Report, EPRI EL-4957. Electric Power Research Institute. March 1987.

Chinery, G.T., Wood, J.M., Larson, A.L., "The Case for Photovoltaics in the Tennessee Valley," Proceedings of the 19th IEEE Photovoltaic Specialists Conference, New Orleans, Louisiana. May 1987.

Chinery, G.T., Wood, J.M., Larson, A.L., "Break-Even Cost for Incorporating Photovoltaic Generation into the TVA Power System," IEEE Transactions on Power Systems. Vol. PWRS-2, No. 3. August 1987. pp.799-804.

Chowdhury, B.H., Rahman, S., "Forecasting Sub-Hourly Solar Irradiance for Prediction of Photovoltaic Output," Proceedings 19th IEEE Photovoltaics Specialists Conference, New Orleans, Louisiana. May 1987.

Čukalevski, N., Medanić, J., Calovic, M., "Power Mismatch Detection and Estimation for Emergency Control," IEEE Transactions on Power Systems, Vol. PWRS-2, No. 1. February 1987. pp.78-84.

Electric Power Consulting, Inc., DYNASTORE--A Computer Model for Quantifying Dynamic Energy Storage Benefits. Interim Report, EPRI AP-5550. Electric Power Research Institute. December 1987.

Fuchs, E.F., Investigations on the Impact of Voltage and Current Harmonics on End-Use Devices and their Protection, DE-RA-50150-23. University of Colorado. January 1987.

Gardner, G.E., "Electrical Generation Aspects of Wind Turbine Operation," Supply Interface Proceedings BWEA-D.En Workshop. May 1987.

Grubb, M.J., "The Integration and Analysis of Intermittent Source on Electricity Supply Systems," Ph.D. Thesis, Kings College, University of Cambridge. 1987.

Grubb, M.J., "Capital Effects at Intermediate and Higher Penetrations," Proceedings Colloquium on Economic and Operational Assessment of Intermittent Generating Sources in Power systems. London, England. March 1987.

Grubb, M.J., "Probabilistic Analysis of the Impact of Intermittent Sources on Operating Penalties: Methods and Applications," Proceedings Colloquium on Economic and Operational Assessment of Intermittent Generating Sources in Power systems. London, England. March 1987.

Hoff, T., "The Value of Photovoltaics: A Utility Perspective," Proceedings of the 19th IEEE PV Specialists Conference, New Orleans, Louisiana. May 1987. pp. 1145-1149.

Hoff, T., Shushnar, G., "Two Years of Performance Data for the World's Largest Photovoltaic Power Plant," IEEE Transactions on Energy Conversion, Vol. EC-2, No. 2. June 1987. pp. 232-235.

Hurwitch, J.W., Scheer, R.M., Electric Energy Systems: Trends and Research Development Needs for the 1990's. PNL-SA-14217. Pacific Northwest Laboratory. January 1987.

Infield, D.G., Halliday, J.A., "The Reading University/RAL National Grid Integration Model and its Application to Storage and Wind Energy," Proceedings Colloquium on Economic and Operational Assessment of Intermittent Generating Sources in Power systems. London, England. March 1987.

Kalaitzakis, K.C., Vachtsevanos, G.J. "On the Control and Stability of Grid Connected Photovoltaic Sources," IEEE Transactions on Energy Conservation, Vol. EC-2, No. 4. December 1987. pp. 556-562. 
Mak, S.T., "The Random Failure Statistics and Replacement Schedules of Remote Devices for Load Management," IEEE Transactions on Power Systems, Vol. PWRS-2, No. 2. May 1987. pp. 451-457.

McGraw-Edison Power Systems. Electric Power System Harmonics Design Guide. ORNL/Sub-81-95011/3. Oak Ridge National Laboratory. September 1987.

New Mexico Solar Energy Institute. Hesperia Photovoltaic Power Plant: 1985 Performance Assessment. Final Report. EPRI AP-5229. Electric Power Research Institute. July 1987.

Nielsen, P., "Integration of Wind Turbines in the Electric Grid," International Symposium on Energy Savings Focusing on Electricity Savings, Copenhagen, Demark. September 1987.

Palutikof, J.P., Watkins, C.P., "Aspects of Windspeed Variability and their Implications for the Wind Power Industry," Proceedings Colloquium on Economic and Operational Assessment of Intermittent Generating Sources in Power systems. London, England. March 1987.

Ranade, S.J., "Characteristics and Impact of Utility Interactive Photovoltaic Prototypes on the Feeder Serving the Southwest Residential Experimental Station," New Mexico State University, Las Cruces, New Mexico. January 1987.

Reddoch, T.W., Taylor, R.W., Miles, W.T., DeSteese, J.G., Hurwitch, J.W., "A View of the Commercial Readiness of New Technology in the Electric Utility Industry," Proceedings of the Fourteenth Energy Technology Conference. April 14-16, 1987. Washington, D.C. 1987. pp.1063-1071.

Saidian, A., Ramakumar, R., "Electrical Load Forecasting in the Presence of Utility-Interactive Photovoltaic Systems," ISES Solar World Congress 1987. Hamburg, West Germany. CONF-870903-Vol.1-Absts. 1987.

Shigeta, S., Tsukamoto, O., Kimura, K., "A Study on Interconnection Between PV and Utility Grid," Advances in Solar Energy Technology. Volume 1. Proceedings of the Biennial Congress of ISES, Hamburg, W. Germany. September 1987. pp. 363-367.

Southwest Technology Development Institute. Photovoltaic Field Test Performance Assessment. Final Report. EPRI RP1607-6. Electric Power Research Institute. 1987.

Stoddard, M.C., et al., SOLARGY--A Computer Code for Calculating the Annual Energy from Central Receiver Power Plants. SAND 86-8060. Sandia National Laboratories. May 1987.

Sugimura, R.S., Wood, J.M., "Utility Application of Photovoltaic Power Generation: A Survey of Recent Literature," IEEE Transactions on Energy Conversion, Vol. EC-2, No. 4. December 1987. pp. 563-569.

Sutoh, T., Suzuki, H., Sekine, Y., "Economic Evaluation of a Residential Photovoltaic System Based on a Probability Model Using Actual Meteorological Data," IEEE Transactions on Energy Conversion, Vol. EC-2, No. 1. March 1987. pp. 9-15.

Swift-Hook, D.T., "Firm Power from the Wind," Proceedings Colloquium on Economic and Operational Assessment of Intermittent Generating Sources in Power Systems. London, England. March 1987.

Thorpe, A., "Intermittent Energy Sources in System Operation," Proceedings Colloquium on Economic and Operational Assessment of Intermittent Generating Sources in Power Systems. London, England. March 1987. 
Vachtsevanos, G.J., Kalaitzakis, K.C., "A Methodology for Dynamic Utility Interactive Operation of Dispersed Storage and Generation Devices," IEEE Transactions on Power Systems, Vol. PWRS-2, No. 1. February 1987. pp. 45-51.

Wind Energy Research and Technological Development in Denmark. Danish Ministry of Energy. 1987.

Yonemori, H., Nagai, S., Nakaoka, M., Maruhashi, T., "System Evaluations of Utility Grid-Connected Solar Photovoltaic Static Generator," Memoirs of the Faculty of Engineering, Kobe University. No. 34. October 1987.

Zaininger Engineering Company, Inc., Electrical Behavior of Wind Power Stations. EPRI AP-5220, Final Report. Electric Power Research Institute. June 1987.

Zaininger, H.W., Benefits of Battery Storage as Spinning Reserve: Quantitative Analysis, EPRI AP-5327. Final Report. Electric Power Research Institute. July 1987.

1988

ANSI/IEEE Std 1001-1988, IEEE Guide for Interfacing Dispersed Storage and Generation Facilities with Electric Utility Systems.

ANSI/IEEE Std 929-1988, IEEE Recommended Practice for Utility Interface of Residential and Intermediate Photovoltaic (PV) Systems.

ANSI/IEEE Std 1021-1988, IEEE Recommended Practice for Utility Interconnection of Small Wind Energy Conversion Systems.

Bakirtzis, A.G., Dokopoulos, P.S. "Short Term Generation Scheduling in a Small Autonomous System with Unconventional Energy Sources," IEEE Transactions on Power systems. Vol. 3, No. 3. August 1988. pp. $1230-1236$.

Bentley, B.W., "Integrating Non-Utility Generation Into the NEPOOL Resource of Planning Process," IEEE Transactions on Power Systems. Vol. 3, No. 4. November 1988. pp. 1754-1756.

Botta, G., Panichelli, S., Salvaderi L., "EC Wind Power Penetration Study--ENEL Perception," Proceedings of an International Congress held at Saarbrücken, F.R. Germany. October 1988.

Chen, C.L., Hsu, Y.Y., "An Efficient Algorithm for the Design of Decentralized Output Feedback Power System Stabilizer," IEEE Transactions on Power Systems. Vol. 3, No. 3. August 1988. pp. 999-1004.

Chowdhury, B.H., Rahman, S., "Analysis of Interrelationships Between Photovoltaic Power and Battery Storage for Electric Utility Load Management," IEEE Transactions on Power System, Vol. 3. August 1988. pp. 900-907.

Chowdhury, B.H., Rahman, S., "Is Central Station Photovoltaic Power Dispatchable?" 88 WM 233-9. December 1988.

Coles, L.R., Conference Notes on US-EC Workshop on Utility Interface Issues for Renewable Technologies. April 1988.

Department of Energy, Summary of Investigations on the Impact of Systems Voltage Harmonics on End-Use Devices. July 1988. 
Department of Mechanical Engineering, University of Massachusetts. Optimization Studies of Wind Diesel Systems//Techniques for Measuring Atmospheric Turbulence. SERI Wind Research Program Subcontractor Review. July 1988.

Farghal, S.A. and Abdel Aziz, M.R., "Generation Expansion Planning Including the Renewable Energy Sources," IEEE Transactions on Power Systems, Vol. 3, No. 3. August 1988. pp. 816-822.

Grubb, M.J., "The Economic Value of Wind Energy at High Power System Penetrations: An Analysis of Models, Sensitivities and Assumptions," Wind Engineering. Vol. 12, No. 1. 1988. pp. 1-26.

Grubb, M.J., "On Capacity Credits and Wind-Load Correlations in Britain," Wind Energy Conversion 1988 Proceedings of the 10th British Wind Energy Association Conference. London, UK. March 1988.

Grubb, M.J., "Firm Power and System Penetration," IEE Colloquium on Wind Power for the UK. February 1988.

Herrea, J.J., Reddoch, T.W., Lawler, J.S., "Harmonics Generated by 2 Variable Speed Wind Generating Systems," IEEE Transactions on Energy Conversion, Vol. 3, No. 2. June 1988. pp. 267-273.

Hoff, T., Iannucci, J.J., "Siting PV Plants: A Value Based Approach," Proceedings of the 20th IEEE Photovoltaic Specialists Conference. September 1988. pp. 1056-1061.

Jewell, W.T., Ramakumar, R., "The History of Utility-Interactive Photovoltaic Generation," IEEE Transactions on Energy Conversion, Vol. 3, No. 3. September 1988. pp. 583-588.

Jewell, W.T., Ramakumar, R., Hill, S.R., "A Study of Dispersed Photovoltaic Generation on the PSO System," IEEE Transactions on Energy Conversion, Vol. 3, No. 3. September 1988. pp. 473-478.

Jones, R.A., Sims, T.R., et al., Investigation of Potential Islanding of Dispersed Photovoltaic Systems, SAND87-7024. Sandia National Laboratories. October 1988.

Keppeler, J.G., "Qualifying Facilities and Their Effect on Generation Planning," IEEE Transactions on Power Systems, Vol. 3, No. 4. November 1988. pp. 1738-1740.

Khallat, M.A., Rahman, S., "A Model for Capacity Credit Evaluation of Grid-Connected Photovoltaic Systems with Fuel Cell Support," IEEE Transactions on Power Systems, Vol. 3, No. 3. August 1988. pp.1270-1276.

Lefebvre, S., et al., "Control System Analysis and Design for an Aerogenerator with Eigenvalue Methods," IEEE Transactions on Power Systems, Vol. 3, No. 4. November 1988. pp. 1600-1608.

McGraw-Edison Power Systems. Harmonic Considerations for Electrical Distribution Feeders. ORNL/Sub-81-95011/4. Oak Ridge National Laboratory. March 1988.

Menicucci, D.F., Fernandez, J.P., User's Manual for PVFORM: A Photovoltaic System Simulation Program for Stand-Alone and Grid-Interactive Applications. SAND85-0376. Sandia National Laboratories. April 1988.

New Mexico Solar Energy Institute. Photovoltaic Field Test Performance Assessment: 1986. Final Report, EPRI AP-5762. March 1988.

North American Electric Reliability Council, Overview of Planning Reliability Criteria of the Regional Reliability Councils of NERC. April 1988. 
Patterson, R., Teekman, N., "WECS Utility Interconnection Standards," 6th Annual Wind Energy Symposium Proceedings. 1988.

Rahman, S., Chowdhury, B.H., "Simulation of Photovoltaic Power Systems and Their Performance Prediction," IEEE Transactions on Energy Conversion. Vol. 3, No. 3. September 1988. pp. 440-446.

Rahman, S., Tam, K., "A Feasibility Study of Photovoltaic-Fuel Cell Hybrid Energy System," IEEE Transactions on Energy Conversion, Vol. 3, No. 1. March 1988. pp. 50-55.

Schlueter, R.A., Voltage Stability and Security Assessment, EPRI EL-5967. Final Report. August 1988.

Singh, C., Kim, Y., "An Efficient Technique for Reliability Analysis of Power Systems Including Time Dependent Sources," IEEE Transactions on Power Systems, Vol. 3, No. 3. August 1988. pp. 1090-1096.

Smith, J.C., Herrera, J., "Windfarm Reactive Power Compensation Considerations for Power Factor Correction Capacitor Applications," 1988.

Southern California Edison Company, Requirements for Operating Metering, and Protective Relaying for Cogenerators and Small Power Producers. June 1988.

Steinbuch, M., de Boer, W.W., Bosgra, O.H., Peters, S.A.W.M., Ploeg, J., "Optimal Control of Wind Power Plants," Journal of Wind Engineering and Industrial Aerodynamics, 27. 1988. pp. 237-246.

Stevens, J., "The Issue of Harmonic Injection from Utility Integrated Photovoltaic Systems, Part 1: The Harmonic Source," IEEE Transactions on Energy Conversion, Vol. 3, No. 3. September 1988. pp. 507510.

Stevens, J., "The Issue of Harmonic Injection from Utility Integrated Photovoltaic Systems, Part 2: Study Results," IEEE Transactions on Energy Conversion, Vol. 3, No. 3. September 1988. pp. 511-515.

Stevens, J., The Interconnection Issues of Utility-Intertied Photovoltaic Systems, SAND87-3146. Sandia National Laboratories. November 1988.

Surman, P.L., Walker, J.F., "System Integration of New and Renewable Energy Sources: A UK View," Commission of the European Communities Euroforum New Energies. Proceedings of an International Congress held at Saarbrücken, F.R. Germany. October 1988.

Thomas, R.J., Phadke, A.G., Pottle, C., "Operational Characteristics of A Large Wind-Farm Utility-System with A Controllable AC/DC/AC Interface," IEEE Transaction on Power Systems, Vol. 3, No. 1. February 1988.

Vermeer, M.P., "Some Aspects of Optimising the Integration of Wind Farms into the Electricity Grid," Journal of Wind Engineering and Industrial Aerodynamics, 27. January 1988. pp. 247-261.

Wasynczuk, O., Krause, P.C., Anwah, N.A., Reduced Order Modeling of Grid-Connected, Photovoltaic Inverter Systems. SAND-87-7017. Sandia National Laboratories. January 1988.

\section{9}

APPA DEED/Research Project Report, Performance of Inverter Protection Systems. Salt River Project. November 1989.

Bakirtzis, A.G., Dokopoulos, P.S., Gavanidou, E.S., Ketselides, M.A., "A Probabilistic Costing Method for the Evaluation of the Performance Grid-Connected Wind Arrays," IEEE Transactions on Energy Conversion. March 1989. 
Begovic, M.M., Phadke, A.G., "Dynamic Simulation of Voltage Collapse," paper presented at the IEEE Power Industry Computer Application Conference, Seattle, Washington. May 1989.

Beyer, H.G., Luther, J., Steinberger-Willms, R., "Power Fluctuations from Geographically Diverse, Grid Coupled Wind Energy Conversion Systems," Proceedings of European Wind Energy Conference. July 1989.

Bull, M., "Bonneville's Least Cost Planning," IEEE Transaction on Power Systems, Vol. 4, No. 1. January 1989. pp. 300-304.

Chow, J.-C., Fischl, R., Yan, H., "On the evaluation of Voltage Collapse Criteria," paper presented at the IEEE Power Industry Computer Application Conference, Seattle, Washington. May 1989.

Coelingh, J.P., Van Der Ree, B.G.C., Van Wijk, A.J.M., "The Hourly Variability in Energy Production of 1000MW Wind Power in the Netherlands," Proceedings of European Wind Energy Conference. July 1989.

Comfort, R.W., Finley, L.A., Kritikson, J.G., Meyer, F.J., Rosenberg, L.D., "Current Operating Problems Associated with Non-Utility Generation," IEEE Transactions on Power systems. Vol. 4, No. 4. October 1989. pp. 1534-1541.

Dialynas, E.N., "Impact of Cogeneration and Small Power Producing Facilities on the Power System Reliability Indices," IEEE Transactions on Energy Conversion, Vol. 4, No. 3. September 1989. pp. 368374.

Electric Power Research Institute. Status of Solar-Thermal Electric Technology. Final Report, EPRI GS6573. December 1989.

Electrotek Concepts, Inc. Analysis of Capacitor Failure at the Kamaoa Wind Farm in the Island of Hawaii. Draft Report. August 1989.

Garrett, D.L., et al. PVREG--A Photovoltaic Voltage Regulation Investigation Tool: Program Reference Manual. SAND88-7036. Sandia National Laboratories. June 1989.

Garrett, D.L., et al. PVREG--A Photovoltaic Voltage Regulation Investigation Tool: User's Manual. SAND88-7036. Sandia National Laboratories. June 1989.

Graf, K.M., et al., Dynamic Simulation of Voltage Collapse Process in EHV Power Systems, EPRI EL-6183, Final Report. January 1989.

Grubb, M., "How Much is Wind Energy Worth?" Wind Energy Weekly. Vol. 8. May 1989.

Guardado, J.L., Cornick, K.J., "A Computer Model for Calculating Step-Fronted Surge Distribution in Machine Windings," IEEE Transactions on Energy Conversion, Vol. 4, No. 1. March 1989. pp. 95-101.

Gulachenski, E., et al. "Current and Voltage Harmonic Measurements and Modeling at the Gardner Photovoltaic Project," IEEE Transactions on Power Delivery, Vol. 4, January 1989. pp. 800-809.

Hirsh, R.F., Technology and Transformation in the American Electric Utility Industry, Cambridge University Press, New York. 1989.

Hoff, T., Iannucci, J.J., "Maximizing the Benefits Derived from PV Plants: Selecting the Best Plant Design and Plant Location," Pacific Gas and Electric Company. 1989. 
Hoffner, J.E., "Analysis of the 1988 Performance of Austin's 300-kilowatt Photovoltaic Plant," SOLAR 89: The National Solar Energy Conference - Proceedings of the 1989 Annual Conference of the American Solar Energy Society. Denver, Colorado. June 1989.

Jewell, W.T. "Electric Utility Experience with Solar Photovoltaic Generation," IEEE Transactions on Energy Conversion, Vol. 4, No. 2. June 1989. pp. 166-171.

Keller, J., "Renewables--A Clean Energy Solution," 15th Annual Conference of the Solar Energy Society of Canada. June 1989.

Kern, E.C., Gulachenski, E.M., Kern, G.A., "Cloud Effects on Distributed Photovoltaic Generation: Slow Transients at the Gardner, Massachusetts Photovoltaic Experiment," IEEE Transactions on Energy Conversion, Vol. 4. June 1989. pp. 184-190.

Kusterer, H., " $\mathrm{H}_{2} / \mathrm{O}_{2}$ Steam Generators Can Supply Short-Term Electric Peak Loads," Power Engineering. June 1989.

Meade, W.R., Teitelbaum, D.F., A Guide to Renewable Energy and Least Cost Utility Planning. September 1989.

Rahman, S., A Study of the Economic Impact of Operating Photovoltaic Systems in the Electric Utility Grid. SAND88-7043. Sandia National Laboratories. March 1989.

Ranade, S.J., Prasad, N.R., Omick, Steven R., Islanding in Dispersed, Utility-Interactive Photovoltaic Systems, SAND88-7042. Sandia National Laboratories. May 1989.

Ranade, S.J., Prasad, N.R., Omick, S., Kazda, L.F., "A Study of Islanding in Utility-Connected Residential Photovoltaic Systems Part II - Case Studies," IEEE Transactions on Energy Conversion, Vol. 4, No. 3. September 1989. pp. 446-452.

Reeder, M., "Competitive Bidding for Electricity Supplies: Utility Responsibility and the Intervention of the Regulator," presented at the 1989 IEEE Power Engineering Society Winter Meeting. New York, New York. February 1989.

Perez, R., Berkheiser III, W., Stewart, R., Kapner, M., Stillman, G., "Photovoltaic Load Matching Potential for Metropolitan Utilities and Large Commercial Users in the Northeastern U.S.," Proceedings of the 9th European PV Conference, Freiburg, FRG. 1989. pp. 903-907.

Smith, K. Survey of U.S. Line-Connected Photovoltaic Systems. GS-6306, Special Report. Electric Power Research Institute. March 1989.

Stoll, H.G., Least-Cost Electric Utility Planning, John Wiley \& Sons, New York, New York. 1989.

Stone \& Webster Management Consultants, Inc., Methods to Integrate Demand and Supply Options and an Evaluation of Least Cost Planning Methods. DE-FG01-87CE27478. April 1989.

Tam, K.W., Kumar, P., Foreman, M., "Enhancing the Utilization of Photovoltaic Power Generation by Superconductive Magnetic Energy Storage', IEEE Transactions on Energy Conversion, Vol. 4, No. 3. September 1989. pp. 314-321.

Thompson, H.H., Jr., Wolf, H.M., Le, K.D., Day, J.T., "Assessing the Dollar Price Tag for Meeting the NERC 10-Minute Reserve Rule," IEEE Transactions on Power Systems, Vol. 4, No. 4. October 1989. pp. 1381-1388. 
Vachtsevanos, G., Kang, H., "Simulation Studies of Islanded Behavior of Grid-Connected Photovoltaic Systems," IEEE Transactions on Energy Conversion, Vol. 4, No. 2. June 1989. pp. 177-183.

Wagner, C.L., Feero, W.E., Gish, W.B., Jones, R.H., "Relay Performance in DSG Islands," IEEE Transactions on Power Delivery, Vol. 4, No. 1. January 1989. pp. 122-130.

Wasynczuk, O., Anwah, N.A., "Modeling and Dynamic Performance of a Self-Commutated Photovoltaic Inverter System," IEEE Transactions on Energy Conversion, Vol. 4, No. 3. September 1989. pp. 322-328.

Williams, S. and Porter, K., Power Players--Profiles of America's Independent Renewable Electricity Developers, Investor Responsibility Research Center, Washington, DC. 1989.

Wasynczuk, O., "Modeling and Dynamic Performance of a Line-Commutated Photovoltaic Inverter System," IEEE Transactions on Energy Conversion, Vol. 4, No. 3. September 1989. pp. 337-343.

1990

Begovic, M.M., Phadke, A.G., "Voltage Stability Assessment Through Measurement of a Reduced State Vector," IEEE Transactions on Power Systems, Vol. 5, No. 1. February 1990. pp. 198-203.

Brown, M.T., Settembrini, R.C., "Dispersed Generation Interconnections Via Distribution Class Two-Cycle Circuit Breakers," IEEE Transactions on Power Delivery. Vol. 5, No. 1. January 1990. pp. 481-485.

Bzura, J.J., "The New England Electric Photovoltaic Systems Research and Demonstration Project," IEEE Transactions on Energy Conversion, Vol. 5, No. 2. June 1990. pp.284-289.

Chiang, H.D., et al., "On Voltage Collapse in Electric Power Systems," IEEE Transactions on Power Systems, Vol. 5, No. 2. May 1990. pp. 601-611.

DeMarco, C.L., Overbye, T.J., "An Energy Based Security Measure for Assessing Vulnerability to Voltage Collapse," IEEE Transactions on Power Systems, Vol. 5, No. 2. May 1990. pp. 419-427.

Edison Electric Institute, Statistical Yearbook of the Electric Utility Industry/1989, EEI Washington, D.C. 1990.

Flatabø, N., Ognedal, R., Carlsen, T., "Voltage Stability Condition in a Power Transmission System Calculated by Sensitivity Methods," IEEE Transactions on Power Systems, Vol. 5, No. 4. November 1990. pp. 1286-1293.

Halberg, N., "Wind Energy Research Activities of the Dutch Electric Generation Board," paper presented at the EC Wind Conference. September 1990.

Hester, S.L., Townsend, T.U., Clements, W.T., Stolte, W.J., "PVUSA: Lessons Learned from Startup and Early Operation," 21st IEEE Photovoltaic Specialists Conference, Orlando, Florida. May 1990.

Hirst, E., Goldman, C., Key Issues in Integrated Resource Planning for Electric Utilities," IEEE Transactions on Power Systems. Vol. 5, No. 4. November 1990. pp. 1105-1111.

Jewell, W.T., Unruh, T.D., "Limits on Cloud-induced Fluctuation in Photovoltaic Generation," IEEE Transactions on Energy Conversion, Vol. 5, No. 1. March 1990. pp. 8-14. 
Murthy, S.S., Jha, C.S., Rao, P.S. Nagendra, "Analysis of Grid Connected Induction Generators Driven by Hydrowind Turbines Under Realistic System Constraints," IEEE Transactions on Energy Conversion, Vol. 5, No. 1. March 1990. pp. 1-7.

New England Power Service Company, Photovoltaic Generation Effects on Distribution Feeders. Volume 1: Description of the Gardner, Massachusetts, Twenty-First Century PV Community and Research Program. EPRI EL-6754, Final Report. Electric Power Research Institute. March 1990.

North American Electric Reliability Council, NERC Operating Manual. 1991 Edition.

Pacific Gas and Electric Company, Power Producer's Interconnection Handbook. May 1990.

Rahman, S., "Economic Impact of Integrating Photovoltaics with Conventional Electric Utility Operation," IEEE Transactions on Energy Conversion, Vol. 5, No. 3. September 1990. pp. 422-428.

Rich, D., Baron, B.N., McDonnell, C., Hajilambrinos, C., "Photovoltaics and Electric Utilities: An Evaluation of Utility Attitudes and Expectations," Solar Cells, 29. 1990. pp. 25-37.

Shugar, D. S., "Photovoltaics in The Distribution System: The Evaluation of System and Distributed Benefits," Proceedings of the 21st IEEE Photovoltaic Specialist Conference, Kissimmee, Florida. May 1990.

Smith, C.L., Utility Integration of Photovoltaic Systems, EPRI RP3179, Summary presented at US/EC Workshop, Madrid, Spain. September 1990.

Smith, D.R., "Wind Energy Resource Potential and the Hourly Fit of Wind energy to Utility Loads in Northern California," paper presented at 1990 AWEA Conference, Washington, D.C. September 1990.

Smith, D.R., Ilyin, M.A., "Wind Energy Evaluation by PG\&E," Pacific Gas and Electric Research and Development, San Roman, California. 1990.

Smith, J.C., "Utility Integration of Photovoltaic Systems, EPRI RP-3179, Task 1 Overview," prepared for US-EC Workshop, Madrid, Spain. September 1990.

Solar Energy Research Institute, The Potential of Renewable Energy--An Interlaboratory White Paper. 1990.

\section{1}

Applied Reliability Assessment in Electric Power Systems, Edited by Roy Billinton, Ronald N. Allan, Luigi Salvaderi, IEEE Press. 1991.

European Wind Power Integration Study - The Dutch Contribution. CEC DG XII. Contract No. JOUR0029-NL (CH). Final Report. April 1992.

North American Electric Reliability Council. NERC Operating Manual. 1991.

Pacific Northwest Utilities Conference Committee, Blackfeet Area Wind Integration Study, PUNCC, Portland, Oregon. August 1991.

Perez, R., et al., "Meeting Utility Load Requirements with Photovoltaics--Resource Assessment Logistics," ISES World Congress, Denver, Colorado. August 1991.

Results From The Wind Project Performance Reporting System - 1990 Annual Report. California Energy Commission. December 1991. 
Rueger, G.M., Manzoni, G., "Utility Planning and Operational Implications of Photovoltaic Power Systems," Pacific Gas and Electric Company, San Ramon, California. 1991.

Sanghvi, A.P. Balu, N.J., Lauby, M.G., "Power System Reliability Planning Practices in North America," IEEE Transactions on Power Systems, Vol. 6, No. 4. November 1991. pp. 1485-1492. 


\begin{tabular}{|c|c|c|c|}
\hline $\begin{array}{l}\text { Document Control } \\
\text { Page }\end{array}$ & $\begin{array}{l}\text { 1. NREL Report No. } \\
\text { NREL-TP-463-4953 }\end{array}$ & $\begin{array}{l}\text { 2. NTIS Accession No. } \\
\text { DE93017080 }\end{array}$ & 3. Recipient's Accession No. \\
\hline \multirow{2}{*}{\multicolumn{3}{|c|}{$\begin{array}{l}\text { 4. Title and Subtitle } \\
\text { Factors Relevant to Utility Integration of Intermittent Renewable } \\
\text { Technologies }\end{array}$}} & $\begin{array}{l}\text { 5. Publication Date } \\
\text { August } 1993\end{array}$ \\
\hline & & & 6. \\
\hline \multicolumn{3}{|c|}{$\begin{array}{l}\text { 7. Author(s) } \\
\text { Y. Wan and B.K. Parsons }\end{array}$} & 8. Performing Organization Rept. No. \\
\hline \multirow{2}{*}{\multicolumn{3}{|c|}{$\begin{array}{l}\text { 9. Performing Organization Name and Address } \\
\text { National Renewable Energy Laboratory } \\
1617 \text { Cole Boulevard } \\
\text { Golden, Colorado } 80401-3393\end{array}$}} & $\begin{array}{l}\text { 10. Project/Task/Work Unit No. } \\
\text { AS815440 }\end{array}$ \\
\hline & & & $\begin{array}{l}\text { 11. Contract (C) or Grant (G) No. } \\
\text { (C) } \\
\text { (G) }\end{array}$ \\
\hline \multirow{2}{*}{\multicolumn{3}{|c|}{ 12. Sponsoring Organization Name and Address }} & $\begin{array}{l}\text { 13. Type of Report \& Period Covered } \\
\text { Technical Report }\end{array}$ \\
\hline & & & 14. \\
\hline \multicolumn{4}{|l|}{ 15. Supplementary Notes } \\
\hline \multicolumn{4}{|c|}{$\begin{array}{l}\text { 16. Abstract (Limit: } 200 \text { words) } \\
\text { This study assesses factors that utilities must address when they integrate intermittent renewable technologies into } \\
\text { their power-supply systems; it also reviews the literature in this area and has a bibliography containing more than } \\
350 \text { listings. Three topics are covered: (1) interface (hardware and design-related interconnection), (2) } \\
\text { operability/stability, and (3) planning. This study finds that several commonly held perceptions regarding } \\
\text { integration of intermittent renewable energy technologies are not valid. Among findings of the study are the } \\
\text { following: (1) hardware and system design advances have eliminated most concerns about interface; (2) cost } \\
\text { penalties have not occurred at low to moderate penetration levels (and high levels are feasible); and } \\
\text { (3) intermittent renewable energy technologies can have capacity values. Obstacles still interfering with } \\
\text { intermittent renewable technologies are also indentified. }\end{array}$} \\
\hline \multirow{2}{*}{\multicolumn{4}{|c|}{$\begin{array}{l}\text { 17. Document Analysis } \\
\text { a. Descriptors } \\
\text { intermittent renew } \\
\text { b. Identifiers/Open-E } \\
\text { c. UC Categories } \\
233\end{array}$}} \\
\hline & & & \\
\hline \multirow{2}{*}{\multicolumn{2}{|c|}{$\begin{array}{l}\text { 18. Availability Statement } \\
\text { National Technical Information Service } \\
\text { U.S. Department of Commerce } \\
\text { 5285 Port Royal Road } \\
\text { Springfield, VA } 22161\end{array}$}} & & $\begin{array}{l}\text { 19. No. of Pages } \\
120\end{array}$ \\
\hline & & & $\begin{array}{l}\text { 20. Price } \\
\text { A06 }\end{array}$ \\
\hline
\end{tabular}

Form No. 0069E (6-30-87) 